

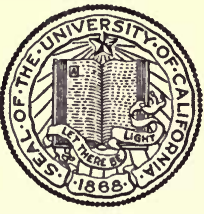

THE LIBRARY OF

THE UNIVERSITY OF CALIFORNIA LOS ANGELES 




\section{ODD HOURS WITH NATURE}




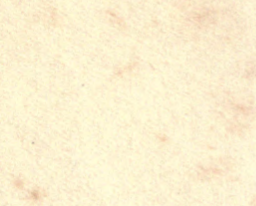





\section{MP \\ P.}

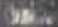
$x+2$ th.

(6) the

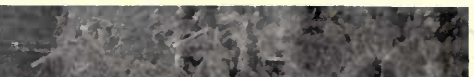
$\sqrt{2}$

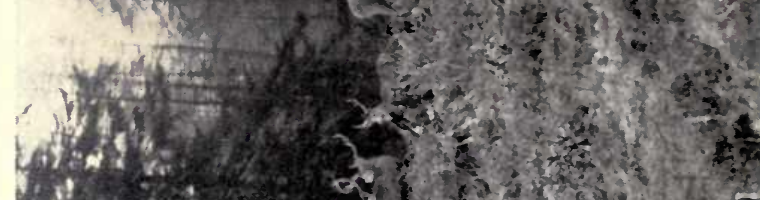

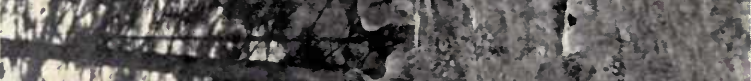

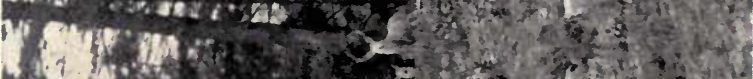

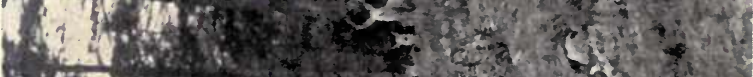

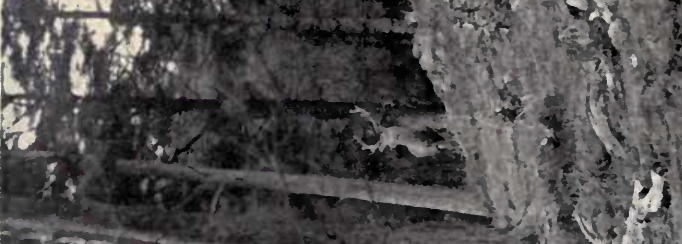

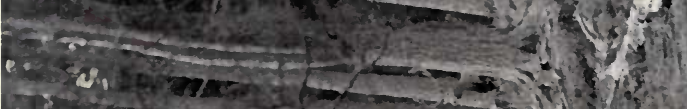

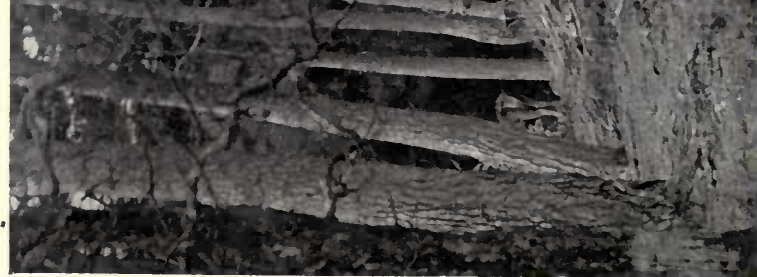




\title{
ODD HOURS WITH NATURE
}

\author{
BY \\ ALEXANDER URQUHART
}

WITH 32 ILLUSTRATIONS

T. FISHER UN WIN

LONDON : ADELPHI TERRACE

LEIPSIC: INSELSTRASSE 20 
First published in 1913

(All rights reserved) 


\section{QH \\ 81 \\ 4790}

\section{INTRODUCTORY}

THESE papers make no pretence to scientific status ; at most they claim the merit of work capable of exciting an interest and of ministering in some small measure to the love of nature so general among people of all classes to-day. Dealing as they do with the class of subject, the study of which forms the writer's recreation, it is hoped that the reader will find in them too some breath of the garden, the river-side, the hills, and the woodland.

Thanks are due to the proprietors of the Dundee Advertiser for their ready assent to the appearance of the papers in this form.

A. U. 


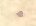

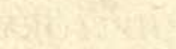

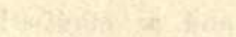

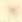

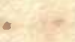




\section{CONTENTS}

\section{JANUARY}

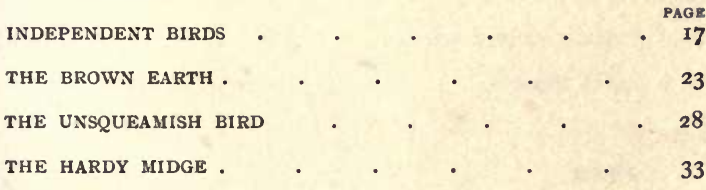

\section{FEBRUARY}

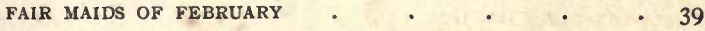

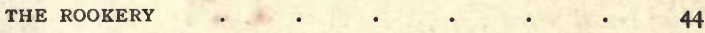

RESPECTABLE AND DISREPUTABLE RELATIVES । - 49

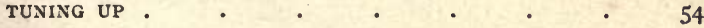

\section{MARCF}

THE CUNNING OF TROUT . . . . . $6 \mathrm{I}$

MARCH SUNSHINE . . . . . . . 67

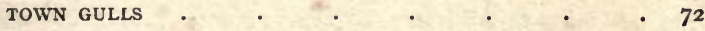

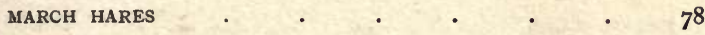




\section{APRIL}

A SPRING TROUBLE PLOVERS' EGGS

THE ROBIN'S COURTSHIP

THE GREAT SCULPTOR

\section{MAX}

THE TOM-TITS AND THEIR BOX

BIRDS IN THE GARDEN

THE NESTING OF THE ROBIN

THE YOUNG DEER .

\section{JUNE}

THE FANCIES OF THE TROUT .

A TERN COLONY

A SUMMER-DAY TRAGEDY

SOME BIRDS' NESTS .

PUSSY HUNTING

\section{JULX}

TROUT IN ISOLATED LOCHS

THE BIRD OF THE BURNS .

MIDGES .

THE RED-DEER IN SUMMER FOXES OF THE HILLS .

- $\mathbf{1} 57$

I62

- 167

I72

- $\quad$ I77 


\section{AUGUST}

THE SLUGGARD'S MODEL

ROBBER BEES

THE GLORIOUS TWELFTH

ARE WILD CATS SCARCE? .

PAGE

185

I90

I95

I99

WASP PLAGUES .

204

\section{SEPTEMBER}

THE BUSY BEE .

2 I I

THE SPARROW'S HOLIDAY . . . . . 216

A gentleman in Velvet - $\quad$ - $\quad$ - 222

THE ANTLERS OF THE RED-DEER . . . . 227

THE FAIRY RING

\section{OCTOBER}

THE BRAMBLE

SEED DISPERSAL

- 245

250

MASCULINE FEMININES . $\quad$ - $\quad$ - $\quad$ - 255

THE SWALLOWS . . . . . . 260

THE STARLING IN AUTUMN . . . . . 265

A BEAUTIFUL CHARACTER . . . . . 270

\section{NOXEMBER}

A QUESTION OF CHOICE

- 279

BIRDS AND STORM

284

THE FLOCKING OF THE BIRDS.

- 289

HAWKS IN TOWN

294 


\section{DECEMBER}

A WINTER SLEEPER THE WILD SWAN WINTER PLAY OF BIRDS . . . . . . $33^{12}$ THE ARMED PLANT . . . . . . 3 I6

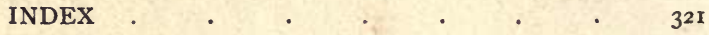




\section{ILLUSTRATIONS}

IN STAG GROUND $\quad$ - $\quad$ - $\quad$. $\quad$. $\quad$. Frontispiece

FACING PAGR

GARBAGE FEEDERS • . . . . . 30

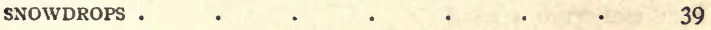

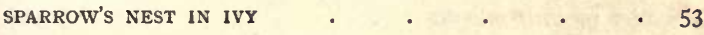

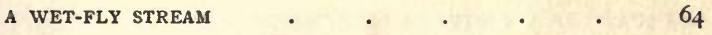

NEST OF BLACKHEADED GULL • • • • 74

NESTING CLIFF OF KITTIWAKE • . • • • 76

THE YOUNG HARE - $\quad$ - $\quad$ - . $8 \mathrm{I}$

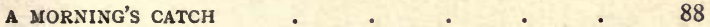

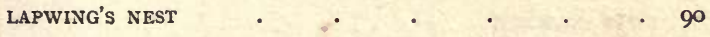

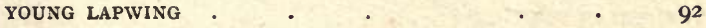


A TOM-TIT FAMILY

FACING PAGE

TOM-TIT FAMILY

INSIDE THE TIT'S BOX

I I I

THE GREENFINCH'S AGE OF INNOCENCE

. 116

FEEDING THE YOUNG DEER

124

WHERE TROUT ARE FASTIDIOUS

- 132

NEST OF SONG THRUSH

I 44

NEST OF THE BLACKBIRD

- $14^{8}$

FALL ISOLATING A LOCH

A HAUNT OF THE DIPPER

- 164

SANCTUARY OF A NORTHERN DEER-FOREST

I74

A FAMILY OF HILL FOXES

- $\quad 178$

THE ROBBER BEE .

192

THE GROUSE

- 196

WILD CATS .

WILD CAT COUNTRY

I99

- 202

THE WATER VOLE . 


\section{ILLUSTRATIONS}

I3

FACING PAGE

THE ANTLERS OF THE DEER . . . . . 232

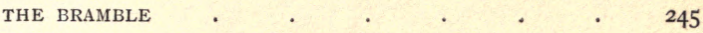

HeN CAPERCAilie ASSUMing Male Plumage . • . 256

NESTING-HOLES OF SAND MARTINS . . . 260

SAND MARTIN'S NEST EXPOSED. . . . . 263 

JANUARY 


\section{INDEPENDENT BIRDS}

IT is a food problem rather than a cold problem that winter presents to the birds. Sympathetic souls pity the feeble little creatures exposed to the blast and the biting atmosphere, protected by no better a dress than that with which nature endows them for summer use. But it is pity misapplied. Give the birds food and the nipping and eager air will trouble them little if at all. The real pinch is the locking of the larder door, and it is locked by frost and buried out of sight by snow. Succulent slugs and snails are withdrawn from the light of day, and the most industrious blackbird or thrush searches for one in vain. No worm comes to the surface, and insect grubs are as safe from inquisitive beaks as if protected by paving stones. Hence that great movement towards the haunts of man, an anomalous creature at the best of times, but a special providence at the worst. For even when he displays no active charity his strange nature-fighting ways are constantly exposing bits of brown earth where a bird's eye can see things worth picking up. Then he has stores of produce from which what many birds filch will never be missed; and the things he rejects are treasure to a legion. 
There are many birds, however, which are little troubled by the hardest winter, and which never court the charity of man. For the most part they are neither large nor strong, and rarely capable of wrestling with the tiniest of physical difficulties. On the contrary, they are amongst the smallest of the whole race. With the first touch of autumn chill the vast majority of insect-eating birds depart for milder lands, but some, and these the puniest of all, remain. Just now every pine wood or plantation in northern shires is inhabited by hundreds of golden-crested wrens. From every tree their tiny cheep may be heard, though little will be seen except by searching eyes. Watch the needle-covered branches and the little creature will be found crawling among them, sometimes back up, sometimes down, never for a moment still, a marvel of intent industry. There is no ca' canny policy here, for, though the gold-crest's whole body weighs but a fraction of an ounce, a full day's toil is necessary to sustain it. Its food consists of the minute insects which find a sufficient shelter at the base of a pine needle, and it takes a very large number of them to make even a gold-crest's meal. Hence the absorbed, mouse-like creep through the needles of the little green bird. Nothing that man has to offer would be of the least value to it, so it never joins the flock of pensioners, though sometimes the evergreen shrubs of a garden may tempt it to a visit of even the suburb of a town. Another insect-eater which relies wholly on its own exertions throughout the hardest winter is the tree-creeper, a tiny native which may much more fitly be likened 
to a mouse. No wood with rough-barked trees is without it, and no human analogy can describe its laborious activity there. Watch it alight at the foot of a tree trunk. It has scarcely touched the bark when its spiral ascent begins. Creeping round the trunk and upward it searches every. cavity with sensitive bill, pulling from their recesses the larvæ of small insects, and apparently getting little reward for a great deal of labour. Up it goes till the smooth bark near the top is reached, when it drops with the swiftness of a stone and the lightness of a feather to the foot of the next bole, where the spiral pursuit begins again. From daybreak to dusk never a moment is squandered, for life is very exacting in the winter woods. Both the gold-crest and the creeper have, however, the reward of their independence, for the natural supplies on which they rely, if scanty, have none of the precariousness of charity, and-rare thing among the smaller birds of Britain-both species are, with the extension of woodlands, steadily on the increase.

Few of the finches disdain the human aid offered by, at any rate, the farmyard. Even the brambling comes down from the heights and joins the goodly company of sparrows, linnets, larks, chaffinches, greenfinches, and buntings which seek at once the shelter and the stores of the hospitable cornstacks. But the siskin is a notable exception. No matter how deep the snow, how hard the frost, or fierce the wind, this little green finch pins its reliance to the alder-trees which fringe the river. The alder catkins are now hardened into cones, but 
they still retain their seed, and the siskin is a wonderful adept at their extraction. Walk along a river bank on a day when the snow covers the ground, and it is easy to follow the movements of the siskin flock. Under each tree the birds have visited the snow is speckled with the débris of broken catkins or scattered seed. Equally easy is it to find the birds themselves. They are social creatures in the cold weather, and move about in flocks which may number hundreds. As they work at the hanging cones, themselves suspended like green fruit, they maintain an incessant musical chattering which tells their whereabouts a hundred yards away. Alarm them, and with heightened note they wheel simultaneously into the air, fly round a large circle, and alight again in a single tree not far from that which they left. - In a moment they are as busy as ever, worrying the seed-bearing cones, more often than not with their backs to the earth. The gregarious habits of the siskin and its absorbed devotion to its work of food-getting render it an easy victim of the birdcatcher, who can, with care, approach sufficiently near to pick it off the branch on which it is feeding with the limed tip of a fishing-rod. The result is visible in every bird-dealer's window, and, there is reason to fear, in the diminishing abundance of the species. In some ways resembling the siskin, though in others very different, is the many-coloured, most parrot-like of British birds, the crossbill. Nothing that man possesses can tempt it from the fir and larch woods in which its whole life is passed, and where it tears 
up the great cones for the seed they contain, with as much ease as the siskin masters the catkin of the alder. Nature in Britain has few more interesting sights than that of a flock of crossbills engaged in this crackling, rending, tearing work of harvesting coniferous seed.

Few of the larger perching birds continue to behave as if man had no place in the land. The feeding habits of rooks, jackdaws, pigeons, and most of the members of the thrush family have come to relate themselves intimately to cultivation, and most of these birds make close approaches when the kindly brown face of the earth is buried in snow. The hooded crow, however, still acts as his ancestors may be supposed to have acted in tertiary times. He keeps to the ancient traditions of the crows, and prefers man and all his works at a distance. In the solemn raucous speeches he addresses to his young he no doubt tells them that man is a parvenu; that the crows were an old family in the land before he had appeared to plague the face of it ; and that they must just contrive to win through the winter as their neolithic ancestors did, and maintain the dignity of the race untarnished by the acceptance of charity from the newcomer. Thus crows show their independence by going to the seaside in winter, and but for man it is possible that many. more birds would pass the hard season there. To set against its wind-swept wintry bleakness the shore has many advantages. It is never frozen up, and every tide leaves something behind it, dead or alive. A dead fish is perhaps not sump- 
tuous faring, but it is sustaining, and the crow is nothing if not austere. So he eats dead fish and maintains his forbidding aloofness and savage selfrespect. When he comes to the back door for scraps the conquest of man will be complete. 


\section{THE BROWN EARTH}

To the landscape of winter the brown earth contributes one of the dominant notes. Grey skies, distances of a deeper blue-grey, fields far greener than those of autumn, and others which plough and harrow have transformed into a chocolate brown-sober tones all-they speak of the time when sunshine is neither abundant nor strong. But the fields of naked earth are not quite so naked as they look. Examine them closely, and the bare surface is found starred with many a hundred of tiny plantlets, each with an expression almost of appeal in its aspect of tender helplessness. That is a misreading of expression if ever there was one, for of all the living things on earth these are perhaps the best able to take care of themselves, and the least in need of considerate treatment. They are, in fact, the weeds with which the farmer wages incessant warfare, on which he is constantly inflicting reverses, but over which he never wins decisive victory. Of these weeds of field and garden it has been said that in the course of their continual warfare with one another, with the animals which prey on them, and with that particular animal which attempts to extirpate them, they have equipped themselves with a code 
of dodges more than equal to any reverse of fortune or assault of art that may be made upon them. And the saying is entirely true. The bare fields speak eloquently of one great and effective dodge. Just consider the significance of the fact that the surface on which the weeds of the summer cast their seeds has been buried many inches deep by the plough with all the seeds upon it. They are much too deeply laid, most of them, to get their heads up, yet here is a pretty crop already. anticipating the spring. What is the explanation? Simply this, that the seeds of the great majority of weeds are equipped with the power of biding their time. Those that are springing on the ploughed and dug ground to-day are not those that were cast a few months ago, but those of it may be many years ago.

A great deal has been written on the vitality of seeds which will not stand the test of experiment. It is an old, old story, for example, that mummy wheat, taken out of Egyptian graves formed thousands of years ago, has been successfully germinated. As a matter of fact, wheat loses its power of germination in a relatively short time, probably ten years at the most. But many other seeds, particularly those rich in oils, will retain their life for three or four times as long; and some of them, especially those of the most familiar of weeds, can wait for the favourable moment, even when buried in earth. Take the case of the familiar charlock-the wild mustard-which makes so glorious a display of yellow gold in the summer fields. It is a familiar fact that along 
with certain crops the charlock will not grow. If the field in which its seeds lie by the million is sown with grass or clover, it will lie low and wait for more congenial company. Knowing this the farmer may put a badly infested field into grass for several years, and flatter himself that he has vanquished the enemy. Vain hope! Dr. Edward Carpenter tells how a farmer of his acquaintance, pestered with charlock, tried to extirpate the pest by laying down in grass a field which the enemy had marked out for its own. At last, after seventeen years, he thought himself safe, turned up the ground, and lo ! the first spring it was ablaze with yellow again. "How," he asks, " did those seeds during all those seventeen years manage to understand the situation, and know that it was best to lie quite still in their little beds without stirring?" Probably they did not " know" anything about it. They awaited the fitting stimulation. But they as good as know, and it is difficult in such a case to avoid the language applicable to intelligence.

The " dodge" of biding time makes for efficiency on a large and conquering scale only when accompanied by the dodge of number, and no really successful weed neglects to make provision in this way. The prodigal plan of providing against the chances of life and death has been made familiar to most people, chiefly in connection with fish. The cod produces ten thousand (or is it ten times ten thousand?) eggs in order that one or two may reach maturity. I do not know if any one has attempted to count the seeds produced 
by a single vigorous chickweed plant, which has appropriated to itself a square foot of earth by its plan of squatting upon it and subjecting rivals to light starvation. It is unlikely that it is far, if any, behind the cod's, for its seed capsules are to be counted in hundreds, and each contains its dozen or score of seed. A dock plant is almost equally prolific, and the more pestilent of the weeds of the composite order, such as the groundsel, probably beat both. For a groundsel plant begins to flower in an open January, and many of the family flower in an open December. They may be said to be puffing out seeds for ten months of the year, and even pulling out by the roots only discourages and does not stop their efforts to inherit the earth. For a groundsel will continue to throw seed after it has been cast on the dungheap, turning up its head to the sunshine when its root is shrivelled. The outcome of all this seed production is that the ground is full of seeds, all biding their time. There is much more than earth in the brown fields which the plough has passed over, and a handful of earth examined with a lens would be found well stocked with dormant plant life.

All this is excellent for the birds. On a piece of dug ground in front of me several sparrows, two or three greenfinches, and many chaffinches, have been busy at intervals all day. They are coming and going, but the "break" is never without some feathered labourers. They are pecking as busily as chickens in a fowl-run, and apparently always getting something, and always 
getting it on the surface, for they never scrape. I examine the face of the soil, and can see nothing but soil. Evidently the birds have better microscopic vision, for they see something everywhere, and are doing the gardener a service which he is not too willing to remember when the fruit comes on. That the little eyes of the seedeating birds are extraordinarily competent in the detection of minute objects disguised in neutral tints is a fact of easy observation. I once lay and watched a wood-lark on a sandy slope near the sea, scantily covered with bent, and noted that it lifted something as quickly and incessantly as if grain had been spread on the place. Examining the surface of the sand I could find nothing but sand, crossed here and there by the wandering roots of the bent. The lark apparently went over the surface with a microscopic lens. But all this careful surface clearance the weeds can stand. They have provided for it, and have plenty of seeds underneath. Those that are buried less than an inch in depth will germinate as the soil warms under the spring sun; those that are deeper down will wait till some incident in agriculture brings them up. And if one in ten thousand reaches maturity, and casts seed in its turn, the purpose of the plant will have been served, for the position of the species will have been maintained. 


\section{THE UNSQUEAMISH BIRD}

IN their natural healthy state birds are, almost without exception, dainty creatures, but daintiness does not always or often characterize their actions. Indeed, one who walks abroad in winter days, and watches the feathered people, is struck above all things by their absolute superiority to that characteristic human trait-squeamishness. They have no objection to dirt, even when it is rank and smells high, and they approach putrescence with the serenity of an analytical chemist.

These remarks were suggested by contemplation of a bird assembly on a stubble-field. The field comprised the brow of a low ridge, and the slope of it extending down to a public road. Ranged on the brow was an immense host of black-headed gulls, a majority of them in immature plumage. They appeared to have "done themselves well," and were reposing, every one with his head thrown well into its shoulders, and its beak extended to the prevailing wind. Close by the gulls-that is to say, well away from the road-was a considerable company of rooks, all hard at work' and the nearer part was "crawling" with starlings, certainly thousands strong. Searching the surface carefully one soon found that besides these con- 
spicuous tenants the field had many others. There were blackbirds and song-thrushes in numbers. Missel-thrushes and fieldfares were abundant, and one little company of redwing, prettiest and trimmest of all the thrushes on the British list, kept in a corner by themselves. All the commoner finches were present, though on the field surface it took some searching to pick them out.

The field on the right was also in stubble, and it contained not a single bird. That on the left was ploughed, but, with its surface frozen hard, it was equally tenantless. What, then, brought all the vast assemblage to the particular field favoured by so many diverse kinds? Simply this, that preparatory to ploughing it the farmer had spread its surface with dung ! To gulls, rooks, starlings, thrushes, finches, this made it a perfect Eldorado, and with the exception of the gulls, which are among the few birds that seem capable of repose, they were working it with the eagerness of miners in a hurry to get rich. What they were finding it is difficult to guess. Undigested grain was no doubt part of the treasure. The larvæ of flies that live in manure doubtless added variety and succulence to the meal. Perhaps the heat of the fermenting stuff had thawed the ground around the heaps, and opened the door of the birds' great treasure-house, the earth. But whatever it may have been it gave to the field all the alluring qualities of a table well spread, and brought the guests in thousands from far and near. And of disgust not a sign. Probably man is the only 
animal capable of experiencing that emotion, and if so, it furnishes material for a new definition, capable of putting him in a class by himself. Most of the others, as in these learned days, everybody knows, have broken down.

One who searches the bird world for other manifestations of unfastidiousness will not have to go far to find them. What could be daintier than a tit feeding from a cut cocoanut or a suspended lump of firm fat? Nothing, unless it be another tit. But if instead of a cocoanut you hang up a dead dog, which has begun to "go wrong," the tit will appreciate the treat equally well. It is just nourishment to him, and he is serenely undisturbed by the fact that chemical or bacteriological processes are liberating gases which do not have the same smell as ozone. There is no daintiness about his senses, and for all the difference a good high odour makes to him, he might be without the sense of smell. He has his own sense of beauty; he knows that his plumage looks very fine, and his mate is reputed to have so nice a sense of colour and arrangement that she chooses her husband on the strength of the superiority of a shade. But neither is repelled by ugly things.

The sea-gull's happiness in the manured field has been referred to. The fascination exercised over him by the exit of a city drain is known to all who happen to live in a town on river or sea. There the wild and romantic seamew may be seen every day of the year breasting the current where it is nastiest, and not to be tempted away to 

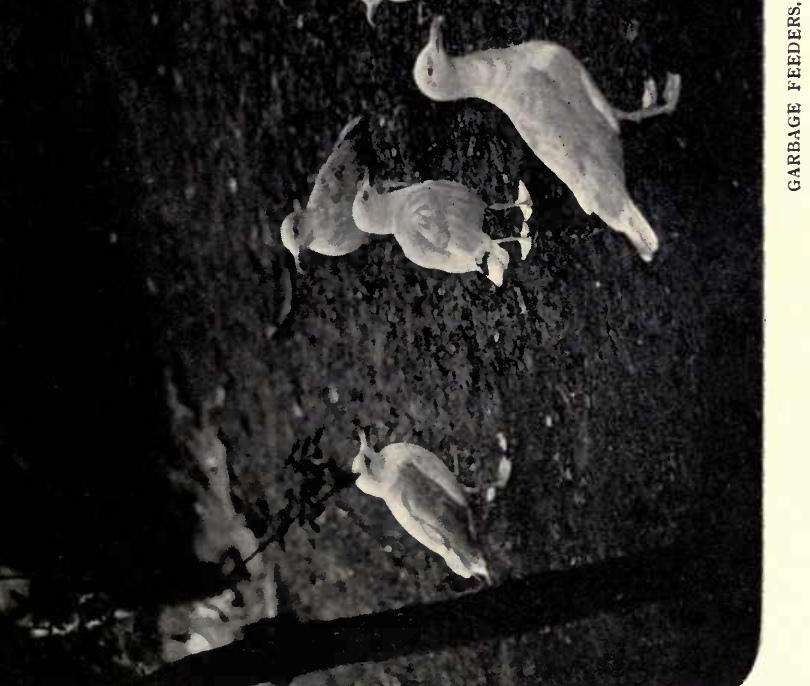

the places where it is clean. What the gull finds there is a matter in dispute. It may be the ejecta of the city, or it may be the little fishes which also gather where the water contains a good deal more than oxygen and nitrogen. Probably it is both. If you wish a really good opportunity to make photographic pictures of the romantic seamew, there is no place to equal a city manure depôt, placed away among the fields and conveniently fenced in. Their hours of labour are passed on the wing, their hours of ease on the rail, and at the time of afternoon repose it is lined with them as tightly as they can squeeze. But though the gulls have a hearty delight in a thoroughly dirty place, it must be admitted that they always manage to keep themselves spotlessly clean. They have mastered the problem of touching dirt, revelling in dirt, absorbing dirt, without themselves becoming defiled, and that is more than humanity has done.

It might be supposed from all this that birds have no sort of natural dislike of dirt. Generally speaking, however, it can be said that as housekeepers they are cleanly animals. With a few exceptions, they keep their nests clean, and put themselves to much pains to remove accumulations. In short, they have a sanitary system which is quite effective if not precisely nice. And where there are exceptions, dirty homes are a result of the birds' mode of feeding their young. Thus the nest of the golden eagle, before its two young inmates are able to take to the wing, might be discovered by the sense of smell. When the 
parent birds take a grouse or hare which is meant for the provision of the young, they pluck their prey clean of fur or feather before taking it to the nest, and they have usually one place, which becomes exceedingly well marked, for the purpose. But the indifferently picked bones are left about the nest, and in due course become very high. What is true of the eagle is true too of the larger hawks. The vicinity of the nest of many seabirds becomes exceedingly foul, and the odour arising from the putrid remains of fish becomes, in the case of the cormorant, overwhelming. The cormorant herself seems to sniff it in with appreciation, and would probably think it a poor home which did not smell of peace and plenty. One of the dirtiest of birds' nests is that of the little sand-martin, but the filth of it, consisting mainly of fleas, is rather the bird's misfortune than its fault. The martin is an expert insect catcherlives on insects, in fact-and never varies its diet. But it takes all its prey on the wing, and itself becomes to a lamentable extent the prey of insects which do not fly. In its case the aptera may be said to avenge the wrongs committed daily, hourly, momentarily on their far-away relatives, the diptera, on which the swallows chiefly subsist. 


\section{THE HARDY MIDGE}

A CoLUmN of midges dancing in the sunshine is a summer-like spectacle, and, speaking in a general way, nothing is more characteristic of winter than the dormancy of insect life. But several midges of the group known to science as Chironomus are exceptions to the rule which sends insects out of sight for half the year. There is not a roadside wall which is not the home of countless thousands of them. If the weather is cold and frosty they retire to its crevices, which afford excellent stabling; if the sun shines long enough to impart the feeblest glow of heat to the atmosphere, out they come and dance-dance like mad. They have little else to do, and they do it very well.

This midge is one of the most insignificant of winged creatures, yet it has virtues which almost entitle it to a respectful study. It is the good brother of the story, and it might advertise, as men of conscious rectitude troubled with bad relations sometimes do, "No connection with the other people of the same name." It does not bite. Its morals may be bad, but its ethics are admirable, and the story of them is one of the most curious in evolutionary science. If one of these dancing midges is examined it will be found 
to present a general resemblance to the familiar daddy-long-legs very much reduced. It has long legs, a thin body, a relatively large, shall I say, chest, and a small head. The head has to casual observation the usual equipment of mouth and sucking parts. Let the examination be pushed further, and it will be found that in the body there is something distinctly resembling the usual equipment of digestive organs. But for all that, the midge never eats, and therefore it never digests any food. Never eats ! How, then, does it live? The truth is it never eats as a midge. By far the greater part of its life is spent at the bottom of water as a larva, and in that state it does " a power of eating." But when it emerges its sole business is to find a mate and reproduce its kind, and in order that it may not go foraging after provender it does not really need, when it emerges in the perfect state its mouth is soldered up.

Probably a long way back in the history of the family our innocent midge was a bloodsucker. The biting midge, better designated as the gnat, is a not remote relative, and its armoury is one of most ingenious things in nature, being a complex arrangement of lancet, fretsaw, and pump. For the purpose of piercing skin and sucking blood it would be impossible to improve upon it, and everybody who has passed a summer day in the parts of the country where swampy ground occurs knows that its appetite is as keen as its weapons. Yet to the vast majority of blood-sucking gnats their weapons and the desire to use them represent in all probability nothing but an exquisitely 
torturing curse. There are large areas of the world's surface where biting gnats and mosquitoes -the same thing-abound in uncountable millions, and where of the larger forms of animal life there is practically none. Mr. Hudson has described such areas in Southern Argentina. The biters exist in clouds, and when a man visits these parts they assail him with a ravenous greed; but year in year out they never taste blood, though they. want it all the time. Their case is very much the same in those large parts of the Amazon area, where the biters thicken the air.

In this state of things the naturalist may find a hint of the explanation of the loss of eating powers in the innocent midge, for the blood-sucking capacity cannot be much of an advantage where there is no blood to suck. At any rate, the loss of its power does not seem to have " hurt its prospects," for its various species continue to abound in regions where the biter has become extinct. And it is altogether a hardier creature. Though the biting gnats abound from Greenland to Patagonia, they are, as flying insects, emphatically creatures of the warm days. The other is much less at the mercy of cold. Every-day experience shows that it can survive the hardest frosts experienced in Britain, and come out smiling in the intervals. Indeed, it has been alleged that even when it is frozen as hard as glass it can be thawed out again into active life.

The statement is not so incredible as it looks. There is a prevalent belief that a hard winter is destructive of insect life, but it is doubtful if 
it has any such effect. Definite observations have proved that in this country insects are not less abundant after a severe winter than after a mild one. But there is ample proof that insects in their larval form can survive almost any degree of frost. There is no country in the world more afflicted with insects than Lapland. In summer they thicken the air, and render even breathing a matter of difficulty. They prove too much for the far from delicate cuticle of the Lapp and of his companion, the shaggy reindeeer, and both are forced to seek relief in the heights. But the larval form of these same insects pass the winter at the bottom of the innumerable shallow lakes of the country, or in the water of its swamps, which are frozen hard to their depths. Stories of frozen fishes resuming their active life are probably indebted to their maker, but that larval insects can endure a freezing hardly admits of a doubt. The midge may carry the power a step further on in its life. 


\section{FEBRUARY}




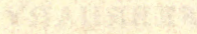





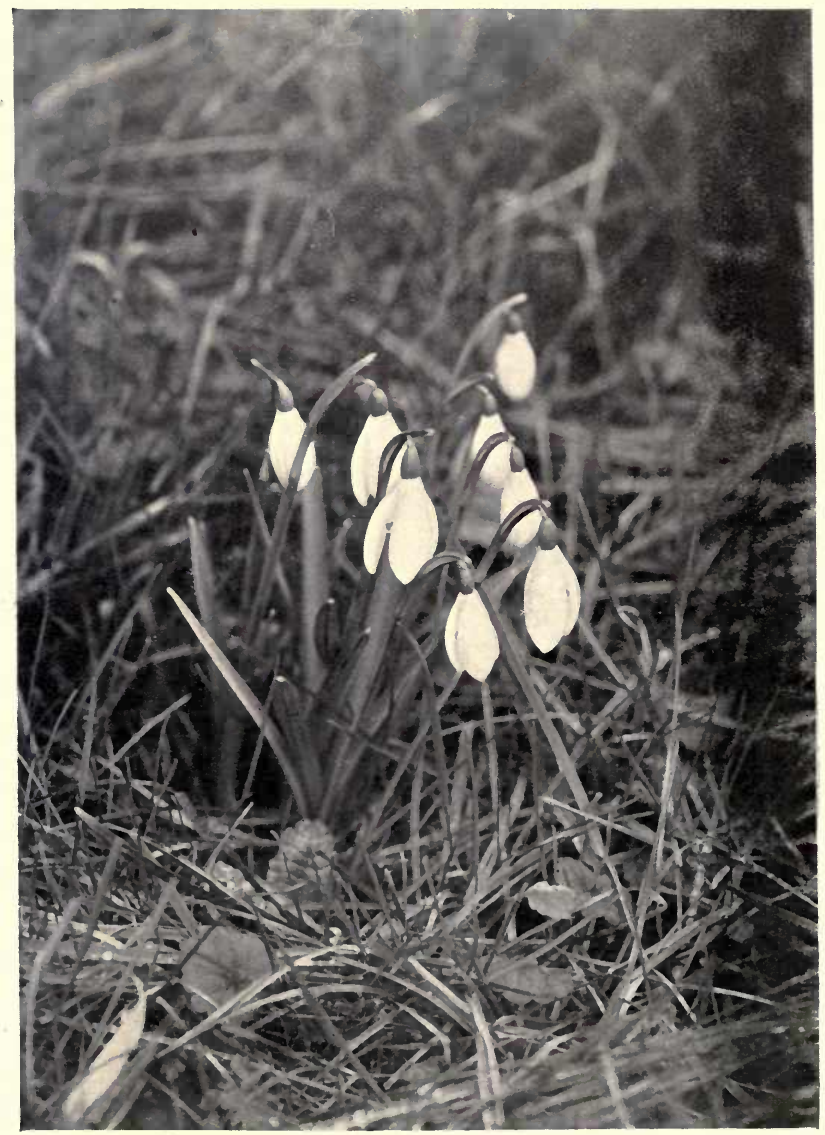

SNOWDROPS.

[L. R. F. Horn. 


\section{FAIR MAIDS OF FEBRUARY}

IN the floral poverty of the early year we lavish admiration on the snowdrop, but it is quite pretty enough to claim a glance even if rivals lay in cohorts around it. Purity could find no more perfect emblem than this chaste little blossom, whose delicacy and temerity in braving what is often the surliest month of the year, excite in us a mixture of emotions in which recognition of pluck is dashed with pity. Daffodils-

come before the swallow dares, and take The winds of March with beauty;

but here is a mere child of a flower, compared with the robust beauty of March, defying the winter as if it were a paragon of hardiness.

The snowdrop is never seen at its best where it is most often seen-in the garden border. Like most flowers which spring from a bulb, its proper place is among grass, and to realize the effect it is capable of producing, one has to see it growing in irregular masses from the sward under old trees. In such a situation as this the flower lives long and multiplies freely, and nothing the year has to show can excel such a family party 
in pure and appealing beauty. Snowdrops form a family known to botanists as Galanthus, and there are about two dozen natural species and some florists' varieties available to the gardener. All the natural species are beautiful, and some of them are much larger than the British species. The florists' varieties, particularly the doubles, are conspicuous failures to improve upon Nature.

Extreme earliness of flowering is the most marked peculiarity of the snowdrop tribe, though there are species which depart from the rule. It has sometimes been jestingly said of the florist that in his efforts to make early flowers flower earlier he has turned them into "lates," and it is certainly a fine question whether a narcissus made to bloom at Christmas is a late flower or an early one. What the gardener has done in this way some of the snowdrops have done for themselves without his assistance. The habit of the family is to begin business the moment there is a break of the snow, but some of the species, in their anxiety, as it were, not to miss a chance, get through with their flowering just before the snow begins. These are the autumn snowdrops.

The snowdrops illustrate a phase in the strategy of life which is by no means peculiar to themselves. We are accustomed to think of the inhabitants of the sterile parts of the earth, whether they be flower people or other people, as exceptional examples of hardiness, and generally they are as hardy as they are esteemed. But it was not hardiness that sent them to the sterile parts. On the contrary, it may safely be inferred that origin- 
ally they went there because they were relatively a feeble folk. They retired before a competition which they could not face, and left the more desirable parts of the earth's surface to the stronger races who were capable of seizing and holding them. This is probably true of most of the mountain plants. Take the case, for example, of the lycopodiums, or club mosses. Far back in the world's history they were among the dominant plants of the earth, and, of tree-like dimensions, played a great part in the formation of the coal. To-day they are dwarfs confined to the higher altitudes, where competition for space is slight. They have yielded up the good grounds to more pushing rivals, and have prolonged existence by adapting themselves to an environment where the struggle is slack.

And just as there is a surrender to competition in space, so there is a yielding in time. June and July are great flower months, but they are also the months of intensest struggle. The plants on the sunny side of the hedge are fighting one another for root space, straining to overtop one another and get the most of the sun, competing furiously with one another for the attention of insects, resorting to all manner of cunning devices for the successful deposition of their seed. Those of them which cannot keep their heads up in the struggle must either submit to extinction or get into a less crowded part of the year. Some have got over the difficulty by waiting till the crowd has passed, and these are the autumn plants. Others have solved the problem by getting to 
work before the crowd has assembled, and these are the flowers of spring. The snowdrops have found it difficult to compete even with the flowers of spring, and have pushed back to the very gates of winter, where they find themselves without competitors for such sunshine as is and for the attention of such insects as are then abroad.

From action of this struggle-evading character it is not necessary to infer a general all-round weakness on the part of the evading organism. A single defect of quality might suffice as the determinant, and there must be powers of adaptation of other kinds if the evasion is to be a success. The American expression, "Get out or get on," describes the case. The bulb plants of spring have got out and got on, and their device of the bulb is the secret of their success. They flower early and scatter their seed, but after getting these vital functions done they use the heat of early summer to store up, by means of roots and leaves, food supplies which enable them to rush through with the vital processes at a time in the following year when without their store they would be lost. They have also furnished themselves with means of resistance to cold, and it is a curious fact that the air within the drooping bell of the snowdrop is always two or three degrees higher in temperature than the air without. This is a matter of importance, for in time of frost the organs of the flower are always the first to suffer, and when the anthers are frost-bitten the flower containing them produces no seed. But bulb plants, with their power of budding from the bulb, are less 
dependent upon seed for their multiplication than most.

The history of plants in time is a very long: story, and we know little about it except by the methods of inference. In human affairs it is well known that races driven into the least desirable parts of the earth by the competition of stronger rivals often acquire in their new environment a new strength, in virtue of which they are able to retaliate upon their ancient enemies, grown soft with easy living. Most of the great conquering races, whether in Europe or Asia, came out of the North, and if we could push back their history we should almost certainly find that they did not go into the North as conquerors. Whether anything analogous to this has occurred in the slow evolution of plant forms no one can say, but there are facts which suggest it. Not a few with the distinctive equipment of the spring plantthe store of nutrition enveloping the well-formed flower, ready to push up at the earliest suitable moment and live in a hungry season on its own capital-occur in the wealth of summer when such a provision is unnecessary. An imaginative botanist would say that they are plants which got out and got on, and got strong and came back. But if there are any such the snowdrop is not among their number. It is still a backgoer, seeking a place for itself outside the competition. 


\section{THE ROOKERY}

THERE is more human nature in the average rook than in many a dry human stick; or, at any rate, that is the opinion a close watcher of the rook community is almost bound to carry away. The rookery I have in mind became a scene of active life during the last week of February. One bright morning the tenants returned to inspect their old homes, and the first beginnings were made with the work of hauling out the sodden and rotten parts of the structures to make way for the new. It was observable that at this time the male rook was more advanced in the seasonal amorous frenzy than his mate. He assumed attitudes before her, flirted his wings, fanned his tail, put his head and neck into queer contortions, and made distinct efforts to sing, eyeing her with glances of devotion the while. She observed those attentions with good nature, just tinged with contempt, and when he approached her " sidled" along the bough, saying in the plainest of rook language, "Get along, you giddy old thing !"

But soon she came under the influence herself, and scenes of sentimental comedy followed, which are probably unique in bird life. When he attitudinized she fluttered her wings in the manner 
of young birds which have just left the nest, and made petted noises in her throat. Sparrows do this, but not what followed; for, having done all that could be done by deportment to manifest the state of his beating heart, Mr. Rook descended to the field, caught a wireworm, and, returning with it, fed the lady, who received the morsel, again in the manner of the young. Many male birds feed their mates after incubation has begun, but the rook alone introduces the function among the offices of courtship. Thus he may be said to have reached that stage of emotional evolution which the comic papers affect to believe has been attained only by cooks who lavish on policemen at once the treasures of the heart and of the pantry.

It is no doubt because he wears a black coat that the rook is reputed to take sober views of life. In truth there is no more frolicsome creature living, and the business of getting a rookery a-going is enlivened with fun and joke throughout. The repairing of old nests and the building of new ones goes on very slowly, and in explanation of this it has been said that the rooks spend more time in stealing sticks from one another than in getting sticks for themselves. It would be idle to deny that they do steal from one another, but when they do so it is probable that they do it to gratify their sense of humour rather than in the spirit of larceny. Often they do no more than pull out the carefully adjusted twigs and leave them on the top of the nest; and those members of the community whose own nests are completed 
up to the lining stage, and who are, therefore, in no need of sticks, are not one whit less active in this sort of sport than the rest. In my rookery the practical jokers were numerous and determined, and their favourite joke was not to steal a stick, but to pull it out, drop it to the ground, and next moment affect to be absorbed in the labours of plumage preening. Then they are all prodigious talkers, and while the renovation went on they conversed without ceasing all the time, criticizing one another's work and engaging in sentimental interludes. Twice the communal sense asserted itself. In one case a couple, presumably young, commenced to build a new nest at a considerably higher altitude than the general level of the rookery. They worked in peace for a day, but on the second day an Act of Parliament was invoked against the aspirants, and their nest was pulled to bits. If a pair of rooks care to build at a lower level than prevails they are permitted to go on; the discomfort will be theirs. But if they try to get unduly up in the world, it is quite a different affair. Then the public interest comes in. The other pair which outraged the law did it by attempting to build in the top of an ash a hundred yards away from the group of elms favoured by the community. They were punished for their aloofness by having their work wrecked after they had laboured on it for three days. As all these leisurely repairing operations are carried out in the mornings, and the greater part of each day is spent in the fields, two or three weeks pass before the rookery is actually a going con- 
cern; but in the last week of March black tails will become visible sticking over the edges of many of the nests, evidence that the labours of incubation have begun.

It is during sitting-time that the rook shows himself at his best-and also, alas ! at his worstas a family man. Some observers of rooks have denied that they ever enter into the bonds of matrimony in the strict sense of the term. Each male undoubtedly does undertake the duty of providing food for one wife and family, but this, it is alleged, is merely an apportionment of communal labour, and does not carry with it monogamist obligations. The indictment is unproved. What is true is that the rook is a great and unabashed flirt. During April he labours hard in the fields to feed himself and collect enough to satisfy the appetite of the sitting lady in the tree-top. But when he has fed her he thinks nothing of hopping on to the edge of another nest and breathing soft nothings to its occupant. In nine cases out of ten the matron will receive him with asperity, but there is generally a tenth case in which the conduct of the tempted fowl will not bear investigation. And the curious thing is that the legitimate spouse of the flirt may be eyeing him all the time, but she retains an unconcerned placidity, and, in the language of Marjory's poem about the turkey, " does not give a single dam."

It has often been remarked as puzzling that the number of rooks in a rookery never corresponds with the number of nests. In the case 
I write about there are twenty-three nests-three, however, untenanted-and I have been able to count forty-nine birds. There are thus nine birds which are either bachelors, spinsters, widows, or widowers. Probably they are bachelors and widows. The rooks that are shot in springtime by farmers who suspect depredations on their autumn-sown wheat are generally male birds, for after rookery business has got well under way the females go little to the fields. It is likely, therefore, that the rookery contains some widows, and as there are some among the supernumeraries which have been observed to do temporary sitting duty while a cramped mother stretched her legs and wings, the probability is increased. But there are bachelors too. Among most birds a proportion of the one-year-olds fight shy of family. responsibilities, and rooks are no exception to the rule. The social instinct compels those unattacheds to join the rookery, and their influence, it is to be feared, is uplifting by no manner of means. 


\section{RESPECTABLE AND DISREPUTABLE RELATIVES}

THE case of the house-sparrow and the tree-sparrow has been employed as one wherewith to challenge the adequacy of the theory of natural selection. There is a slight difference in the colouration of the males, and whereas in the case of the housesparrow the male and female have distinct plumage, in the case of the tree-sparrow the sexes are nearly indistinguishable. " Such differences," says a distinguished naturalist, " cannot be explained by any theory of their survival value." The case is not one of the strongest, for sex dimorphism, whatever may be its explanation, is undoubtedly a considerable fact. But probably most Darwinians would admit that there has been a great deal too much of that sort of fine-spun argument which detects survival value in fine shades of difference in plumage. It is widely recognized that an obvious mark of difference between species, as in plumage, may have no direct significance whatever. Modifications rarely take place singly, and there are certain modifications of parts which always take place in groups or pairs. One of them, and that not the patent one, may be the change that counts. The stock case is that of 
white cats with blue eyes, which are always deaf. It seems impossible for a white cat to acquire blue eyes without at the same time losing its power of hearing. To put the matter in the form of a proposition: the patent modification may be only the outward and visible sign of some invisible grace or defect, which grace or defect tells in survival and not the thing that meets the eye.

In the case of the two sparrows it is perfectly safe to say that the thing that counts is not the slight difference in plumage, but a psychological difference which may or may not be related to it. And here it is too readily taken for granted that we have a case of a remarkable success in life -the house-sparrow, and a comparative failure -the tree-sparrow. Despite its obviousness the assertion may be challenged. In a good natural history sense the tree-sparrow, a perfectly respectable finch, is an honester and more stable success in life than its squalid relative. To begin with, the species has proved its adaptability to an area of enormously wide geographical range, extending from China to Britain. Nor is it a back-going species, for though nowhere outrageously numerous, it has extended its range in quite recent times to such outlying parts as the Faröe Islands. But the important thing about it is that its success is securely based on nature, and if all the artificial conditions created on the earth's surface by civilized man were to disappear, the treesparrow would not be seriously incommoded by their disappearance. Human cultivation is not 
inimical to it; it even takes advantage of it. But it is no more dependent upon it than any other member of the finch family. Thus it may be said to be a healthy success.

How does the case stand with the house-sparrow, commonly called ubiquitous? As a matter of fact, it is not ubiquitous by any means. There is hardly a country in the world to-day in which the housesparrow, or one of its local races, does not abound, but in each and every one of them its area is almost strictly the area of cultivation. There are still vast expanses of Russia where it is unknown, though it faithfully follows upon the heels of the cultivator when he breaks open new ground. Even in Scotland there are considerable tracts where it is unknown-a glen which has neither habitation nor cultivation is a place where it cannot live. In short, the house-sparrow is a parasite, and despite its seeming success there is that precariousness in its state incident to the state of all parasites. It is sometimes spoken of as the " avian rat," but it is really more of a parasite on mankind than the rat. The rat enters into and enjoys the fruits of human industry to the full, but it can get on without them. There are rats on the seashore far from human works, and rats have been trapped very near the top of our highest mountains. To these and many more likely places the house-sparrow does not penetrate.

What does all this imply? It probably implies that at no distant date, biologically speaking, the house-sparrow was a creature of much more limited range than its cousin the tree-sparrow, 
which is of no such dependant nature. If it existed at all in the time of palæolithic man, who was a hunter, it must have been a very moderate success indeed. The psychological modification which marks it off from all the other finches, and is its real distinction, could have been of no survival value to it, but when neolithic man, the cultivator, came in, Mr. Sparrow got his chance. His case is like that of the sub-species of man, flourishing greatly to-day, distinguished by preeminent ability to operate successfully on the Stock Exchange. There were doubtless always men with this talent embedded in their brains, but it was no use to them-a worthless modificationthrough all the ages of simple industry. They got their chance for the first time when Stock Exchanges were invented.

I have said that there is something of that precariousness in the position of the house-sparrow incident to the position of all parasites. The success of a parasite always depends on the success of its host, and if the host discover a means of guarding itself the parasite's day is done. The sparrow's human host seems in a fair way to survive, but if he made up his mind that the sparrow was seriously injurious to him and must be extirpated, the work of extirpation would not be really difficult. If an order were issued for the destruction of almost any one of the finches it would be extremely difficult to carry it out. They are not easily found when wanted, and their nests, without exception, are well hid. The nests of the house-sparrow, on the other hand, are always 



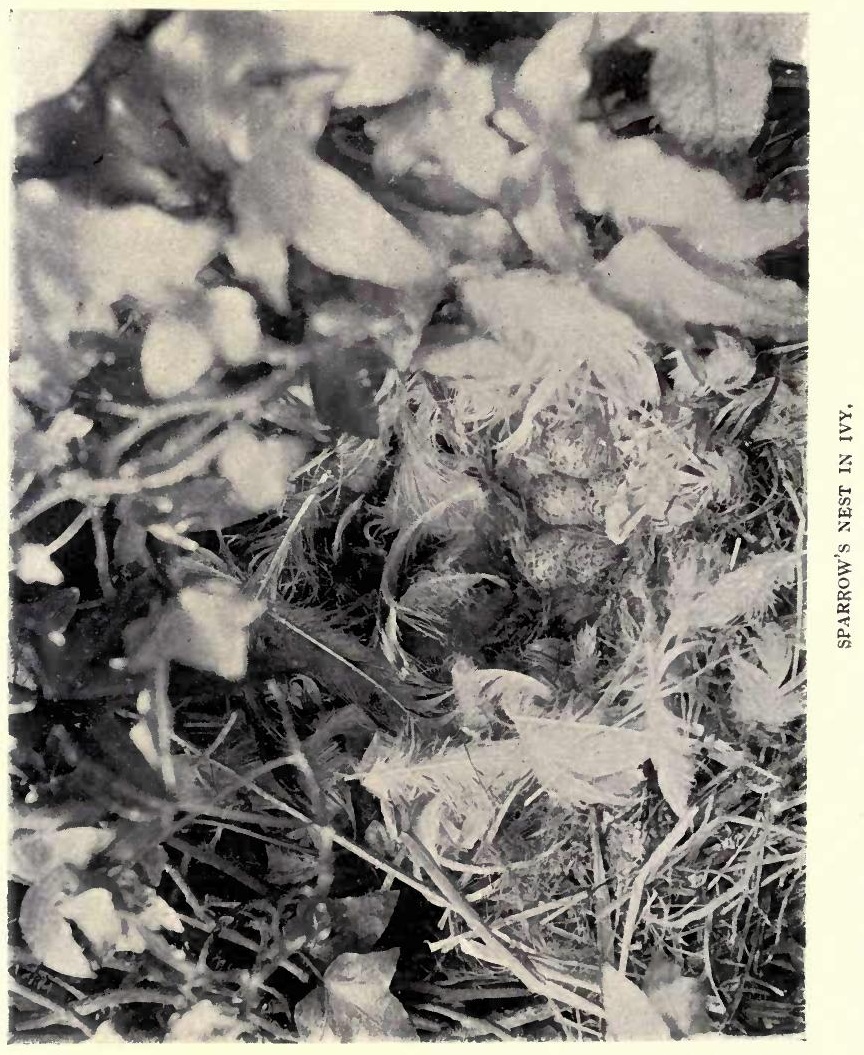


easily found. Were an Act of Parliament passed requiring the owners of property to destroy the nests of all sparrows harbouring on their property, it would be a somewhat laborious but otherwise easy thing to give it effect. A ladder would be the sole equipment necessary. for the campaign. Five-sixths of the nests are placed in buildings, and if they were not advertised by their untidiness their owners would obligingly point out where they are. Those placed in trees are invariably of studied conspicuousness.

In their nesting habits the house-sparrows exhibit another phase of their tendency to parasitism. What we may take to be their own natural nest is a clumsy domed structure placed in trees. When they nest in buildings they omit the dome, and are always ready to dispense with nest-building altogether if they can steal another bird's nest. In this connection the swallows are their chosen victims, and there is some reason to believe that they occasionally steal nests from one another. But they give no symptom of a desire to pursue further than this the road of the cuckoo, for the sparrow has a genuine pleasure in the labours of family-raising. 


\section{TUNING UP}

THERE is an early phase of the spring madness of the birds which so far has little to do with love. A quickening of the pulses, an accession of vitality, comes with lengthening days. Spirits are rising high with the temperature and call for liberation. They are highest in the case of the early nesters. Here, for example, are the tits. They are high-spirited little animals at the worst of times, but they are pre-eminently summer nesters, and it is still winter with them. They have not broken up their companies, and they come all day long to feed on the lump of suet hung up for their benefit. The note of the great tit has risen in shrillness and frequency, and the saffron (or is it sulphur?) of his breast is perceptibly brighter than a month ago. But he is not yet thinking of love, and he is not more sportive than it is his prevailing habit to be. With the blackbird it is very different. $\mathrm{He}$ is in the jocund mood of early spring, and in a very few days he will rise to the blithe heights of pugnacity and fight allcomers of his kind just because he feels astonishingly vigorous and fit.

To watch the ongoings of the blackbirds as February advances is a pure pleasure. Here are 
two cocks on the same lawn. One is diligently. searching for worms, and from the gusto with which he goes at the labour of hauling one out whose head he has caught it may be inferred that spring worm is good. There may even be intoxicating qualities in spring worm capable of accounting for much. However that may be, the first blackbird is intent upon the extraction and deglutition of the unhappy annelid, which doubtless had its own hopes in a world warming up. The second blackbird is probably digesting the contents of a full crop, and for the moment has no need to look for worms. Suddenly he fans his tail, droops his wings, and with head turned towards his fellow begins a curious posturing march or run in front of him. To all appearance he is " trailing his coat." The other goes on with his worm and takes no note. It is a fine big worm, and has to be cut into sections. The cutting is done in a truculent fashion, the poor victim being simply dashed and shaken till he breaks. When the last wriggling fragment is down and the feaster has lifted his head and twisted his neck to settle the feast in its right place, his eye falls upon the posturer a yard away. Then his tail opens out, too, in a downward fan, his wings droop and trail, and he performs his own semicircular march. In this way the two keep performing around one another, till suddenly, with a clash of harsh notes, one of them breaks up the performance and flies away.

There has been no approach to a fight. The two have merely performed at each other, and 
there was no lady to show off before. Some distance away, under the shrubs, a hen blackbird was busy looking for anything good to eat, scattering the dead leaves in the blackbird fashion, which is quite different from the fashion of the fowl and its kind, in that the beak and not the feet performs the chief part. But she never looked up at the little play, and the players never looked towards her. In a week or two their manner will change, and so will hers, for when the courtship fury really blazes up the hen blackbird takes a masterful share in it.

The robins are a trifle further advanced than the blackbirds, for they are engaged in little pugilistic passages-not the furious fights that will take place next month when an angry pair of cocks will grapple and roll over one another, making the feathers fly-but showy encounters with less rage than style. Here is one on the lowest branch of an apple-tree, wings half-expanded, beak open, making threatening bobs at another on the ground. The groundling is looking up with beak half-open, wings just raised from the body and no more, evidently watching for the next move in the game. As the upper bird drops the lower rises, and away the two go on a swift chase, passing through the branches, one close behind the other, with a speed which seems to court a crushing mishap. But they thread the maze in safety every time.

There has been curiously little love-making among the sparrows, which always make an early start with their family affairs. But, perhaps, that is because the sparrow, when he does begin, gets 
to business with great expedition. He does not dispense with courtship by any means. On the contrary, no small bird goes through a more ostentatious love-making. But the lady is not coy ; she quickly makes up her mind to accept a good offer, and then the two proceed to nest-making: without an hour's delay. In the meantime they are getting up steam on yellow crocuses. The passion of the sparrow for yellow crocuses has never been explained. It is not a simple matter of gastatory taste, for if it were the question would be simple. Most of my yellow crocuses have been torn to bits, but most of the bits are lying about still. And why are the white and purple flowers left untouched?

During all the winter I have obtained entertainment by hanging up suet for the tits, but have just learned late in the day that this sort of amusement may be varied with no loss of sport. A piece of fat suspended clear from a string is the tits' own property. No other bird can make anything of it, and only the robin tries. The other day I was offered a very large lump of fat, and as the tits' string was well plenished I hung this fresh supply among the branches of a currantbush nailed against a wall. There was one excellent perch from which it could be assailed. Blue tits were the first to find it out, but soon the sparrows found that they, too, could share, and from that moment the blue tits had hardly a chance. The sparrows kept the treasure, and there were seldom fewer than four of them waiting a turn on the perch. The great tit alone among the smaller 
birds could bounce them out of the way. But soon another claimant appeared upon the scene in the person of the starling. Now the starling is about as vulgar a fellow as the sparrow, though a much better humoured vulgarian, and he is twice or three times as strong. The manner in which he dominated this situation was as good as a piece of low comedy. He simply ignored the very existence of his vulgar little brothers. When he arrived to have his peck there was always one of them on the perch ; Master Starling just hopped down on its back as if it were not there, leaving Master Sparrow to find a way out for himself, which he did, ruffled and angry. But though the sparrows must make way for the starling, as a light-weight must make way for a heavy-weight, they are not afraid of him. They sit on the perch beside him waiting till he moves away, and when he tears off more fat than he can get inside his beak all at one time the sparrow next to him complacently, and without evoking any sign of resentment, picks off the projecting morsels. 


\section{MARCH}




\section{THE CUNNING OF TROUT}

IT is possible for a vast aggregate of thinking to be performed around a particular problem without advancing its solution. Thus, on the first brilliant Saturday afternoon in March ever since the close of the ice age the goodly army of anglers have turned a willing mind to the great question of fish. From then till October, throughout all the intervening ages, they have speculated on fish, told stories about fish, and even lied about fish. They have fondly rolled their agile conceptions of fish into and out of every corner of their crania. They have despised and mistrusted their fellowmen who are in imperfect sympathy with fish; and even the angling peasants of Cumberland looked down with lofty contempt upon Wordsworth because, as one of them put it, "there wasn't a bit o' fish in him." Yet, notwithstanding all this, the psychology of trout remains in a backward state. Indeed, it is highly probable, though not subject to proof, that neolithic man, after a day of it on the river with hooks made out of thorns, black or white, said precisely the same things about trout as are said to-day by every little assembly of fishers gathered at a wayside station to await the last train. He paid his tribute to 
the great mental powers of the trout; so do they. $\mathrm{He}$ remarked on its great ability to learn from experience; its mastery of the disguises of hooks; its profound wisdom in old age-so do they. He wondered what trout thought about him; and to-day they raise conjectures on the subject of what the old fellow "is saying to himself " about them as he lurks in his favourite hole beneath the big root of the alder-tree. Neolithic man credited trout with firmly held views as to the relative safety of blackthorn hooks used with or without the bark, and his modern descendant has merely changed the mechanism of the opinion, and credits his quarry with views on tinsel or hackel of hare lug. Then, as now, the sceptical man who ventured (within reach of water) to declare that trout have no power of thinking at all, that they are as unteachable as a dead machine, would stand in imminent danger of a watery martyrdom as fit retribution for his most accursed heresy.

And yet the heretic would be very near the truth, for it is only in fables and anglers' tales that fish are creatures of intelligence. They are born with a certain endowment of fear, suspicion, and fixed utilitarian instinct, and an endowment which experience hardly, if at all, modifies up or down. When a naturalist wishes to find examples of unteachableness he goes to the fish kingdom; for though fish stand higher in the order of life than the insects and other articulated creatures, their adaptive intelligence is universally lower. A spider, for example, may be taught in ten minutes 
to get the better of its inherited instincts, if some disagreeable result follows the attempt to gratify them. Present one with a fly dipped in an unpleasantly tasting substance like turpentine, and after two trials it will learn to subordinate the whole teaching of its countless ancestors that a fly within reach is a thing to be pounced upon. But a fish will go on plunging at a thing which, were it a teachable creature, experience would have warned it to leave alone. There are countless examples of salmon, and even trout, taking the fly within a few minutes of being struck, and there are many cases of a salmon being caught with the hook still in its jaw which it had broken off after a mighty struggle half an hour before. But more striking experiments than these have attested the unteachableness of fish. Mr. Bateson tells how none of the fish in his aquarium seemed to get a lasting appreciation of the nature of the glass wall of the tank. The same fish again and again knocked their heads against the glass in trying to seize objects moving on the other side, and some of the oldest inhabitants continued to the last subject to the fish's natural instinct to pounce, though it meant a damaged snout every time. Even the examples of teachableness in fish only emphasize a general belief in their unteachableness, as in the well-known case of the pike which dashed itself for three months against a glass partition in the attempt to get at some minnows in the next division of the aquarium, and became at last so firmly persuaded of the danger of attacking them that, when the partition was 
removed, it left them quite unmolested. In this case the pike never learned anything about the partition. It merely got fixed hard in its head a dull notion that there was something about those minnows which interfered with their usefulness as articles of diet. Of course, in support of the belief of the teachableness of fish there will be cited the case of those young hatchery trout which come up in shoals to be fed on their attendant making the customary sign. This, however, is not a case of intelligence. It is but a free response to a natural impulse, the almost mechanical performance of an action in the direct sequence of a stimulus acting on one of the senses. The stupidest moth will quickly learn to respond in the same way to a scent which it associates with food. It is not in responding to, but in the inhibition of, such impulses that intelligence, and particularly the sort attributed to fish, should be shown.

How, then, is the so-called cunning of the trout to be accounted for? The question is not very difficult if one keeps steadily in mind the fact that they have been fished for since, at any rate, the days of neolithic man; and teachableness has not necessarily any part in the problem. Through all those ages man has.been steadily extracting from the water the fish with an inferior original endowment of suspicion; and, considering the length of time during which the process has been going on, the surprising thing is, not that fish are suspicious, but that there are any strains left with so little suspicion that they may still be deceived 


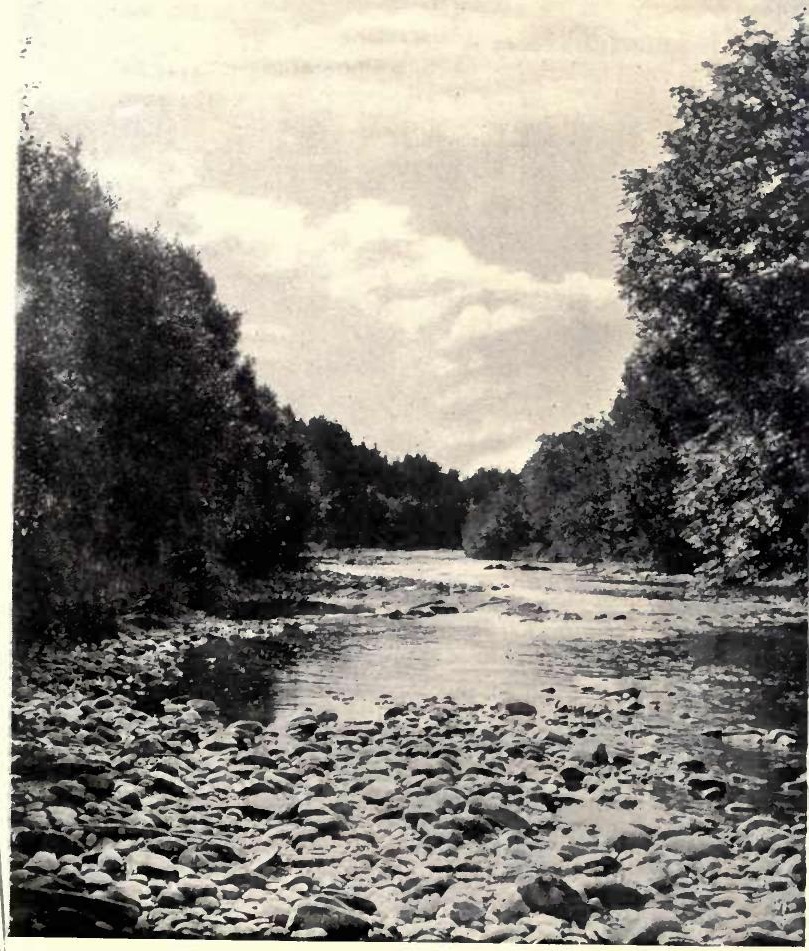

A WET-FLY STREAM. 

with a confection of steel, feathers, tinsel, and hair. There were wary and less wary fish in the waters when man began to operate with rod and line. The wary strain, or the more wary members of it, have survived to multiply their kind, while the unwary and the less wary have found their way into the basket. Thus the fish in muchfished rivers have not acquired their reputation for cunning because greater experience has taught them more, but because all the simpletons have been taken out. Nor is the case of the cunning old trout at all destructive of this theory of elimination. It is argued that this trout must have learned a lot, or he would never have grown so old. But the dangers of the old trout were just as great-they were even greater-when he was young as they are now that he is old. As he successfully eluded them then, the probability is that he was as naturally wary then as now. The theory that fish are taught great cunning by experience is hardly capable of statement in a particular case, and is, indeed, always set forth in general terms applicable to entire rivers. Just consider the amount and kind of experience necessary to teach a trout the sort of angler-defying wisdom attributed to it. It is known already that the amount of experience needed to teach a fish is very great, and in this case the kind of it must be actual contact with a hook. By this proposition, therefore, the fish must have been on a hook and escaped hundreds of times, if hundreds of experiments would suffice to impress the kind of brain which fails, after months of constant 
teaching, to learn the obstructive nature of a glass barrier. The idea that fish can learn from seeing others drawn out is absurd, since it credits them with powers both of indirect observation and logical reasoning. It may even be questioned if the so-called wisdom of fish is at all of the nature of intelligence, whether acquired by experience or by heredity, assisted by elimination. To a large extent the elusive actions of fish are mechanical responses to stimuli acting through acute senses; and when the effectiveness of the senses is reduced, as in darkness, the caution of the fish is proportionately diminished. There is nothing more certain, however, than that trout will continue to be credited with keen, conscious wisdom, accumulating with experience in old fish. It is necessary for the angler's story that it should be so, and that truth-loving person will not tamely be deprived of the groundwork of those moving dramas in which, with marvellous success, he matches his intelligence against the more than human sagacity of ancient fish. 


\section{MARCH SUNSHINE}

FINE days in early March are, by an ancient tradition, placed among "the flatteries of the faithless year." This year (I9II) flatteries of such sort have been few, and every dust-liveried servant of the soil will tell you that the season is backward. Yet some of the processes of Nature go on without consulting a laggard thermometer, and even when skaters and curlers were still active on the ice the blackbird was making furtive dashes at his future mate. He had no notion why he did it, and after each dash shamefacedly accused himself of idiocy unworthy of a blackbird male. But the foolishness was repeated, and all the while the bird's black coat was becoming glossier and his bill a richer orange. The hen bird has been slower to respond to the seasonal feelings, and the silly outbursts of the males have surprised the still sane gravity of her temper. As she hastily evaded that mad dash of his, and turned to look at him from a safe distance, with head critically jerked to one side, her judgment was contemptuous in the last degree. After all, she concluded, male blackbirds were not among the things of life to be taken seriously, and she promptly resumed the search for slugs, which was real business. But 
her day came, too. It may have been a mere glint of wintry sunshine on his glossy wing or the set of his wonderful waxy bill. Something, at any rate, has happened, and if the little chases are stopped she feels neglected; if directed at another bird she feels an intolerable sense of wrong, which is promptly gratified in a fierce feminine fight and a scolding which disturbs a whole shrubbery. All the birds of the thrush family fall in love betimes. The song-thrushes were courting in the hard frost of a fortnight since, and the queer antics of the missel-thrushes have now for many days been working out the prologue of the summer comedy. Anthropologists tell us that marriage by capture was once a universal practice among mankind, and that traces of it continue in some marriage rituals and in some children's games. One might almost suppose that time was when the missel-thrush took a wife in this way too, and that he pretends to do it still. His courtship is a chase with something in it of the formality of ritual. A wire fence may be the scene of it. There the birds hop swiftly from post to post, the male alighting on one top precisely at the moment the hen alights on the next ahead, the pursuer uttering a very curious and rapid clucking note all the while. The whole performance is ridiculous, and so from time to time the performers think, for every now and then, " coming to themselves," they abandon it precipitately, and zealously search for worms like sensible birds, subject to an unaccountable aberration.

Of course, there is excellent reason for birds 
of the thrush tribe beginning an early courtship. Summer commences for them with the first real sunny day-the first day to soften the hard earth and send life stirring among the many creeping things that inhabit it. Leaves and blossom are, no doubt, an amenity, but grubs are the thing. To the blackbird, indeed, grubs make a summerthe rest are trimmings and pleasant flummery. On the other hand, there are many birds to whom summer is still far away. Hang out a broken cocoanut or a lump of suet, and the tits will be little less grateful than if the rigours of February were still at their worst. Summer to them means the sumptuous time when the myriads of the insect world are about and laying eggs, when caterpillars lurk in the folds of every leaf ready to be eaten, and when five-sixths of the day may be devoted to the gratification of a lively curiosity. And as that time is not yet for many days, winter continues for the tits, no matter how the sun may shine. So we still have them in gardens, about stables, on the roads, and about houses whose inhabitants know how to treat them. Nobody but a professional humorist ever saw a tomtit look dispirited, but to see the birds at their best hang out for them a lump of suet suspended by a string. While it lasts their whole life is an acrobatic ecstacy; when it is done they may be supposed to give a few moments of sad thought to the unanswerable question, Why does not suet grow on every tree? Why titmice-which never found anything like it in Nature-think cooked fat superb feeding is a matter only less difficult of explanation 
than their mad and reckless devotion to cocoanut, for which they are ready to forget the dangers of both men and cats. Even to the robin, which can feast upon a worm, the opening of the frozen ground is much less of a summer reality than to the thrush. For though worms are very fine in their way, and provide an excellent and substantial basis of a meal, there are infinitely finer things in the insect world shortly to be unsealed. Insects, however, must wait upon vegetation, and so far life has hardly made a move. There are catkins on the willow, but not even the adventurous lesser celandine has shown a blossom.

The most pleasing result of March sunshine is the sudden stimulus it gives to the song of birds. Even in hard frost the tuning of the orchestra had proceeded. Blackbird and thrush have been tentatively trying their notes, and the starlings have been chattering in competition with the sparrows. But with the first real spring day the blackbird essays a full song. These early songs of both blackbird and thrush are by no means the perfect flute-like utterances we shall hear as the season advances. There are broken notes and halting phrases. The songster seems conscious of effort. He goes back upon defects, repeats halting passages, and gradually rises to elaborate combinations, becoming more and more wrapped up in himself as he develops his own powers as a musician. There is little doubt that the birds listen to one another, learn from one another, and deliberately, even passionately, compete. Thus, to an attentive listener, a still bare 
orchard becomes a kind of school, where rivalries. are marked by intermittent outbursts of harsh and brawling notes, and even by angry combats. Then the starling supplies a real comic element. Nature presents few sights more exquisitely absurd than that of the starling posted in a tree not far from one in which a blackbird is singing. It takes up its position on the topmost bough, and throws itself into the ecstatic attitude of a great artist. The bill is set at a high upward angle, the throat swells, and the feathers which cover it are in rippling motion. The whole body of the bird quivers as if with the pride of masterly execution, yet at twenty yards not a sound can be heard but a low, castanet-like rattling of the rapidly moving mandibles. At ten yards the song can be heard-an unmistakable imitation of the blackbird's, wonderfully perfect in its way. It would be admirable, but the whole pose of the songster seems to express his absolute conviction that his reduced version is even superior to the real thing, and the impression is one of comicality alone. The starling's own song is a far from unpleasant twitter, but the bird is full of vanity, and is constantly proving to its own satisfaction that it can out-sing the finest songster in the grove. In a week or two its greatest efforts will be lost in the grand chorus. 


\section{TOWN GULLS}

SPRINGTIME is excellent, but it is not all tulips, crocuses, and "daffodillies rare." From the point of view of the dweller in towns the season of bud and blossom, if a great bestower of good things, is in some measure a robber as well. To those who take no careful note of such things the long list of birds that dwell in or visit towns during winter is an astonishment. It runs into dozens, and includes many which are by no means the most common of avian names. But with the advance of spring most of these town-seeking species bid a ready or reluctant farewell to urban scenes, and betake themselves to the fields, the hedges, or the shore. Reluctant, because there are some birds which in modern times have developed a fancy for town life which only the strongest of natural instincts can overcome, and notable among them are the gulls. "The wild seamew" has a place all his own in the stock scenery of romantic literature. There he is the very spirit of aloofness and self-dependence. $\mathrm{He}$ rides upon the storm, and experiences all the primal emotions which surge through Ossianic poetry. Perhaps the gull was once like that. In our time there is not a bit of poetry in him, and 
it is almost painful to speculate upon the grossly prosaic nature of his real thoughts. There seems to be little doubt that the town-frequenting habits of the gulls are of recent origin. Certainly the habit has developed enormously in the last twenty or thirty years, and-unsavoury thought-some authorities have traced it to the development of modern sanitary systems. The gulls revel in sewer outfalls, though, perhaps, the attraction in their case is secondary, for the sewer draws to it many species of small fish on which gulls feed. But they are foul feeders themselves, and scorn no garbage. Whatever be the cause, they delight in the life of towns. The ridge of a roof is an excellent place for them to perch upon, and if a human citizen cares to offer those feathered citizens food they will quickly discover his good intentions, and no false pride will stand in the way of their accepting his charity. And generally the human citizen is interested in his gulls. They are charming objects on a river front, whether swimming with the tide or sailing on easy wing. Their readiness to " come to be fed," their deftness in catching a thrown morsel, the perfection and dainty spotlessness of their plumage, all dispose him to reckon them among the redeeming amenities of his environment; and in some places, as in London, they have stirred in him an almost proprietary interest.

But the moment comes when the gulls must seek the haunts of their ancestors. Sitting for the last time on the great pipe which has been their town seat for many months, the conversation that 
passes among them is easily imaginable. "Why should we leave this most eligible sewer," objects a blasé young bird; "there is everything here that could delight the heart of a gull." The truth of the observation is admitted, but the patriarchs of the flock point out that this going away in the -month of March is a very ancient custom of the gulls, which, even in these unsettling times, it would be unwise to disregard. Young gulls sneer at ancient customs with the levity of bachelor men-about-town, but one fine morning they are all gone. Five-sixths of the gulls which haunt the river are of the black-headed breed, a species which is on the high road to the abandonment of all claim to be considered a sea-bird. They are at home in towns; they follow the plough like rooks, and in the breeding season they betake themselves to inland lochs and marshes, often far away among the hills or woods, where they may be seen in the company. of such purely inland birds as coots and waterhen. This choice of a breeding haunt can, however, be no modern custom, for it has consequences of which the gulls must strongly disapprove. For one thing their eggs are regularly " harvested," a process which is carried out amid great emotional clamour. As, however, the birds go on resolutely laying more, they are always able to raise a brood. But it is much more interesting to follow the common gull and kittiwake to nesting-places more characteristic of the tribe. The cliffs are the great gathering ground, and from a convenient post on the crest of them the whole comedy of gull love, 


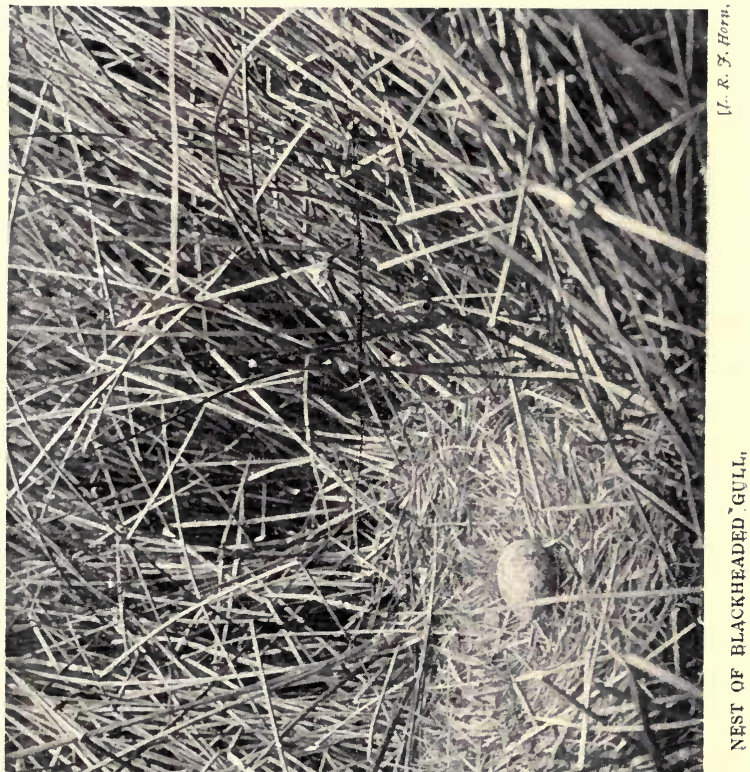

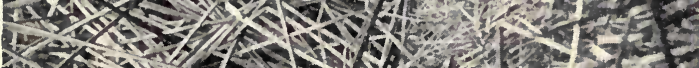

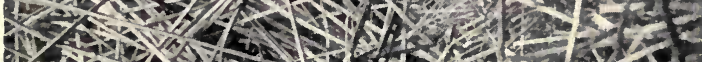
25.

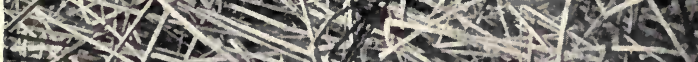

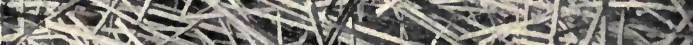

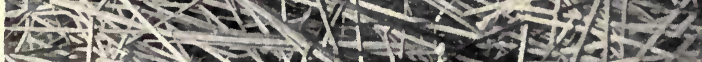

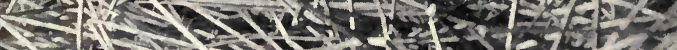

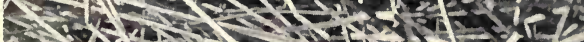

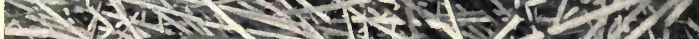

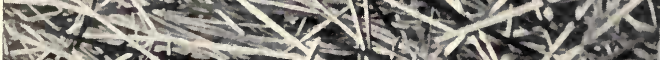

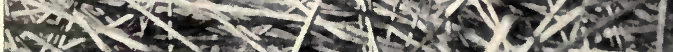

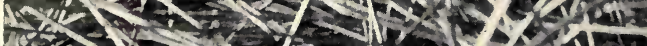

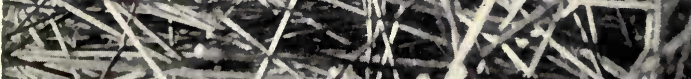



courtship, and marriage may be observed. Ardour is not the word to describe a gull's courtship. A mated pair will sit together by the hour, rarely looking at each other; but an intruding unmarried bird is at once assaulted with vigour. If defeated, he may take up his post on a point of rock where he can watch the pair, and from which he seems to throw sarcastic remarks which check any tendency to public endearments. When nesting has actually begun the blandishments are all on the side of the female, and the male gull seems to think the whole situation a trifle absurd. He spends most of his time over the water hunting for fish, occasionally remembering his mate, and bringing her a trifle, which he disgorges before her in an apologetic sort of way, as if to say, "Try this little kickshaw. Young whiting is excellent for incubating gulls." When, however, the young are hatched, the male gull drops his half-ashamed demeanour, and brings little kickshaws with fatherly assiduity. And parents and young have reason to bless the ancestors which selected a nesting-place practically inaccessible to the marauder, man.

Gulls do not tarry long at the nesting-places when their domestic duties are over, and we shall have them back to the delights of estuary and even town life before the autumn. The young rapidly reach maturity, and their first lessons in fishing are got in the water below the nesting cliffs. What they feed upon in these positions is a matter of some doubt, but it must consist in the main of very small surface-swimming creatures, for, as no 
gulls dive, they are quite unable to follow the larger fish. From time to time they are able to pounce upon a fish too big to be swallowed at a gulp, and when that happens there is a strong probability that the captor will be mobbed by his own kind till he drops the prize. But even when a gull has swallowed his fish he is not sure of it. The skuas are great gull robbers, and there is reason for suspecting that they have quite abandoned the habit of hunting for themselves. Instead of doing so they watch the gulls, and when one takes a fish in the sight of these bullies it is chased and battered till it disgorges. Then the fish is caught by the robber as it falls. This particular experience of gull life has affected the gull's way of thinking in all emergencies. It is in its natural state accustomed to escape a great annoyance, and even danger, by disgorging its food, and under totally different conditions it tries the same expedient. Thus if a tame gull in a garden is chased by its owner it imagines that he is after its last worm. It will run, but as soon as the chase becomes critical it will "up with it," croaking out in gull language, "There, then, have it," and it is mightily surprised if the chase is continued after that. Considering that gulls are among the commonest of birds, it is a little curious that erroneous ideas are general about some of their commonest actions. People who see them every day will be found ready to swear that they are expert divers. Yet they never get under the surface of the water. When hunting they fly slowly over it, the head moving from side to side; 


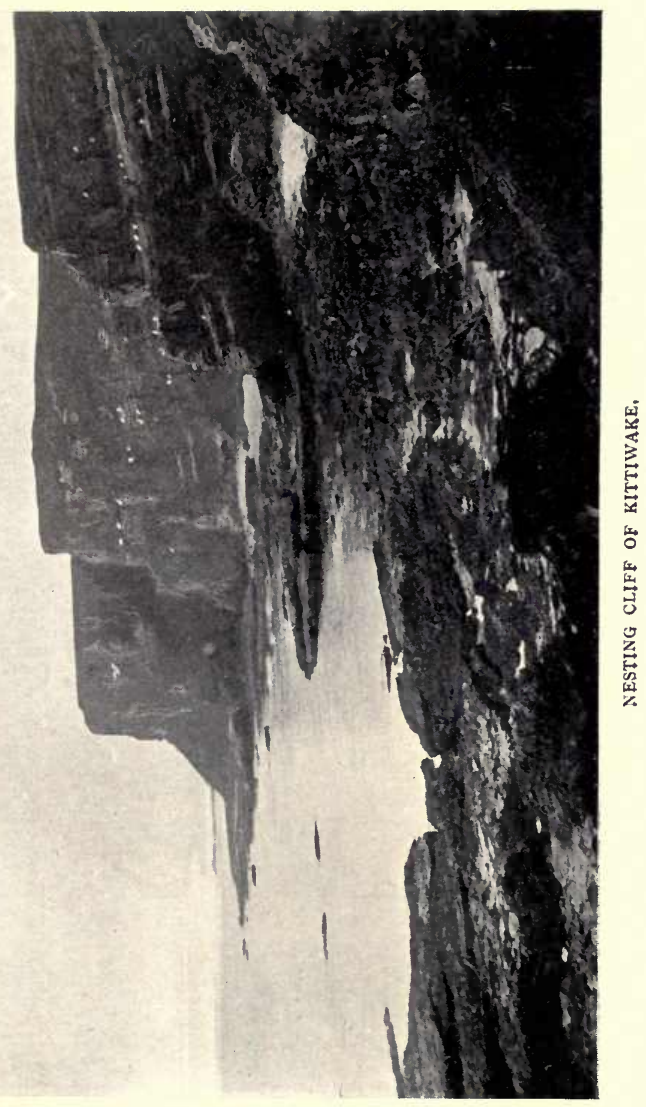



and the descent upon the prey is rarely, except in the case of the kittiwake, to be described as a swoop. The kittiwake plunges, but never disappears. Thus if food thrown to gulls does not float they lose it unless it is caught in the air or just as it touches the water. But perhaps in the prevalent error there is nothing strange at all. Few are accurate observers. Five people out of six are "floored" with the question, "Which are in front, the horns or ears of a cow?" 


\section{MARCH HARES}

"MAD as a March hare" is an expression which goes with "Mad as a hatter," and there is as much of a mystery about the one as about the other. The learned Brewer conjectures that " $\operatorname{mad}$ as a hatter " is a corruption of " $\operatorname{mad}$ as an atter" (the Saxon for adder); and he makes the searching suggestion that hares are reputed mad in March because it is their mating season. One's only difficulty with this is that March is the mating season with three-fourths of the animated creation in the temperate zone, and many other creatures get quite as mad over their love affairs as puss. But he who seeks an explanation of popular lore about hares has a big task on hand, part of it being the natural history of the witch.

Hares begin the business of love-making in February, and sometimes earlier, and if high spirit is madness they can be mad enough. Though ordinarily as timid creatures as any that run on legs, a couple of bucks that have placed their affections on the same doe manifest a most amazing pugnacity and valour. It is even said that they have been known to fight a duel to the death, and certainly in quite a common encounter in the lists of love they make the fur fly. Possibly 
the hare's reputation for madness has been put about by witnesses of these fights, in which there are always some remarkable and arresting passages. The combatants, for example, have a habit of indulging in most astonishing sidelong jumps which might well suggest that the animal is "off its head." But these curious jumps are not exclusively a feature of the love fights, and the performance is not by any means confined to the month of March. And at his maddest a hare does not look half so mad as a tom-cat in the throes of amorous sentiment, adding to many wonderful contortions of body a vocal performance more suggestive of all-gone insanity than anything for which four-footed creature is responsible.

The hare is pre-eminently our type of fleetness, and it is interesting to speculate on the conditions of life which evolved its remarkable powers in this respect. Only the very swiftest of our dogs can run a hare down, and it is doubtful if the one surviving native British canine hunter, the fox, could capture a hare which had a yard of a start. Manifestly, therefore, the hare's wonderful running power is not an adaptation to existing conditions. But as the hare existed in its present form long before the human period, it is not a matter of conjecture but of fact that the evolution of its swiftness was an adaptation to a danger present in a very old environment. That danger was in all probability the wolf. Nearly two centuries have passed since the slaying of the last British wolf, but there was a time when wolves roamed the British fields and woods in numbers, 
and were the chief enemy of all lesser animals capable of furnishing them with a meal. It may thus be said in no very fanciful sense that in the long legs of the modern hare we have a record of the activity of the ancient wolf, which played the part of natural selection on all those hares which did not evolve the needed length of bone and strength of sinew to escape.

It is not only the swiftness of the hare that speaks eloquently of a prolonged course of schooling in which the schoolmaster was a swift chaser. In running before a $\operatorname{dog}$ a hare shows itself a perfect bundle of tricks, all aimed at delaying a pursuer. Instinctively it selects ground which is more difficult to the dog than to itself, and it cleverly leads for obstacles which it can run under, but which the larger pursuer has to surmount. The most characteristic point in the hare's strategy of escape is, however, its invariable choice of the uphill line. If there is an inclination in the country over which the hare is being chased it will go up it, and in an uphill run the great length of its hind legs give it an advantage which is generally quite decisive. This instinct, though common to the whole family of hares, is most strikingly manifested in the case of the blue or variable hare of the Highlands. On most Highland properties these hares are the objective of a grand annual hunt, in which they are driven towards the guns. But it is absolutely useless to attempt to drive them downhill and the easiest thing in the world to drive them up. The beaters are under no necessity, as is the case with other game, to advance in continuous 

line. They have merely to zigzag upwards, while the shooters are posted at or near the top. The hares will with one mind ascend from danger. It is a good case in which an instinct acquired for the avoidance of a particular dangerous emergency comes into play to the owner's undoing on the stimulus of any kind of danger whatever.

To many people the hare and the rabbit are such close allies as to be hardly distinguishable, and the resemblances are certainly very real and considerable. Cousins by descent, they have the same general protective colouration and the same general shape. But considering the close genetic connection, the differences are really very astonishing and deep. The flesh of a pig does not differ more completely from that of a deer than the flesh of a hare does from that of a rabbit, and when it is remembered that both animals derive from a common ancestor and subsist on the same kind of food and live in the same climate, the difference is one which the evolutionary physiologist finds it far from easy to explain.

There is an equally marked, though by no means so difficult to account for, difference in the mode of production of the young of the two species. Rabbits, as at any rate every country schoolboy knows, produce young which are naked, blind, and helpless. The young hare, on the other hand, is born complete, clothed, with its eyes open, and capable of running almost at once. Like the young. plover, it is also born with its hiding instincts fully developed, and within an hour of birth the members of a hare family know enough to scatter 
and hide on the approach of danger. Probably it is in this habit that we should find the explanation of the erroneous but widespread popular belief that the hare produces only a single young at a birth. The chances are strong that the countryman who puts up a brood hare will only find one of her young in the form or in its vicinity, and stronger still that he will fail to get his hands on that one.

Of course the very great difference between the two species in the matter of young production is an adaptation to their respective modes of living. Being a burrower the rabbit can afford to produce immature young, and being a surface dweller the hare is compelled to carry her progeny till they have developed powers of body which young rabbits do not acquire till a fortnight after birth. A strain of hares which produced helpless young would promptly be exterminated by the host of enemies, from crows to foxes, which, even as it is, levy a heavy toll on the race. 
APRIL 



\section{A SPRING TROUBLE}

ANY one who looks into the gardener's calendar for the month of March will find that the salient feature of the month's zoology is-snails. More lively and arresting animals, it is true, present themselves for observation in the days of early spring. But the gardener's calendar is a compilation of a practical turn, and the relations of the snail to the practical economy of the garden in spring are among the considerations that really matter. Just consider the situation. Late in the autumn our mollusc, fat with rich feeding, sought out for himself the dry under side of a stone in rockery or broken wall, well out of the way of draughts, reasonably sheltered from frost and rain. Finding the retreat to his taste, he retired into his shell, and with one operation glued up the front door and attached the whole house to its winter site. With the growth of spring warmth he emerges to find his fat consumed and the demands of a reviving appetite slowly but surely asserting themselves. Slowly but surely is the snail's plan of life. On the first sensation of hunger he does not rush from his bed. He takes a day or two to think of it. But at last, cautiously and tenderly, his "foot" is extruded, and the snail finds that 
he is awake. And what is the first thing that catches his eye as he pokes out his horns? Seedlings.

There are still people who believe that the whole universe has been arranged to serve the purposes of man. The snail can hardly doubt that it has been arranged to serve the purpose of snails, and in the spring circumstances point very definitely to the truth of this doctrine. In the first place, a wise and ancient mollusc (and snails, barring accidents, are long livers) might point out to the juveniles of the breed, that when the snail awakes with a delicate and fastidious stomach after a long fast, he finds that by a providential arrangement the most delicate kinds of young plants are laid out in rows to tempt him. It is not much he wants in March, but it is an unusual season if he does not find ready for him a row of early vegetablestender shoots which may be browsed without the trouble of climbing. After a feast or two of seedlings the inevitable touch of sour, surly weather will send him back to his bed. Probably his next awakening will be in April, and then what a time is his !

Probably the British snail dates the beginning of the millennium from the time when the sale of flower seeds became an organized business. Prior to that the amateur's garden, at any rate, was a very so-so affair. The amateur himself dealt largely in roots (mostly begged or borrowed), which means hardy perennials. Now hardy perennials have the vice of coming up strong from the very start, and though a snail can do with a four- 
year-old wallflower, he certainly does not like it. The advent of the cheap and ready seed assortments made a wonderful change. The amateur who does not buy at least twenty kinds is a poor creature. He sows the contents of his packets on nice little plots, perhaps in pretty geometrical patterns, and, leaving the rest to Nature, hopes for a summer display which will dazzle the beholders' eyes. It probably happens that 50 per cent. of the assortment is of seed badly adapted to the ground, and that 25 per cent. more are difficult to persuade that the British climate is quite the right thing. But in reality these are considerations of small moment, for most of the seeds do germinate, and that is the great thing. They are required to make delicate seedlings, nothing more, and the grateful snail eats them off flush with the ground. The result is neat and tidy-so different from the time when the snail had to depend wholly on hardy herbaceous feeding, and, by reason of its tough nature, was obliged to select the softer parts of leaves, imparting to the whole the ragged and unkempt appearance so objectionable to sensitive taste.

These assortments and "selections" carry snails through April with a variety and delicacy of diet unknown to them in past ages, and when May comes they are sportive and carry a heart for any fate. In other words, they are just ready to appreciate the bedding-out plants which a beneficently developed commercial system brings into the market at the gastronomic moment. Asters, stocks, marigolds-tough enough later on-are just 
nice at the time selected for planting out, and it does a snail-raiser's heart good to see the way his efforts are appreciated. But that is the charm of snails-they are so appreciative. Get something very special and they are sure to like it-no coaxing needed. They may be said to dote on chrysanthemum slips, and if the variety is new and expensive they will travel far to show how highly they esteem it. They eat it down close to the ground, and do not leave a fragment lying about.

There can hardly be an amateur gardener who has not lamented the fact that the British people are not, like their Continental neighbours, able to appreciate snails as food. Their indifference detracts greatly from the charm of gardening. With the aids alluded to almost anybody can make gardening a triumphantly successful branch of stock-raising. Indeed, one can hardly help oneself. It is about as simple as pressing a button. Dust out the seed, keep the sparrows from absorbing an undue share, and the snail stock appears upon the land and does the rest itself. But it is disheartening to find, when you have discovered the thing you can do really well, that there is no market for the produce. The waste is positively heartrending. Getting up unusually early one morning last May, I captured fifty-nine snails on about ten square yards of varied culture, edged with a rockery rich in conveniently situated sites. They were browsing with an appreciative abandon which quite touched the heart. Next morning I made the hundred of it. There were slugs, too, which are to snails what sheep are to cattle, and 


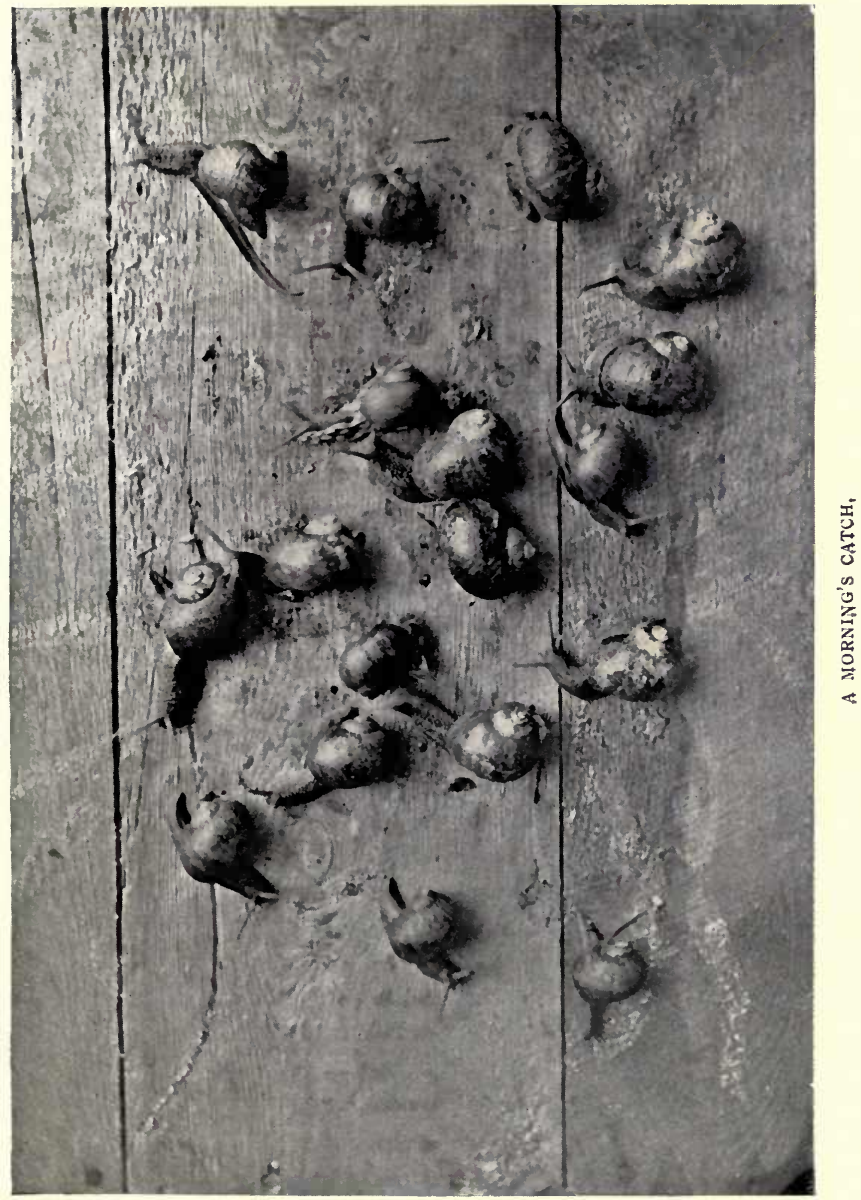



the variety of breed added interest to the stock. But it did detract from the pleasure of having so many animals on one's estate, all doing well, to think that they could be turned to no sort of use.

Of course, this utilitarian spirit can be overcome. One can educate oneself to the point of appreciating snails for their own sake just as one used to rear rabbits and cherish sticklebacks without any ulterior purpose in view. But this state of mind is not reached in a day. Old ideas will keep on asserting themselves. You put down lettuces, and, in spite of yourself, keep on expecting a crop of lettuces; and when your snails eat them all up before they are an inch high an unreasonable sense of disappointment will not be kept back. But when once you have taught yourself that a success with snails is better than a failure with the finest vegetable that ever grew, all goes well; then you put down seeds with a sure and certain faith that you will not be disappointed. If, on the other hand, you stick to the idea of raising flowers instead of snails and their little brothers the slugs, there are means which may be adopted. You can surround your most precious plants with defences of soot, which no snail will rush so long as the soot is dry; or you may get up before sunrise and collect the browsing herds, popping each individual as you find him into a vessel containing salt. In the early morning they are very tame, trustful, and approachable. But this is a cruel business. 


\section{PLOVERS' EGGS}

THERE is a story of a wealthy convalescent who was heard to say, with a wistful look in her eyes, "What a nice thing a new-laid egg would be if it were not so cheap." This is the whole secret of the charm of the plover's egg, whose first appearance in the spring market is to some the first genuine proof of spring. Plovers' eggs are delicacies, partly because they are tolerably good eggs, but chiefly because they run to a fancy price. They are better " to eat " than terns' eggs; but terns' eggs are often sold as plovers' eggs, and 90 per cent. of the eaters declare that they perceive in them that subtle deliciousness of flavour which they believe to be appropriate to the egg of the lapwing. Having consumed eggs in great variety and number, at an age when consideration of price is incapable of affecting gastronomic judgment, I should say that those of the barndoor fowl, fresh, hold, for sheer merit, an easy first place; that those of the game birds-pheasant, partridge, grouse-are entitled to tie for second place; that those of the plover come in before, and those of the tern and black-headed gull after, those of the duck. But the plover's egg is early 


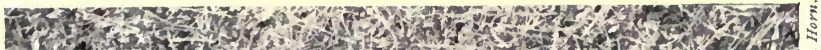
20.5.

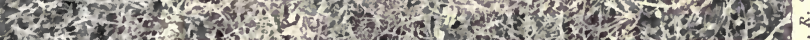

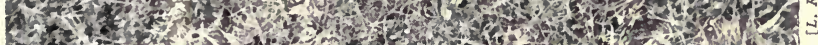

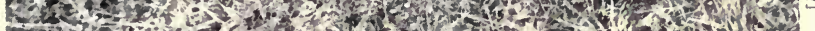

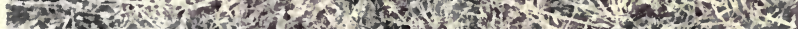

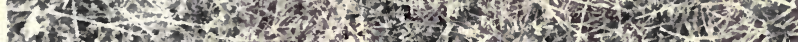

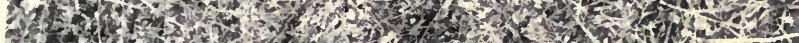

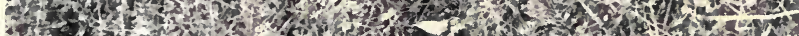

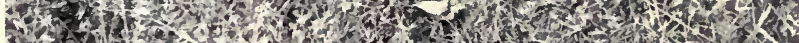

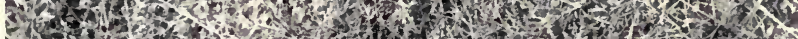

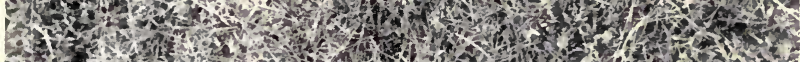

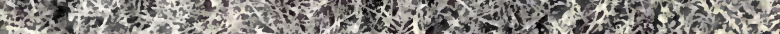
-

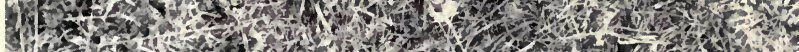

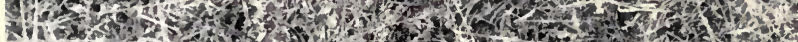
19.

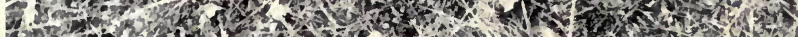

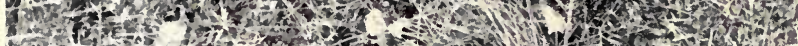

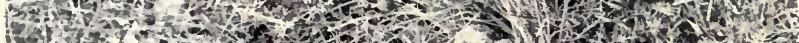

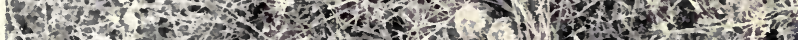

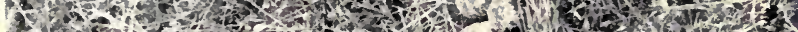

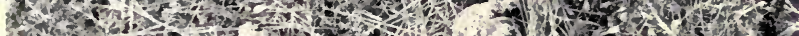

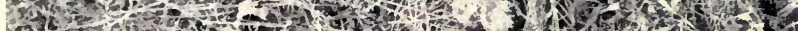

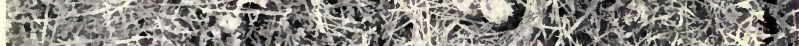

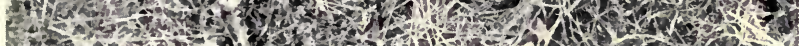

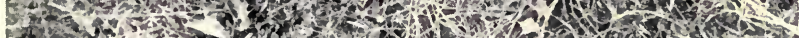
Ft

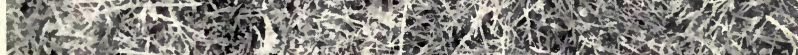

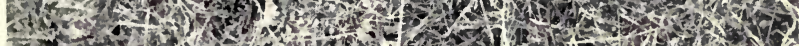

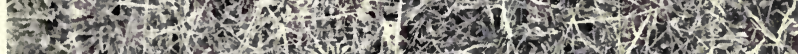

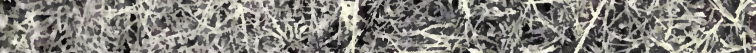

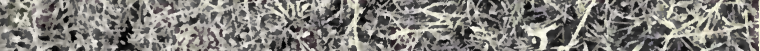

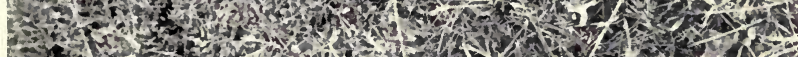

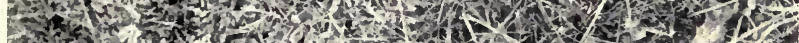

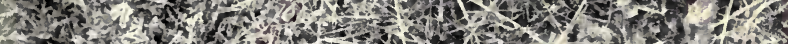

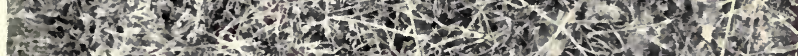

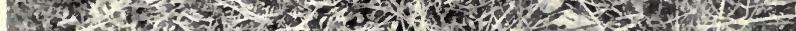
Fy.

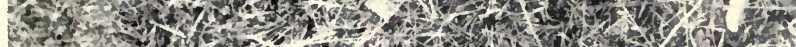
3.5.

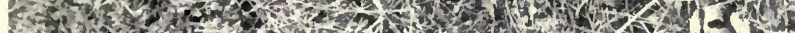

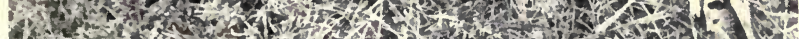
If.

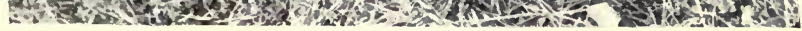



and its season is short, and it is, therefore, nicely. situated in the calendar for adoption by fashion.

The people who pay eighteen shillings a dozen for plovers' egg's, if they pay more than the article is worth, can at least flatter themselves that twenty to one they get the thing they pay for. When the lapwing begins to lay it has few rivals in egg production, and those few of its own kind. A little later the tern's egg, which is a colourable imitation, comes into the market to deceive the inexpert. But nobody need be deceived who takes the slightest trouble to learn the points which distinguish the two. Both are about the same size, and though the tern's is an extremely variable egg in respect of colour, both present the same general aspect of blotched black and brown on olive-green. But the tern's egg is of a perfectly normal egg-shape, whereas that of the lapwing is invariably more pointed at the thin end. The eggs of all the members of the plover family present the same peculiarity-dunlin, sandpiper, seapie, redshank; but these others differ so markedly in colour and size that they are not in the competition. There are other less satisfactory tests. When boiled the white of the tern's egg becomes a white opaque, while that of the lapwing's egg remains translucent.

The lapwing holds a very distinct place in the common stock of Nature knowledge. There are few who ever come into touch with rurality who do not know it as the typical bird producing eggs with a "protective colouration," and fewer still who do not know it as the stock instance of the 
bird which, by devious arts, decoys the intruder from eggs and young. Those who know nothing more about it know these things. Yet, strangely enough, both statements may be, and have been, disputed. Though usually described as a bird of the moor and natural pasture land, the lapwing has really a much wider range. The most productive nesting-place I ever knew was a stretch of low-lying links-land, on which grass and short bell-heather held about equal space, and which was broken up with ramifying channels filled at high tide with the water from an estuary. But the peewit nests on all sorts of permanent pasture where the grass is not long ; and cultivated fields, particularly of winter-sown wheat, serve its purpose perhaps better than any other kind of ground. Wherever it lays the eggs are always easily found, partly because the bird never fails to call attention, in the most clamorous fashion, to the fact that they are there, and partly because the formal cross in which they are arranged is, despite the colouration, conspicuous. The protective colouration is undeniable. Seen on a piece of heathy pasture, their olive-greens, with brown and black blotchings, stand as a perfect mingling of the colours of the environment. But they fail to protect, at any rate, from human eyes. In some related birds the protection is incomparably more effective. The oyster-catcher or seapie, for instance, makes its nest among the large gravel spreads of river-beds or among the pebbles of old beaches which abound on some parts of the coast, separated by newer deposits from the sea. 

Among the stones one may find oneself looking at the large cream-coloured eggs, - irregularly spotted and blotched with brown and black, without seeing them. They are in colour the exact reproduction of the stones they lie among, and their shape and shadowing are not noticeably. different. Shape and shadowing make the lapwing's eggs stand out. It is probable, none the less, that the colouring of the plover's egg does protect it, though not from its chief modern enemy, man. It is as nearly certain as anything of which we have little direct proof can be, that the lapwing and all its family are much, older inhabitanłs of the earth than man, and that both its defensive instincts and its egg-colouration were evolved for the evasion of foes of quite a different kindcrows, ravens, and, once upon a time, possibly; wolves.

The artfulness of the lapwing in decoying intruders away from its eggs and young is almost proverbial. Chaucer refers to the bird as "the false lapwing full of trecherie" (trickery), and Shakespeare has his allusions to its pranks. In almost every natural history book it is taken as the stock example of the birds which feign a broken wing to draw enemies away. But it certainly does not perform this trick with anything like the perfection of deception of the snipe and more than one kind of wild duck. Mr. Edmund Selous, who has made bird-watching an art, is inclined to deny that it ever does it at all. Come upon a wild duck with young or a nesting snipe and the bird contracts broken wing with almost 
automatic certainty. It is like pressing the button and the figure works. "Whilst these birds," says Mr. Selous, " have always, in my experience, gone off, so to speak, like clockwork when the occasion for it arrived, I have never known a peewit to do so, though I have probably disturbed as many scores-perhaps hundreds-of them, under the requisite conditions, as I have units of the others." It is not a point on which one can affect certainty unless fresh from observation; but if the peewit does not try broken wing, it unquestionably does try, by. methods of its own, to lead possible enemies away from eggs or young. The strategy I have watched scores of times, and in its main lines it is always the same. The hen bird runs away furtively, hardly ever rising. Meanwhile her mate flies about in a low and distressed fashion, uttering cries of alarm. He always manages to convey the impression that it would be easy to catch him. Tried on a man the device is invariably a failure, for the stupidest schoolboy at once sees through the dodge. Indeed, far from being a protection, the trick is a disadvantage, since it acts as an advertisement that eggs or young are here. But it is very different when the enemy is a dog. The most intelligent canine is at once filled with a wild faith that he can catch the bird, so away he goes after it ; and one has only to see the performance to feel that the instinct was originally developed for the frustration of enemies of this kind. The Wild Birds Protection Acts do more for the peewit in these days than all its native arts. 


\section{THE ROBIN'S COURTSHIP}

AT any season of the year bird-watching is an occupation with some of the interest of drama, but for emotional passages there is, of course, no time like the spring. Then, as the poet says, the robin's breast assumes a richer orange, and the robin himself assumes certain airs and graces most remarkably unlike those worn by him at all other times. Everybody is supposed to know the ordinary bearing of the robin. As a matter of fact, the robin has two very distinct and yet quite ordinary manners of carrying himself. Most frequently we see him as a prim and trig little bird, with all his feathers neatly and tightly laid down on his slight but vigorous frame. He suggests that he is all there, very capable of taking care of himself, and very well and hearty despite bad weather and shortage of the grub supplies.

But very nearly as often, especially at times of cold thaw, we find the robin resembling a loose ball of feathers, with its circular contour broken only by a head at one end and a tail at the other. Robins in this state are sometimes thought to be sick. They look just a little sick, as if they had swallowed a worm which was 
proving just a trifle big or a trifle tough, and was taking an unconscionable time to digest. Actually they are not a bit sick, and if you dig up a few spadefuls of earth for them they will demonstrate on the spot that they have room and the appetite for more. Probably the rotund, loose-feathered pose is adopted for warmth, and feathers thus disposed have undoubtedly the power, common to blankets and fluffy fabrics in general, of retaining in the form of warm air the heat emanating from the body they invest. Be that as it may, these are the two common poses of the robin.

The love-making pose is a thing all by itself. The other day I devoted an hour to the ongoings of three robins, two of which at least were affected with the season madness. One of the three was a hen, and still calm as calm could be. For eight months out of the twelve robins are solitary birds, disliking particularly the society of their own kind, and this hen was still indisposed for company. But wherever she liked to fly the other two flew after her. She looked at them with what novelists call mingled annoyance and surprise. They were most troublesome, not to say rude, and she manifested her sense of their unseemly conduct by running a tilt at each on turn as it came too near, and letting it have "one" on the ribs with her beak. But though robins are pugnacious or nothing, they retaliated with no violence. Their one object, from time to time achieved, was to get posted right in front of her, and there go through a little pantomime. This consisted in turning up the tail till it hung over the back at 
an angle which made its wearer resemble in general outline a wren, and to puff out the red breast and sway the body from side to side. The whole air of the bird in this performance was one of intense satisfaction with himself. "I am unmistakably beautiful," he seemed to say, " and if this little person would only look at me, she could not possibly help admiring." And from the way in which he puffed it out and threw back his head, he appeared to be very conscious that the colour of his breast, now at its brightest, was his strong decorative point, and a feature of which he was well justified in making the most.

From time to time the little comedy was interrupted. Cock robin Number One would become aware of the proximity of Number Two, and make a flying dash at him. They fought with great heartiness, tumbling over one another, pecking hard, speaking high, and disarranging one another's feathers. But each bout was short, and a moment after it was over, the one who had the best of it was back at his love-making and going through the same attitudinizings again. $U p$ and down the garden they went, now among the berry bushes, now on the bare ground, the lady soberly looking for worms, the others in a fever of fine sentiment. And in the end she went over the wall out of my territory, and they followed a yard in her wake.

As everybody knows, fine theories have been spun around the courting habits of birds. What is known as " sexual selection" is then supposed to be going on. It is a theory in two parts, and 
it is quite simple, though it has been worked out in rather bewildering detail. In the first place, male birds fight with one another for possession of the plumpest, most vigorous, and best-looking females. The strongest succeed, and, in the case of polygamous birds, get the biggest harem, and, in the case of monogamists, the best mates. In both cases the triumphant warrior gives rise to a large progeny of good stock like himself. The vanquished, on the other hand, has to content himself in the one case with a small harem, and in the other with an old, unattractive hen of diminished fertility, with a result of small and feeble progeny. Thus the race is improved by the increase of the good fighting stock and the reduction of the poor fighting stock. In these cases the cock selects the hen.

To a much greater extent, however, the theory of sexual selection concerns itself with those cases in which the hen is supposed to select the cock. In a great number of cases, as everybody knows, the males of birds are much more magnificently clothed than their mates. The hen peafowl is quite a plain customer, and the same is true through the whole family of pheasants to which it belongs. As a family, this one includes the most gorgeous birds in the world, but all the finely coloured individuals are males. Why? By the theory the males are finely coloured because the hens, themselves plain, have a most remarkably well-developed taste, and, other things equal, will always prefer to ally themselves with the finest cock bird of their acquaintance. In support of 
the theory, there is the indisputable fact that male birds do, in the mating season, display themselves in the most ostentatious way to the females; and nobody can look at a peacock exhibiting his magnificent tail coverts, quivering his feathers, and strutting before the hen-always keeping in front of her-and doubt that he is conscious of his splendour, and is trying to impress her with it.

There is a certain obviousness about the theory, and yet it has fallen in recent times rather seriously into dispute. The fighting part of it stands all tests; the best fighters undoubtedly get the mates they want. But the other part of it credits the hen birds with æsthetic perceptions of so extraordinarily fine a kind that credulity is very seriously strained. We may admit that even a hen peafowl is capable of realizing that her lord's tail is something very fine as well as large. But the theory supposes much more than that. It supposes that when two peacocks are competing for her favour, she is capable of critically selecting the one whose amazing blazoning is just a trifle finer than the others, for by this selection of fine differences on the line of improvement the wonder is supposed to have been produced. Belief becomes none the easier when it is remembered that such undoubted æsthetic tendencies as birds display-take, for example, the thefts of shining objects and coloured rags by magpies and jackdaws-are of the crudest sort. 


\section{THE GREAT SCULPTOR}

IN the low country of a northern shire one of the common stock of stories was concerned, in goodnatured derision, with a Highland woman who, on a journey, came to a river and sat down to wait till it ran past. I have been spending some rainy days in the country where this lady came from. Before me is a very steep and rocky hill. It is about a mile long, of nearly uniform height, irregularly notched in a score of places at the sky-line. The upper half of it is very nearly precipitous grey rock, and the lower half slopes more freely to a flat glen bottom. After three weeks of fair weather it looked nearly as dry as a cinder-heap, and could not, one would say from its appearance, ever become very wet.

But after the drought one of those " depressions" the weather prophets are always telling us about comes creeping across the Atlantic, and as soon as its edge is over us our scene is changed. The barometer had stood at $30^{\circ} 5$; it went down to $29^{\circ}$. With almost startling suddenness great vapour masses begin to condense on the mountaintops, differing both in character and extent from the nightcap they are apt to assume of an evening in the best of times. No nightcaps these, but 
great wet blankets, detaching ample portions of themselves to occupy and fill up the corries and the hollows between the ridges that occur on even the steepest mountain-side. When you look at a mountain in sunlight, it seems to offer an almost uniform upward climb. If you have ever climbed one you know that there are many breaks in the rise, many flat and even hollow places to cross, where you lose some of the altitude you have achieved. When the vapour mass of a depression comes upon the hills, its wandering arms of grey reveal those large irregularities, and, even in concealing much of the hill, disclose important aspects of its true character which the brightest sunshine conceals. With nightfall comes rain-no gentle shower, but the downright, determined "precipitation" of wet weather in the hills.

Next morning it is still at it, and there is nothing to do but look out at the hill opposite, with a description of which I began. I said that in about a score of places its sky-line is notched, and each notch was the apparent starting-point of a long scar, seaming the hill from top to bottom. To-day each scar is marked out with the white of falling water, each with its little tributary threads, and the whole system covers the hillside with a loosely woven lace. When a gust of wind comes along, the threads of the lace are caught at the steepest places, lifted clean out of their courses, and transformed into fine clouds of travelling spray. With an extra strong gust the whole hill-face seems to be involved in white smoke, but the smoke disappears, and the white-lace 
system is restored the instant the gust has passed.

I brave the elements, and pass over to examine the hill-face. At the bottom of each scar I find a rushing burn, which in two or three cases can only be crossed at a more than ordinarily boulderblocked part of its course. Looking up, each important thread in the lace system is seen to be a deeply cut gully, down which the stream comes in a long series of leaping cascades.

Returning, I resume the more distant examination of the whole with the aid of a glass, and note that the notches that break the sky-line are of very diverse degrees of importance. The chief of them is, in reality, the opening to the main slope of a little glen cut into the tableland on the top, and the gully through which its burn descends is a glen in the making. Over a part of its course this gully-glen has widened its sides so far that it has captured to itself the waters of three smaller gullies. Each of these starts on its own course straight down the hill, and about halfway down is deflected abruptly to the larger gully, whose lateral erosion has cut into the channel of the smaller neighbour. It is still possible to detect the now streamless lower part of the gully whose water has been arrested. By this process of annexing neighbours the stream in the big gully is gathering power, and its manifest destiny in the course of ages is to cut into two hills the single hill down whose face it is now tumbling and leaping. At both ends the hill is separated from neighbouring hills by deep glens cut down 
to within a couple of hundred feet of sea-level. The work of the streams which occupy them is well on the way to completion. But at one time, very long ago, they were just long gullies in the long range they have now cleft into three distinct hills.

To return to my starting-point. On the third day the depression has passed over us far enough to give us the easterly slant of wind which means dry weather on the West Coast, and the type of weather changes from steady downpour to " showers." On the fourth day we have blue sky. While it was still "showers" more than half the white lacing of the hill-face disappeared. With dry weather all the threads of white water vanish but two, and a single day of dry weather reduces their number to one-that in the large gully. And the stream in the large gully : twentyfour hours ago a torrent seething and boiling among boulders in its channel at the bottom of the hill hardly covers the small pebbles in its course. Its fine waterfalls where it leaps down the hillside have become mere threads. It never runs dry, for by lowering its col it has appropriated a large gathering-ground; but a month of drought brings it very near to the vanishingpoint.

If the old lady of the story had spent her days in this glen, and derived all her notions of streams from those that occur in it, experience would have justified her expectation. Most of the hill streams begin to run after a day or two of heavy rain. Those of them that never run dry become for- 
midable only in heavy rain, and they diminish with almost incredible rapidity when the rain stops. The main valley river itself, to which all those hill streams are tributary, becomes in rain a great and impressive body of water, and within a few hours of the appearance of blue sky dwindles to fordable proportions. On the last day of the rain referred to, it became so fine a spectacle that I resolved to take photographs of it " as soon as the light became good." Next morning the light was excellent, but the impressiveness had gone completely out of the picture. The spate outlived the rain by only a few hours.

The geologist pictures Scotland of a very remote past as a tableland which has been cut and furrowed by the forces of erosion, chiefly running water. In regions of easy slopes and mild rainfall the idea is not easily absorbed, and hence the persistence of the popular notion that our mountains are the results of great upheavals. Among the western hills in rainy weather the conception of the country as a low dome sculptured by running water "soaks in." 


\section{MAY}





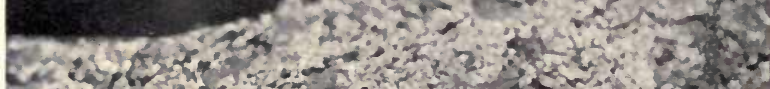

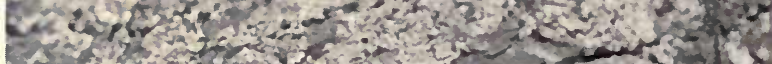

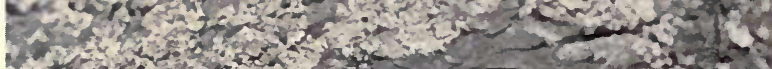

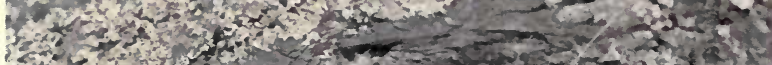

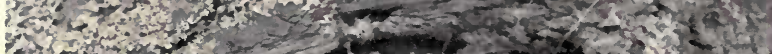

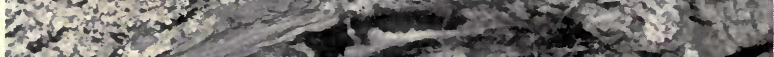

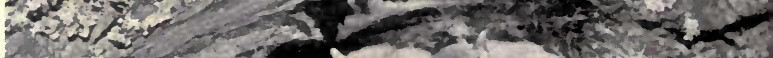

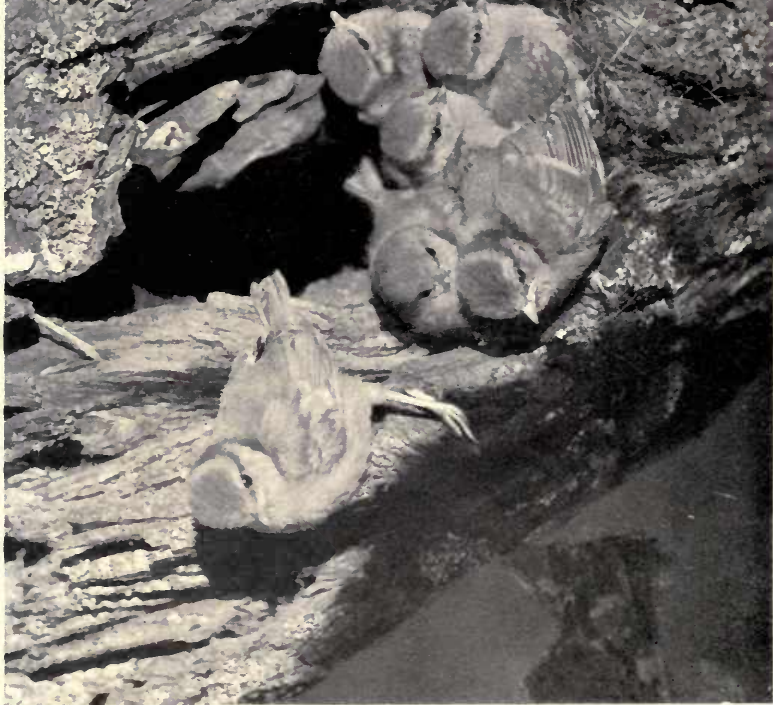

 


\section{THE TOM-TITS AND THEIR BOX}

I HAVE a pair of subtenants, and though they pay no rent I take a great interest in their welfare. A year ago they took up their quarters in a hole in the wall of my domicile. It was a narrow hole, but within its cavernous recess the subtenants, being merely tom-tits, managed to rear a large family, if not with comfort, certainly with security, which is the chief thing a nesting tom-tit seeks. This year, in the middle of a robustuous April, they came upon the scene again, and to show there was no ill-feeling on the landlord's part a lump of suet was hung up for their favourable consideration.

Between the suet and the hole the pair passed a hilarious day, and within a week they commenced the business of furnishing. It was begun in no very resolute fashion. Mrs. Tom-tit would approach the aperture with a beak laden with bedding material, warranted not to shrink, but as often as not she would forget why she had gathered it, drop it to the ground, and have some more suet. Soon, however, business began in earnest, and it was at this stage that the sense of my duties as a landlord came home to me, and I resolved to provide a box. The hole was mani- 
festly a poor place in which to bring up a family, and the Local Government Board would condemn it on the score of air space alone. Was I to be reckoned among the bad landlords? Never. And so the box was built, six inches by six every way, with a nice slit at the right upper corner in order that the opening might be placed as near the opening of the hole as might be, and all possibility of mistake avoided.

The placing of the box was a delicate business. It had to be done between visits, and done it was in the most masterly style of philanthropy. A piece of wood was driven into the hole while the tenants were away, blocking it, and to the wood the box was screwed. It was so bestowed that the slit was in the angle formed by box and wall and within half an inch of the place where the hole ought to be.

Then the drama began. The proud husband flew on to the nearest rose-tree, beak laden with nesting stuff, and thence to the hole. But no hole was there, and never was little animal more surprised. He clung to the wall, and inspected all that remained of the domiciliary aperture, first with one eye, and then with the other, many times. The identity of the rose-tree was questioned, but found all right, and the wall was swiftly examined lest peradventure the hole had moved. But there was no other hole, and it became stupefyingly certain that dark influences were at work. His remarks were easily translated out of the blue tit language.

"Great cats I" he ejaculated, "what has gone 
wrong? Am I in my sober senses? The hole was here five minutes since, and it is gone. Did ever any tit hear of a hole which shut itself?"

Then after rubbing his eyes he had another inspection. Flying up, he tried the off-side of the box, but there was no hole there. From the top of the box, by the sure and certain method of the alternate eye, he once more inspected the remains of the hole, and finally popped into the box itself, saying as he vanished : "Well, I never I If this isn't the hole after all." But the interior was new and strange, and he emerged declaring in emphatic soliloquy that never since the beginning of the world had such a thing happened to any little bird. Clearly the situation demanded the best advice, and on swift wing he sought it.

Inside of three minutes the tit, whose cosmos had been shaken, returned with his mate, the two in rapid conversation.

"I tell you," he was saying, as they reached the rose-tree, "it is gone, vanished, shut."

"And I tell you," the lady remarked, " that those spring caterpillars have been too much for you. I find them heady myself."

"Well, look for yourself."

"Follow me, you old stupid, and I'll soon put you — Eh I Great sparrow-hawks I It should be here-here-here !"

The tom-tit laughed a twittering, irritating laugh, and said: "Well, put me right !"

"It's gone," she admitted.

"Oh, not at all. Those spring caterpillars have been too much for you." 
"Brute !" she exclaimed with a sob. "You have the heart to jest, and I shut out of house and home."

That took the laugh out of him, and they kissed and made it up. But the great fact stood out now in both brains that a cruel, heartless eviction had taken place.

The succeeding conference in the rose-tree was long and solemn. The possible causes of the catastrophe were debated, and when the tom-tit attributed everything to the vernal equinox his partner agreed that he had had an inspiration. But practical considerations asserted themselves.

" Another hole must be found," said the tom-tit.

"Something within tells me that it must be found at once," replied his wife.

" Isn't it horrible," went on the gentleman, " and me so partial to this garden? I was hatched in that hole."

"I wonder," queried the lady, "if anything could be made of this new hole? I hate novelties, but good holes are scarce."

Thereupon she hopped on to the top of the box, and applied first her left and then her right eye to the aperture.

"Looks rather nice and dry," was her comment.

" I can't endure damp," said he.

" None here," the lady proceeded. " Situation nice and airy, in close proximity to all the best fruit trees. Lighting just right."

"What about cats?"

"Might have been made to keep them out," 



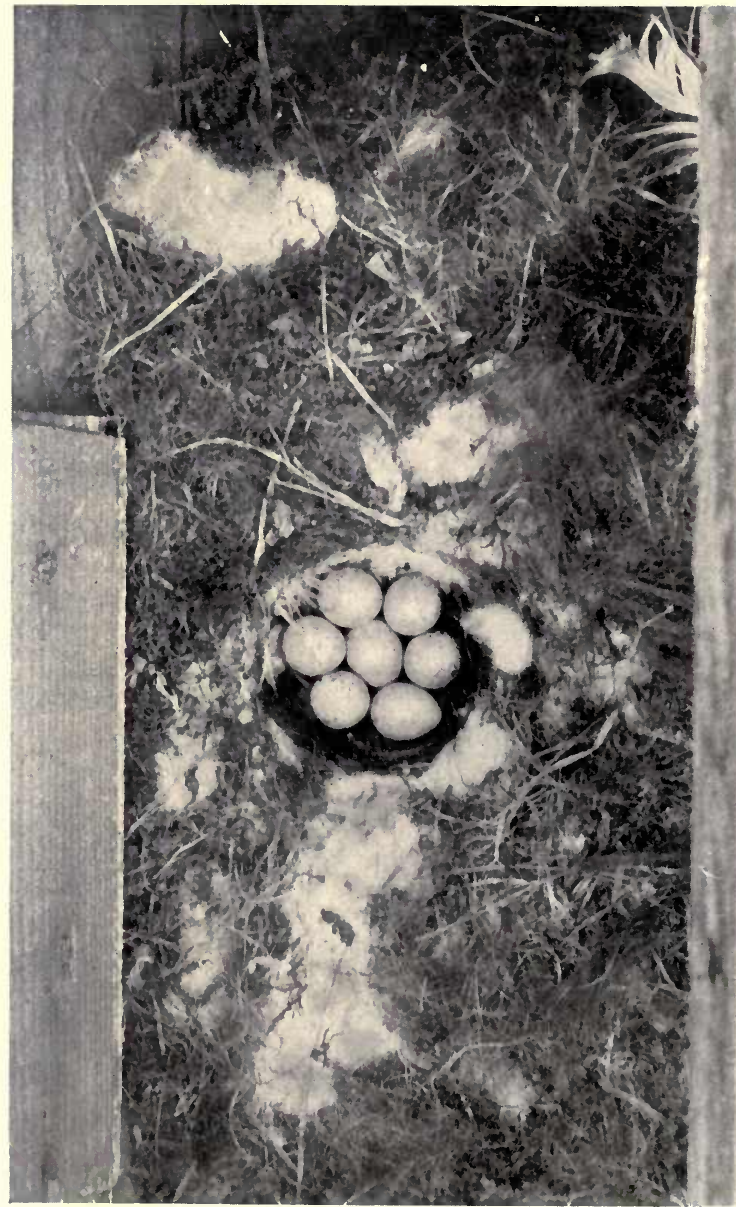


she replied. "Really, we might do worse than think about this hole."

"And neighbours?"

" They're all right. I saw the man putting water on flowers and raking ground. Men of that sort are quite harmless."

"One can't be too careful about one's neighbours. Fortunately, there are no children."

But before coming to a final decision the troubled pair evidently resolved to inspect all the other holes in the neighbourhood, and they vanished for a whole day. The search cannot have been productive, for when next seen they entered the box, and made a long stay. Conversation was resumed on the rose-tree.

"I think," said the lady, "this will make a most eligible residence-dry, secure, self-contained, cat-proof, and quite beyond the reach of small boys."

"I really believe we could not do better," said her mate, " and house-hunting is such a bore."

" Then let us take it," said she decisively ; and the other said, "Done."

And "done" it was. They have now got in all their sticks, and there may be an egg in the box any morning. It has one great advantage over the hole-that I can open the lid, just to see that the conditions of a reasonable tenancy are being observed. 


\section{BIRDS IN THE GARDEN}

VEGETABLE life in the garden has sprung into activity with almost startling suddenness during the past week, a common enough but always striking and pleasing experience when spring, instead of stealing upon the country by inches, is delayed, and comes in with a stride (1910). The first day of March was so passably good that the cultivator of the soil found himself asking, "Is this the lion or the lamb?" Many decided that it was good enough for the laying of seed, and no small quantities of peas and sweet peas were put down. On the second of the month the leonine characteristics declared themselves, and leonine March remained to the end. Throughout the month seed sown on the first made not a move, and, saturated with cold water for many days, much of it may have rotted away. But late April sunshine brought up with a rush what remained good on well-drained slopes, and then the carnival of the birds began.

Most birds I am ready to defend through twelve months of the year, but there are periods when partizanship is put to a severe strain, and one of them is here now. Probably the brilliancy of April's opening, following upon the prolonged 
dourness of March, had an intoxicating effect on sparrows, blackbirds, and tits ; certain it is they set themselves now to the work of destruction with a spirited abandon suggesting nothing but revelry. When the sweet peas came above ground Mr. Sparrow nipped off every plant flush for the sheer fun of the thing. He did not pretend to eat them. He merely hauled them out and left them lying, chirruping loudly the while, and dusted himself with the dried surface earth when his wicked work was done. His whole demeanour was that of a gamin let loose. The blackbird's sins were equally bad in effect, though less wanton in intention. He specialized on the larger peas, carefully seizing the plant well down its stem and pulling it free of the soil. Germinating peas are not a food he cares about, but his ancestors long ago made the discovery that when a young plant is pulled out by the root some succulent grub may be pulled out along with it. So the information was passed on, and every blackbird makes a point of acting upon it. The tits, great and blue, liberated the wickedness of their nature on the apple and pear-tree buds, and watching half a dozen of them at work raining down the fragments, I found it difficult to believe that they, were after food, and not merely, revelling in spring-time fun.

Curiously enough the wickedest sinner of the three is the most easily, circumvented. Since stretching black threads along the lines of the sweet peas not a sparrow has come near them. Mr. Sparrow is not only. clever, but thinks himself even cleverer than he is. He knows that mankind 
is capable of tricks, and flatters himself that he is just the bird whom those tricks won't take in. When I descended upon the pea lines, thread reel in hand, the marauders hastened to the nearest tree and watched. What was done they could not see, for a black thread against black ground is very nearly invisible. But they showed by their prolonged conference that they suspected some nefarious plot. At last one made a cautious descent, and, finding nothing wrong at the first hop, reported all well. Then the others, with varying degrees of doubt and boldness, ventured upon the ground. Suddenly two found the thread against their legs, and with a shriek, "I told you so," they started away, followed on the instant by the whole flock. The succeeding tree conference was loud and prolonged. In every variant of sparrow language they assured one another that they were convinced all along there was devilry afoot, that if they were not wonderfully clever the last sparrow among them would have been snared, that nevertheless the thing was impossible considering the brightness and alertness of their intellects, and that once again the human enemy was to be baulked in his fiendish desire for sparrow pie. So the sweet peas are left alone. The blackbird is a creature of another nature. When he runs his legs against a string and falls over it, he just gets upon his feet again and resumes work. A well-constructed scare may keep him away for half an hour, but an object which does not move has no permanent terrors for him, and soon he will be found perched upon it. At another 
period of the year the blackbird will be found robbing the fruit-trees, currant bushes, and strawberry beds, and nothing will render him harmless now or then but a net, and if there is a tear in the net he will find it out. Small wonder that as he goes round his hedges and finds in them the well-constructed nest of the tuneful robber, the gardener, without scruple or mercy, tears it down. But the act is of small avail, for the blackbird which means to rear a family will not be discouraged by one domestic catastrophe or two.

What the tits are after as they tear up the flower buds of the apple and pear-trees is still something of a mystery. They certainly do not eat the buds or any part of them, though occasionally a bud-scale, which is not food, has been found in the crop of a little wrecker shot in the act. It is hardly more than a surmise that they are searching for minute insects or larvæ concealed in the buds, but a careful examination of buds thrown down by them has resulted in a failure to find a brace of insects of any kind. Probably, however, they break up the buds with the hope of finding insects, just as the blackbird tears up the peas in the hope of finding grubs, and as the rooks tear up the young corn on the offchance of bringing up a wire worm or leather jacket at the same time. That it is food they are after is pretty. nearly proved by the fact that a counter-attraction has been found completely successful in diverting their attention from the trees. As long as pieces of fat, meat, or bones (with something on them) are hung up in the 
vicinity, no tit will trouble about buds. Their appetite for meat, cooked or raw, is insatiable, and they become very bold in the attempt to gratify it. There is, indeed, a record, on unimpeachable authority, of blue tits entering the window of a butcher's shop and feeding on the meat exposed for sale. Another tale is told of an orchard owner who secured immunity for his trees by hanging up in one of them a dead dog, and if he only took the trouble to skin the dog there is no reason why his story should not be accepted as true. As a carnivore the tit is superior to prejudice.

The bullfinch, as most people know, is one of the worst of garden pests in the bud season, in the districts where it abounds. Bully's red breast has made him a favourite with the birdcatcher, and hence the species is never abundant in the vicinity of towns. Another finch, however, which goes through the world with no very bad name, can make himself very troublesome in the spring. On the balance the greenfinch is emphatically a useful bird, consuming as it does enormous quantities of weed seeds, and particularly those of the charlock or wild mustard. But it has one troublesome passion, for it is ready at any time to risk its head for a meal of germinating radish seed, and it has just completely cleared a bed for me. The unnetted bed of radishes which it discovers is doomed. 



\section{THE NESTING OF THE ROBIN}

THERE is no British bird whose habits all the year round provide more interesting, and, what is about as important, more easily available matter for study than the robin. And this because, having adopted mankind into its scheme of life, it is a bird passing through an experimental phase, imperfectly served by the long-descended instincts of its race. To appreciate this point it is necessary to know something of what may be called the stock habits of the species. The range of the robin is wide, including most of the European and some part of the Asiatic continent, and our robins are an insular strain of the family. It follows that the continental robins, being the main body, will exhibit to better purpose the natural manners and customs of the bird than the insular detachment. And the British naturalist on the continent is soon struck by the fact that the robin is there by no means so closely associated with humanity as here. It is, on the contrary, a shy bird, solitary for the most part, spending the greater part of its life in shady and retired parts of woods and thickets, and avoiding familiarity with mankind at all times almost as decisively as its most furtive relative the nightingale. 
How account for the difference? There can hardly be a doubt that the character of our insular robins is one of the many by-products of our insular climate. Over the greater part of Northern and Central Europe, where winter descends with continental rigour, the robin is a migratory bird. It shifts its quarters in winter to the regions bordering on the Mediterranean. Thus neither in its summer nor its winter home is it urged by necessity to seek human aid in the working of its economy. The British robins, on the other hand, stay within the British Isles. The climate is not hard enough to drive them out, yet, subject to burst of boreal energy, savage enough to make robins grateful for pensioner's fare. So they come to the bread crumbs and develop latent aptitudes for turning mankind to account. For it is highly improbable that there is any sense of friendship on the robin's side of the account. They recognize mankind as objects in the landscape usefully associated with the food supply, and utilize us just as the water wagtails utilize cattle, having recognized that cows are excellent for disturbing insects that lurk in the grass.

Naturally the robin in its nesting habits is a shy bird, choosing a well-hidden place for its home; and many of our robins retain the race habit in this respect to the full, particularly those that live in the country. Shallow holes at the bottom of trees, recesses in banks well shrouded with herbage, and low set holes in walls are its typical resorts-and the discovery of the nest in these natural conditions is never an easy matter. 
But no bird can compare in adventurousness as a nester with the robin which has thoroughly familiarized itself with humanity by a residence in town or village gardens. About this time of the year there is always a crop of paragraphs in the papers about strange nesting-places, and if any one took the trouble to collect these paragraphs he would quickly make the discovery that they are almost entirely related to the nests of thiree birds. About twenty per cent. of the cases of queer nests would be cases in which great tits or blue tits had chosen letter-boxes or hollow iron gate pillars in which to rear their families. The other eighty per cent. would be cases of robins. With the humanized robin the one natural idea about a nesting-place firmly held is that it must be a shallow hole. It is not necessary that it should be a secluded hole or a hole in any way hidden by greenery. An old boot, a flower-pot lying on its side on the ground, a watering-pan hung on a nail, are likely to be pronounced " the very thing." But these are almost normal sites compared with others on record. The greasebox of a railway wagon lying in a siding has been resorted to more than once, and only the other day the case was reported of a robin which insisted on making its nest in a fold in the tarpaulin covering a tradesman's van, which every day went its rounds.

The courage of the robin is at no time greater than when it is on the nest. During the month I have paid a daily visit to a sitting bird which has its nest in an open recess in a wall against 
which currant bushes are nailed. On my first visit the bird flew off when I advanced a finger within half a foot of her. Since then she has kept her place, even when touched. The pair, cock and hen, take turns in the labour of incubation, though probably the hen does the most of it, but in both the feathers of the tail show traces of cramped quarters.

It is very generally thought that the robin, so ready to be a dependant during hard weather, is indifferent to human assistance in the summer. This is by no means the case. I have only to take a rake in hand and begin scratching the ground to have one of the pair referred to in front of me within a couple of minutes. During the period of dry winds my gardening friend has been putting in odd half-hours, pushing the Dutch hoe through the beds of his growing plants to kill the young weeds. Well do the robins know the significance of this manœuvre, for they are in front of him in an instant, watching the broken earth with eyes marvellously capable of detecting the movement of any creeping thing. A big worm is seized and rapidly pecked to fragments, and a small one is got over whole. Centipedes and millipedes are regarded as a special dainty, and the unearthing of one will bring the robin almost into the hoe's grip. Every now and again the feaster remembers his companion on the nest, and vanishes with a wriggling dainty, which he deposits in her beak.

With their liberal and experimental views on nesting quarters, the robins are of the small num- 
ber of birds which are ready to utilize a place specially provided for them. They are well served with a box about six inches square, having an entrance hole quite twice as large as the hole in a tit's box, that is to say, a hole about two inches square. The box should be placed against a wall, about three feet from the ground and facing the east, where the entrance will catch the morning sunlight. But though your garden may be the regular haunt of a pair which have fought away from it all intruders of their own kind, and though this box is undoubtedly the most eligible building site within its wall, the chances are just about two to one that the robins will find some outrageously inappropriate place and prefer it. In that case they have just to be humoured.

In a week or two the young robins will be hopping about the gardens and hedgerows, and it is worth while to note that in their first, immature plumage they are dressed not as robins, but as thrushes. Their speckled coat closely resembles that of the mavis, and indicates a relationship about which no ornithologist is now in doubt. In other words, robins are of the thrush family, and both young robins and old thrushes get their speckled feathers from a common ancestor. 


\section{THE YOUNG DEER}

FEw would hesitate to answer with an emphatic "Yes" the question whether the fear of man in the red-deer is innate. It is certainly in full operation at a very early age, and, of course, through life is a most powerful factor in the animal's conduct. The deer, where it is not made familiar with much artificial provisioning, is ceaselessly vigilant, and its vigilance is wholly directed at man and his companion-the dog-for no other animal survives in this country which it has any occasion to dread. Altogether this fear of man, with the elaborate strategy that serves it, has the appearance of an instinct engraven on the deepest nerve tissue, innate in the strictest sense of the word.

Yet it is doubtful if the fear of man in the reddeer is any more innate than in those birds of newly discovered oceanic islands, the description of whose conduct on first acquaintance makes such entertaining reading in more than one of Darwin's books, particularly in the "Voyage of the Beagle." During June I had an opportunity of making some observations bearing on the subject. While holidaying in a northern deer forest I read Scrope's "Deer-stalking in the Scottish Highlands," and 
asked a keeper his opinion of the passage in which that old worthy describes the conduct of the hind and her calf at the time of the birth of the latter. The passage is as follows :-

"She drops her fawn in high heather, where she leaves it concealed the whole day, and returns to it late in the evening, when she apprehends mo disturbance. She makes it lie down by a pressure of her nose, and it will never stir or lift up its head the whole of the day unless you come right upon it, as I have often done. It lies like a dog, with its nose to its tail. The hind, however, although she separates herself from the young fawn, does not lose sight of its welfare, but remains at a distance to the windward, and goes to its succour in case of an attack of the wild cat, or fox, or any other powerful vermin. I have heand Mr. John Crerer say, and it is doubtless true, that if you find a young fawn that has never followed its dam, and take it up and rub its back, and put your finger in its mouth, it will follow you home for several miles; but if it has once followed its dam for ever so small a space before you found it, it will never follow human beings."

My friend's comment on this was that no such formal ritual was necessary, or, as he put it, "You don't need to take so much trouble." If a young deer is found in this early stage and handled, it will follow the person who has lifted it. $\mathrm{He}$ and his fellows were collecting a number of hind calves for transportation to a remote forest, whose owner wished an admixture of fresh blood. The finding of them called for a prolonged and patient watching 
of the mature hinds with the glass, and about half the calves discovered were young stags. These were liberated immediately after their sex had been ascertained. But in most cases they tried to follow the person who had lifted them from the lair in which the dam had laid them, in some cases so persistently that, in order to shake them off, the finder had to climb some bit of rock where it was too difficult for them to follow.

I was offered an opportunity of accompanying a searcher, and found the work far from exciting. It meant a long tramp over a rocky mountain-side, several long lies while the hinds in sight were watched through the glass, and finally the discovery of one which seemed to have just left her calf. When the spot was reached, there was the calf, sure enough. The searcher carried a long stick with a hook of wire at the end of it. Sometimes, I was told, the young calf would start up and keep moving a yard or two ahead of its pursuer, hence this implement. But in our case the implement was unnecessary. The calf never moved till it was lifted, and then it showed not the slightest tremor of alarm. It was stroked, and at once accepted its finder as trustfully as if he were its dam. Rather from want of faith in its ability than its will to follow he put it in his game-bag, with the head and neck sticking out, and in that way carried it home. At headquarters half a dozen persons had to stroke and admire it, and it accepted all without a hint of disturbance or hostility. And when offered the bottle, it took to it with the readiness and eagerness of a ewe-bereft lamb. 


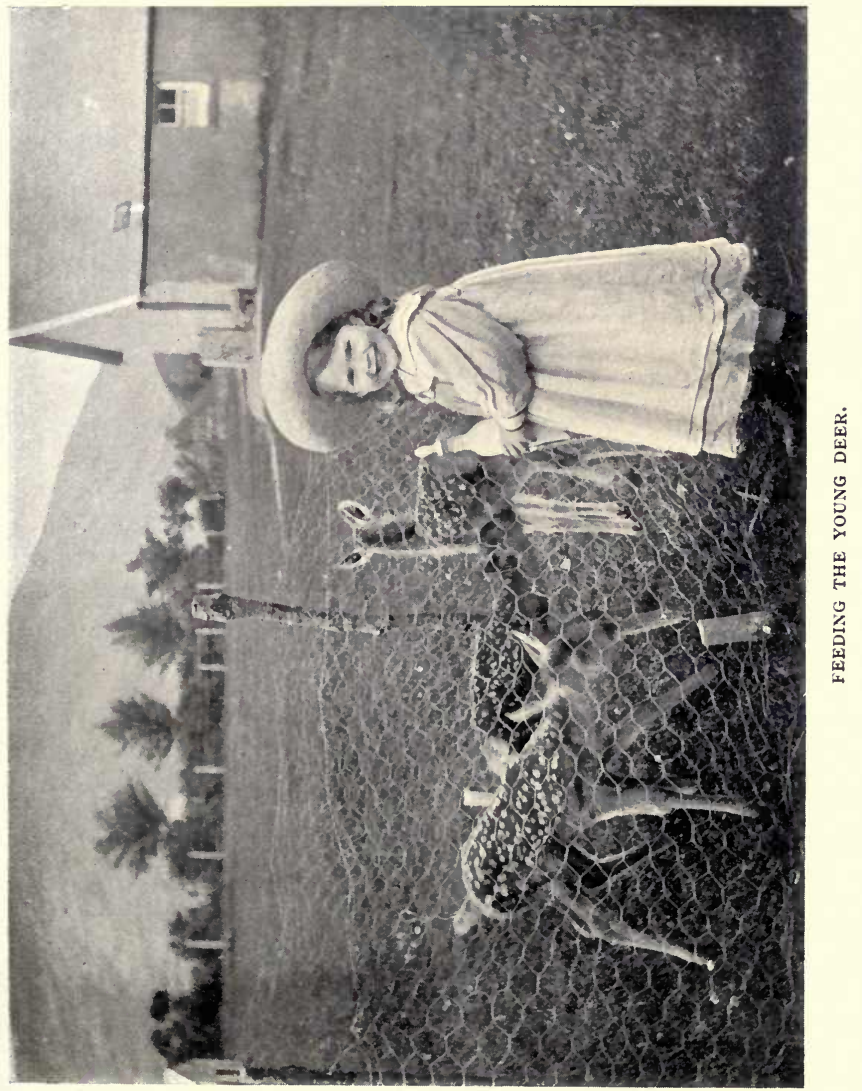



At all stages of its life-history the red-deer is a beautiful animal, and but for one thing a fair case might be made for the assertion that this first stage is the most beautiful of all. The deer has then much of the exquisite and delicate grace of form of the gazelle. The body is not much larger than that of a good-sized hare, and the skin has a velvety smoothness and gloss which quickly diminishes. It is marked throughout with fallow-like spots, which also disappear early in life, but at this stage speak very plainly of a remote spotted ancestry. As is the case with the young of the horse, however, so with the young of the deer: the legs are a trifle disproportionately large for the body, though this is a defect which hardly diminishes the exceeding grace of the animal's movements.

Scrope's assertion that a deer which has once followed its dam for ever so small a space will never follow human beings might be questioned. The fear of man, which certainly is not innate in the very young animal, though it rapidly develops in it as it accompanies its dam and catches up her alarms, is easily overcome in later life, especially in the case of the hinds. In the forest referred to, as in most others, winter feeding is provided, and many, of the immature hinds keep about the customary feeding-place throughout the summer. During our search for calves we had to pass this place, and in order to entertain and possibly surprise me, the keeper blew a shrill whistle on his fingers. In any other part of the forest such a sound would set every deer within a mile on 
the move away from its point of origin, for the deer is hardly less attentive to sounds than to smells. As old Scrope puts it, the red-deer " takes the note of alarm from every living thing on the moor "-and I have myself seen a bunch of them suddenly lift their heads on the first cry of an anxious redshank, whose family feeding-ground I had invaded. Here the effect of the keeper's whistle was very different. From three sidesthe fourth side was a loch shore-hinds began to troop in till there were about thirty of them in the space of three acres. They came quite close up to their friend of the snowy days, and followed the two of us in a troop till we were a considerable distance beyond the feeding-ground. None of these deer had been hand-reared or taken from their dams in youth. Their tameness was a result of their winter feeding and nothing else. 
JUNE 



\section{THE FANCIES OF THE TROUT}

Most people who go into the remoter parts of the Highlands to fish for the first time carry with them a light-hearted contempt of the trout of these out-of-the-way regions. They are unsophisticated rustics, with none of the highly developed intelligence which marks (in books) the educated denizens of chalk streams and some lowland lakes; therefore, to deceive them will be almost too easy a work to be interesting. Dwellers in a hungry country, they are ill-fed ; therefore, they will rush greedily at anything presenting the semblance of the material of a meal, and, in particular, they will prove unable to resist the beautifully finished lures which the visitor has taken with him in a wellstocked fly-book. As regards some of the lochs of Sutherlandshire, one is, or a few years ago was, tempted to accept this view of Highland trout as true. As regards Highland lochs in general, the visitor soon learns that he has carried a fond delusion, and comes to understand that among the mountains, as elsewhere, the trout is a creature of the most unaccountable moods and appetites.

Consider a perfectly common experience of the curious fastidiousness displayed by trout, which should be reckoned among the most unsophisti- 
cated of their kind. During the last week of June I fished two Ross-shire lochs-one lying high, and probably untouched by gut twice in twelve months; the other larger, and at a much lower level of the same district, but regularly fished throughout the season. On the first a cast was used of three flies of medium size-a grouse and claret, a teal and red, and a blue Zulu, very popular as a dropper in recent years in the North. For an hour, though wind and sky were just right and the water ideal in character and depth, nothing came of this tempting offer. The loch might have been uninhabited. Then, overcoming a reluctance, partly theoretical and partly indolent, I took off the Zulu and put on a teal and greena pretty thing to look at, but in this part of the country a fly with no sort of reputation at all. But straightway the fish began to rise, and within an hour and a half the basket contained thirteen trout, " sizable," but not large. Every one of the thirteen was taken on the teal and green, and at least as many rises, unfollowed by capture, were to the same fly.

Feeling that I had struck, by a happy chance, upon the secret of success, I hastened to the lower loch, in which the run of fish is larger. But here, strange to say, in the same weather and the same water (the burn from the upper loch discharges into the lower), the teal and green was of no use whatever. It did not even excite an idle curiosity. But, on the other hand, the teal and red found itself in a first-class market. Eight fish, running from half a pound to a pound and half, were all 
taken on it, and in the end a big one went away with it in his jaw. I had not another teal and red, so put on the nearest thing to it-a nondescript teal and claret. But the trout would not have it, though the difference between teal and red and teal and claret is merely the difference of a shade. Thus in one loch teal and red and blue Zulu were treated with a cold indifference, and teal and green was seized with gustatory zest; while in the other, teal and red was accepted with avidity, while teal and green, grouse and claret, and teal and claret were all presented in vain.

This, as I have said, is no uncommon experience, for every angler who habitually fishes Highland lochs can recall many one-fly days when all other flies are as untempting as bull-beef to a Spaniard. But the experience is none the less puzzling on that account, and none of the many theories offered to explain it-some of them offered with extraordinary cocksureness-satisfies many besides their authors. What may be called the fly-on-the-water theory is probably first favourite among them all, but there are many occasions, at any rate, when it will not do. On the day referred to I was particularly attentive to the fly on the water, and it-for one abounded and others were extremely rare-presented no sort of resemblance to teal and red or teal and green, the successful lures. This abounding fly was a blae, and rested on the surface with upright wings. An upright Greenwell would have imitated it very closely; but I did not try a Greenwell, partly because it is a bother to change flies, but chiefly because 
the natural Greenwell seemed to rest on the water in perfect security-at least, so far as the assault of fish was concerned.

But for what did the fish take the two teals? Tremblingly one ventures to doubt whether they took them for anything with which they are familiar in the air above or in the waters beneath, and to suggest that, like the Athenians of old, they are drawn by some new thing. Some of the artificial flies are carefully modelled on the natural fly, this being particularly the case with the May-fly, the March brown, and the Alder; others were possibly sketched on natural flies, and have been improved out of all semblance. Certain it is that, were an expert entomologist asked to name the species in a fly-book, he would, as regards the vast majority of them, recoil from the task in dismay. But even if all artificial flies were models of natural flies, it does not follow that the fish would take the most successful model among them for the fly it imitates. To justify this doubt, one has only to take the natural fly and as close an imitation of it as can be found in the fly-book, and, immersing both, pull them through the water. Thus circumstanced, the appearance of the two becomes widely different, for the behaviour of the tissue of an insect's wing in water is quite unlike the behaviour of a confection of fur, pig's wool, and feather. As regards the lure, colour and even pattern are changed. Then the flies with which the fish are most seriously concerned are not the flies which are the most obvious objects of their attention-those resting 


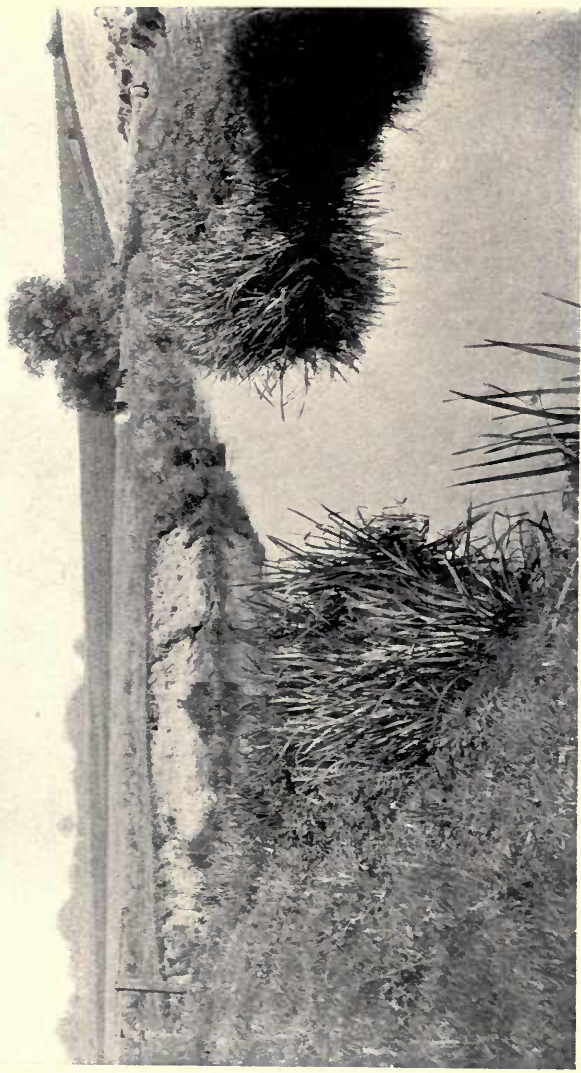

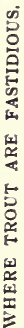



on or skipping above the surface, at which trout jump or thrust up their noses. For one fly taken in that way, probably scores are taken as they rise from the bottom, where they have passed their larval life, and while on this rise their wings are as yet unexpanded. If, however, the fish takes the immersed artificial fly, seen by it darting through the water some distance below the surface, for any sort of natural fly, it is for this rising fly with the unexpanded wings, on which no fly is modelled.

Yet nothing is more certain than that fish have fancies for patterns, or something in patternsfancies which vary from day to day, and even from hour to hour, but are absolutely determinative while they last. What that something is it is hard to determine, but it is a something which often remains when the wings of the fly are almost entirely frayed away. And it may be more decisively present in the most crudely dressed fly than in the finest product of the shops, as I have often noted on that dour stream, the Clyde, where the Lanarkshire miners, with home-dressed hooks of the least promising aspect, always get the best baskets. And whatever it is, the unsophisticated trout of the remote lochs are just as discriminating in picking it out as their relatives anywhere. 


\section{A TERN COLONY}

THERE is the widest possible diversity of opinion as to the effect of the Wild Bird Protection Acts in securing the object they have in view. A writer, dealing with the county of Kent, declared that the Acts had completely eliminated the interest of the small boy in birds and nests, from which followed a long sequence of effects, eventuating in the disappearance of large trout from the chalk streams-no bird-nesting, more birds ; more birds, fewer insects ; fewer insects, reduced supplies of the best fish-fattening provender; fewer sizable fish, disappointed anglers. Without working out a story about it, the owners of Scottish fishings allege something of the same sort when they say that black-headed gulls have increased in number, and that their increase involves the destruction of countless salmon ova and fry.

So far as the North Country is concerned, the writer has had good reason for thinking that where no special protection is afforded the pleasing pastime of gathering eggs is as much indulged in as ever it was. Twenty years ago he was very familiar with a colony of common terns which, many hundreds strong, had its quarters on a low headland projecting into the waters of the Moray Firth. 
Revisiting the scene this month, after a long lapse of time, he found the community a mere shadow of its former self, about a hundred nests being found on an extent of surface where five times as many could have been easily counted two decades ago.

Despite this, however, "the Point" remains an excellent place for studying the nesting customs of what is certainly the most graceful of the British sea-birds. An arid promontory, with the waves ceaselessly singing or sighing on two sides of it, it nevertheless presents a diversity of surface which would be interesting if only because its geological history is so easily read. Patently, it is composed of a series of pebble beaches, whose varying ages are marked not only by their position inside one another, but by the degrees in which a scanty vegetation has been able to effect a lodgment upon them. The outermost beach is composed of wave-rounded pebbles, the shining whiteness of whose piled-up mass is broken only by the line of dried seaweed and other marine jetsam flung there at the highest reach of winter tempests. On the second beach, well marked off from the first by a depression, but following the same line within, patches of stonecrop have taken root, and redeem it from utter barrenness. A third beach, just traceable inside the others, is partly hid with stonecrop, bent, and patches of depauperized bell-heather; and into the heart of the angle fringed by all three, the neighbouring moor has thrust a long finger of its own substance, and the family of heath plants imperfectly cover 
the expanse of stones, here blackened with such lichens and mosses as flourish in sea air.

Like most ground-building birds, the terns lay eggs which hint very broadly at protective colouration. Ranging in ground shade from a dull yellow to a deep olive-green, and in the blotches from a black-brown to a dirty grey, they harmonize with their surroundings in a wonderfully perfect fashion, despite their diversity, when placed amid the lichen-spotted pebbles of the oldest of the beaches. Again and again the searcher is startled by the success of a deception which fails to human eyes only through the formal and orderly arrangement of the clutch, and which, it is easy to believe, would effectually deceive the eyes of the marauding crow. Yet, though Nature seems to have endowed the tern with this useful provision of a protectively coloured egg, wandering over the beaches one is driven to the conclusion that the birds themselves have quite failed to realize their advantage and, so to speak, play up to it. For it appears to be the merest chance if the egg is deposited in a harmonious setting. At the extremity of the point there is an area of about an acre of perfectly white sand, unbroken by any scrap of herbage or any other object, save here and there the projecting twigs of ancient and buried driftwood. No more unsuitable spot could be imagined for any purpose of concealment, yet of all the varied surfaces presented by the point none is more favoured by the terns than this. It is unnecessary to search for their eggs here; they stand out with the conspicuous- 
ness of absolute contrast from a ground on which they form the only contrast.

But if the terns have no notion of selecting the best places for the concealment of their eggs, the colony, excepting those members of it which lay on the sandy extremity, do seem to follow a method in nest-making. Moving at random from clutch to clutch, one is struck by their extreme variety of practice in this respect. Here the eggs are deposited on the ground with no rest whatever; there on the merest perfunctory sketch of a nest; and here, again, on quite a massive and elaborate bed. But soon something suggesting an order is discernible. There on the outermost beach, which is strewn with bunches of dried seaweed, the birds construct a bulky nest. They rarely lay on one of the bunches provided by Nature, but the collection made by themselves resembles one of these. The whole nest, therefore, fits into its surroundings. The sketchy nests are found on the inner beach, where the patches of stonecrop occur; and as they are made of the dead fibre of this plant, they closely resemble those numerous patches of it which have succumbed to the aridity of the situation. Among the lichen-spotted stones the terns make no nest whatever, and, as has been said, those which select this situation achieve, in the matter of concealment, the largest success.

It is not improbable that in a modification of habit we should seek the explanation of the tern's haphazard use, or no use, of the protective colouring of its eggs. Almost certainly the general 
scheme of their colouration is a very ancient adaptation, for it is common to the whole group of sea-birds of which it is a highly specialized member. A description of the tern's egg, as regards everything but size, would apply to the eggs of the kittiwake, common gull, lesser black-backed gull, and the black-headed gull ; and such a community of colouring points to the scheme being an adaptation to the breeding conditions of the common ancestor. But to-day each species selects a different kind of nesting-place, and in the case of some of them the protection of colour is obviously not even sought. The kittiwake depends upon the security of its rock shelf, and the blackheaded gull on the isolation of its swampy islands ; perhaps, too, on the strength of its communities, which is always sufficient to keep thieving birds at a distance. Of the common gull something of the same might be said. Since inspecting the " ternery," the writer has visited a colony of the common gull (not, by the way, the commonest of gulls by any means), which has its home on the rock-strewn shore of one of the largest of the inland Highland lochs. The eggs are in perfect harmony with the mossy blocks among which they lie, but all the advantage of elusive colouring is thrown away by the structure of the nests, which are in every case large and conspicuously made of pale yellow, bleached grass-stalks and kindred dead vegetation. Apparently in some members of the family the protective colouration of the eggs is a functionless survival of an acquisition which may have been advantageous at some remote time. 


\section{A SUMMER-DAY TRAGEDY}

A WEEK ago the rookery was the gayest place in the world, and its clamorous population had a mighty fine opinion of themselves. They began fifty strong in February, and found themselves nearly three times that strength in the second week of May. On every nest-bearing bough sat three, and in some cases as many as five, young rooks, intent at once on acquiring the art of balance and the proper inflections of the rook language. They took to language more readily than to balancing-no doubt because every time they nearly tumbled off they felt obliged to make a tremendously long story about it. Now and again one actually tumbled off, and learnt with a pride which nearly overcame his fright that he could fly. It was, to be sure, a downward fly, an agitated parachutic descent, ending with a splash among the leaves and twigs of a shrub dreadfully near that alarming country, the ground. But flying is flying, up or down, and a great thing to accomplish. Moreover, it is the first step, for even a young rook can recognize that if he comes down he must get up again, and in the effort to get up he really and truly learns to fly. And in this way quite a score of the new generation had 
learnt to use their wings, and could make very creditable circles in the air above the rookery clump of elms.

Old rooks told one another without ceasing about the phenomenal success of their colony. "We are a great colonizing people," they said, " and the wisest of birds. Next year the rookery will be five hundred strong, and the finest of its kind in a day's flight. When we go to the fields it will be the grandest sight ever presented to bird eyes." To the young ones they explained that the rooks were a very ancient family upon the earth, and that their heads were positively heavy with the wisdom they had accumulated in many generations. Sagacity was almost a failing with them. To which the young ones replied, with many a "caw," that they felt within them the truth of all this, and meant, in the hundred or more happy years in front of them, to add to the vast accumulations of corvine lore.

The day's conversation had just got well under way when three figures of the human enemy were observed to approach. Old rooks inspected them uneasily, and explained to the young that though the risk was small it was always just as well to keep these animals at a safe distance. "Therefore," said they, "let us all go up." And they set the example by circling skyward. But, alas ! the young rooks did not go. On the contrary; they were very curious about the animals coming over the ground, and straddled along their boughs in search of the very best seeing-perches. Aloft the old birds screamed out in clanging chorus, 
"Come up, come up !" but only succeeded in communicating to their progeny a feeling that all was not well. But if all was not well, they said, surely the safest place was at home. Then came a horrid, disconcerting bang, and a glossy young bird flew downward with a strange directness and struck the ground with a sickening thud. All the young ones cried out, using up the words they knew ; and they had just begun to go over their repertoire a second time, the better to express their surprise, when that dreadful noise came again, and down went number two. And then, amid lamentable cries from tree-top and sky, the work of destruction went on fast and furious. Young rooks strewed the ground, some dead, some dying, and in pauses of the fusillade the shooters seized the dying and wrung their necks. Perhaps it was those seizures that at last caused the survivors dimly to realize the significance of the parental admonitions. It was bad to think that some unrealized power might cause them to fly down in that strange, headlong fashion, but worse still to think of being handled by those monsters below. So, a sorry score, they betook themselves to the wing and joined the crying host aloft.

A rook-shooting at the end of the nesting season is one of the most melancholy functions of rural life. To begin with, it takes the community just at the grand moment of accomplishment. They have worked incessantly for two months at the labour of bringing up their families, and chattered about every incident in the process with the volubility of the true social animal. Parental and 
communal pride combined to welcome the young generation on their first unsteady excursions among the branches. And just in the crowning hour of success, with all kinds of care behind and the glorious summer before, comes this heart-breaking tragedy. It is now, by general consent, admitted that birds of the crow family possess the highest development of avian intelligence, and the fact lends credibility to the belief that the massacre means more to them than to most birds liable to a similar experience. This, of course, may be no more than an impression of the senses. Grouse, after a drive, slip away into the heather, and if they lament the losses of the tribe they make no show of it. An outraged rookery, on the other hand, gives every evidence of lamentation. Hours after the slaughter has stopped they are still on the wing, at a great height above the scene of it, deploring with hoarse outcry the injury their community has suffered, and, doubtless, expressing their opinion of the hideous barbarity of the destroyer-man. To birds of most species the sight of a dead member of their kind is quite without meaning. The rook is intelligent enough to realize that there is something sinister and of ill-omen about a dead rook. Farmers learnt this long ago, when they found that a dead rook hung on a stick makes a genuine scarecrow; and the fact is still more strikingly shown when a feeding flock comes without warning upon a dead rook lying on the ploughed land. When this happens the host fly with vast clamour to the nearest trees, and debate the horror with an 
excitement which can be recognized half a mile away.

Whether, in the interest of the farmer, rooks should be thinned down at the end of the nesting season is a question whose answer depends on their number. In a recent publication of the Board of Agriculture, on the subject of the food of birds, they are pronounced "decidedly beneficial." Probably no bird does more good work in the destruction of peculiarly noxious insects, such as the wireworm and the leather-jacket, and their skill in finding the latter and extracting it from the soil is not short of wonderful. The leather-jacket lives in a J-shaped burrow, and retreats during the day into the curve, where it is safe from most bird enemies. But rooks systematically search for the burrows, and, thrusting their powerful beaks into the soil above the curve, pick out the larva with certainty and ease. A piece of ground over which a flock has worked will not at the end of the day contain many of these destructive root-eaters. But doubtless there can be too many rooks, as of other good things, for the bird is catholic in its tastes, and has often been shot with a crop stuffed with wheat and other grains. It is therefore reasonable to assume that where the birds are too abundant they levy an undue toll on the kinds of food that are more easily procured. As a general thing, however, rooks work well for their wages. 


\section{SOME BIRDS' NESTS}

BIRDS, as everybody knows, make nests, as well as produce young, " after their kind." Over an immensely great area the individuals of a species build their domiciles with an astonishingly close adherence to a uniform architectural plan. The chaffinch, to take an example, ranges from Britain to Japan, with one or two considerable chaffinchless spaces between; and the British boy familiar with the bird's dainty structure at home would instantly recognize it for what it is, were he to find it in the land of the Rising Sun. How are we to account for this uniformity of design?

$\mathrm{Up}$ to a certain point there is virtual agreement as to the answer. The form of the nest was struck out or reached by remote ancestors of the chaffinches, succeeding generations faithfully reproducing it in all the lands over which they have since extended their range. To this extent the nest is explained in much the same terms as the bird itself. But the inheritance of structure and the persistence of a complicated act, involving something very like volition and choice, cannot be conveniently further compared. Thus arises the other question: How is the knowledge of the design passed on? To which many naturalists 


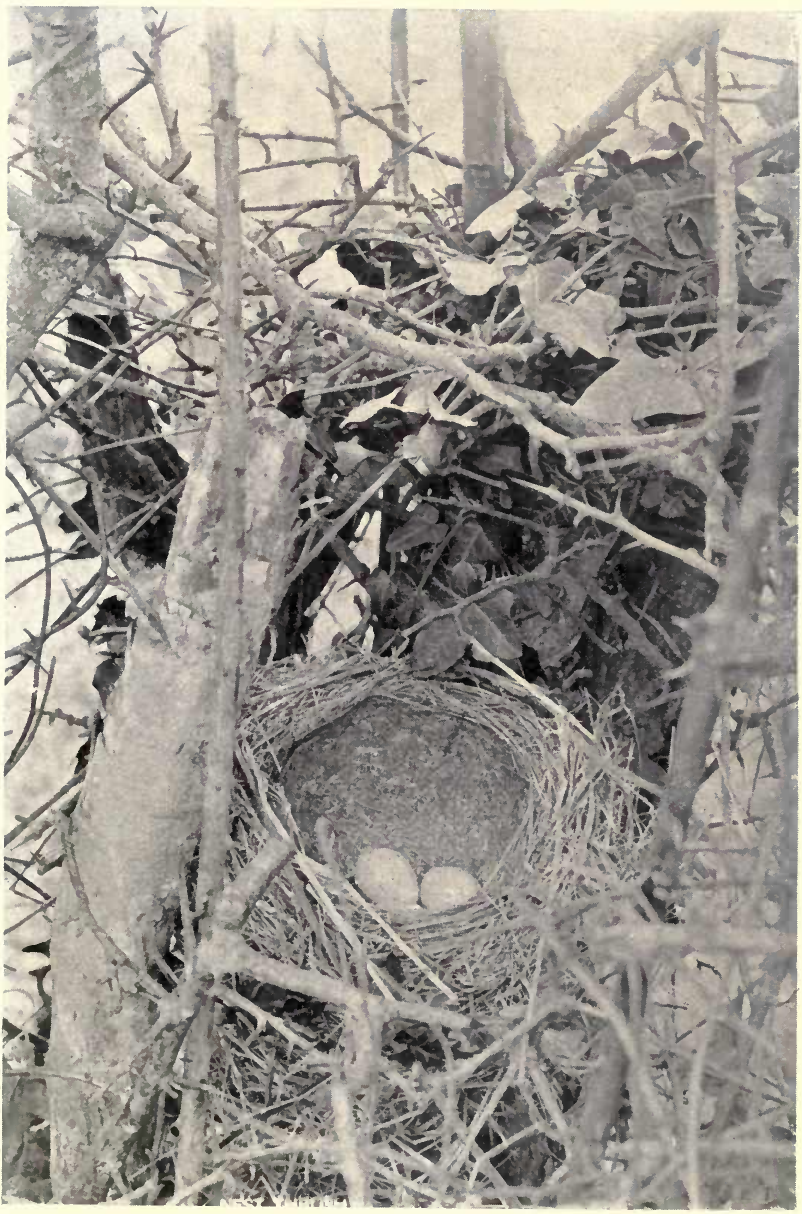


attempt no answer, while those who try are far from being at one.

Some naturalists of great authority have recently adopted the theory that the young bird lays up a mental picture of the nest while still an inmate of it, and from this picture works when its own nest-building time comes, and they support their theory by relating some very curious facts regarding the behaviour of birds hatched out in captivity. Broadly, these are to the effect that a wild bird hatched out by, say, a canary will, if it subsequently mates, fail to make the nest of its kind, even if supplied with the right material. Its ideas are hazy: it fumbles with the building stuff, and the thing it ultimately contrives is a mere generalized sketch of a nest, lacking in every distinctive detail. Hence, it is argued, instinct prompts the nest-making; but without actual knowledge of nests acquired by the individual bird it cannot do more. And as building birds do not gladly tolerate onlookers, it is assumed that the year-old bird must work on a memory of the nest in which it was reared. At present the hedges are full of the nests of blackbirds and thrushes, both interesting specimens of avian architecture, and both capable of throwing some light on the question raised. Though not precisely pretty, the nest of the mavis is one of the neatest and least haphazard of the nests built by British birds. Its plan, moreover, is adhered to with an unvarying rigidity over an immense area. Wherever the bird occurs in the Old World the nest has the same marked charac- 
teristics, and Darwin has commented on the strange fact that those characteristics reappear in the nest of the thrush of South America, separated as it is from its European relative by half the world, and, as it must be, by geological ages in time. The foundation of the nest is laid with rough grass roots, dead leaves, and root stems. As the work proceeds, a finer kind of root fibre is employed, and with this a bowl-shaped structure is fashioned, which would pass for a fairly well-finished nest if the bird did nothing more. But it does more. Having built its nest, it proceeds to plaster it. This is done with a mixture whose composition varies with the resources of the district. Sometimes mud alone is used, with just enough fibrous material to give it coherence. Not infrequently decayed wood enters largely into the composition of the plaster, and more frequently still horse or cow dung. Whatever is used it is worked into a paste in the beak of the thrush, which, at the nesting season, may often be seen resorting to rain puddles for the purpose. The plaster is laid on to the inside of the nest with the beak, and if the nest is. examined at the right stage the soft coating will be found scored all over with bill-markings. But when the bird has finished its work the inside is perfectly smooth. When the work is finished the thrush leaves the nest to dry, and by the time the first egg is deposited in it the whole cup is firm enough and hard enough to hold water. It would be difficult to say what special advantage the mavis gets from a nest of this type, with its 
indurated interior, the great majority of passerines showing a marked preference for a soft lining to the house destined to accommodate helpless and featherless young. The point to be noted just now is, that it is a physically possible thing for the inmates of such a nest, given the intelligence, to see and lay up a mental picture of it, outside and in. Assuming them capable of the examination, most of the nest is open to their inspection.

But examine the nest of the blackbird, which is also a thrush with a difference. In size, general form, and external appearance it is the same as the nest of the mavis. Inside, however, instead of the hard lining of dried mud, there is a yielding lining of fine root and other fibre. It would seem, therefore, that the blackbird, as nest-builder, makes a simpler nest than its cousin the thrush, leaving off operations at that point where the mavis begins its plastering. And so it is represented in more than one book of natural history. But the truth is very different, as any one who takes the trouble to carefully break up an old or deserted blackbird's nest finds out. The first stage of the building process is the same in both, and the second stage is not very different. Like the thrush, the blackbird lines with mud a nest which has already a passably finished look about it. The plastering is not so carefully done, as in the case of the thrush, particularly in the matter of finish, but it is done. Having completed it, the blackbird proceeds to a third stage, and lines the plastered lining with soft fibre. The com- 
pleted structure looks a less fine piece of craftsmanship than the nest of the thrush, but, to human eyes, a more comfortable cradle for nestlings. The point is, that it contains a stage in the workmanship which is absolutely concealed. Neither by inspection while in the nest nor by inspection after leaving it could the blackbird's young discover the existence of the intermediate cup of mud. So far as the blackbird is concerned, we are therefore pushed back to the old theory of instinct. The idea that instruction enters into the work of nest-building is not, however, excluded by excluding teaching of the young. Both birds take part in the work, and, unless they are both birds of a year, one of them has already learnt the way. If it could be assumed that one of a pair is always older than the other, we should have a manner of transmission. Unfortunately for that theory, there are cases not a few in which the male takes no part in the building. 



\section{PUSSY HUNTING}

THERE is no census of the cats that prowl about the sleeping town, but everybody who knows the streets between midnight and dawn knows that their numbers are very great. A proportion of them are, of course, animals which own a home and are merely out for a night of it, a kind of relaxation on which even the most respectable and domesticated of cats insists every now and again. But a goodly number are cats that owe allegiance to no man, or maid, and manage to make a living of a kind on a footing of independence. How do they do it? They search the dust-buckets laid out by householders for the disposal of the Cleansing Department, and doubtless find something in them occasionally to stay the pangs of hunger. But, on the whole, the economy of the town cat is involved in obscurity, and a benevolent society which interests itself in feline happiness thinks that it does these ownerless animals a service by " putting them out of pain." For my own part I have a very strong belief in the competence of the cat to look after itself, and think that much of this lethal kindness-considered strictly as kindness to cats-is misplaced. In the early summer months, however, there is 
no mystery whatever about the sources of pussy's income. She is living on the daintiest of bird diet, and is able to get it in plenty. The other day I met a cat walking in very leisurely fashion along a garden-path with a young mavis in her mouth. In the interest of bird-life I threw a stone at her, and she dropped the bird and moved away in no very hasty manner. There was something about the whole action and gait of the animal, and particularly her readiness to abandon her prey, which struck one as being strangely out of character, for generally a cat will perform prodigies of exertion rather than relax her grasp upon a living thing she has captured. The gardener explained it by saying that the cats which frequented his domain were "fair glutted with young birds." They were killing them and leaving them half eaten, and for the time being, at any rate, were able to lead the life of overfed epicures.

It is only necessary to have some acquaintance with the larger gardens and shrubberies about the town to realize the truth of this. In these places the birds nest in security and in numbers which it is difficult to realize. Most of the blackbirds and thrushes have now raised their first brood, and the young birds are to be met with' everywhere. Awkward in their movements, with obtrusively yellow edges to their beaks, they have inexperience written all over them; and they regard with only half-aroused suspicion any animal, human or other, that comes within their vision. A little later they take no chances, but 
for the time being they take a good long look at any moving object approaching them. And having decided that the object is not to be trusted, they as often as not reckon that it will suffice for the emergency to hop away. So the cats get a great number of them, and enjoy life hugely while the feast lasts, feeling very fine and wild and perhaps despising themselves for ever having 'descended to garbage when it is so clear that Nature meant them for the hunter's life. If they have any fault to find with the conditions it is that their prey is too easily captured, and hardly. justifies the skill they put into the work.

To watch a cat at its hunting is an extraordinary interesting spectacle, if only one can keep one's sympathy with the birds well enough in hand to appreciate the beauties of stealthy movement displayed. I watched a cat the other day stalking a fledgling mavis through a large bed of rhubarb in a market-garden, and nothing could have been prettier in its way. Pussy was no stray. She had all the appearance of a well-cared-for house cat, but she might have had a prolonged and thorough jungle education, so perfect were her jungle manners. She was uphill, and sighted the bird on the farther side of the rhubarb-bed about thirty yards away. The first part of the approach was made by crawling under the large leaves of the plants, and as each row was passed she lifted her head cautiously during a long pause. When about quarter of the distance had been covered the mavis happened to turn tail on to its unsuspected enemy. Instantly the cat took advantage 
of the movement, and advanced over a dozen rows in a succession of rapid loups, without, however, shaking a blade. Another movement of the bird and the cat crouched out of sight, and resumed its stalk in the old way, getting at last, still 'in cover, to within a yard and a half of its prey. There it extended itself flat on the ground. Little nervous, side-to-side movements of the tail indicated a state of high muscular and nervous tension, and movements of the hind quarters and of the feet showed the animal preparing for the fatal spring. But just at that moment the still unsuspecting mavis flew into a neighbouring apple-tree, and pussy's fine work was all thrown away. She took her disappointment very calmly, having, no doubt, already breakfasted delicately on young bird.

A friend of mine, who has a leopard among his trophies, has described to me its manner of approaching a goat tethered as a bait. In every detail its action resembled that of the cat approaching the bird, even the reflex actions which moved the tail at the approach of the critical moment being the same. The difference is wholly a difference of size. This detailed similarity of almost all the members of the extensive cat family is one of the most remarkable facts about them. It means that the typical form is very ancient, and it means, too, that since the typical form was evolved Nature has been able to make few improvements upon it. The adaptations of the various species have been in the main adaptations of size and colour. Save in these regards 
the wild cat of the Highlands and the despised prowler of the back yards are in all essentials the same as the leopard and the tiger, down to the nerves which at exciting moments agitate their tails. There are exceptions. The cheetah has evolved length of leg and has become a chaser, losing to a great extent the characteristically catlike power of retracting its claws in the process. The most apart members of the family, the lynxes, are more particularly adapted to an arborescent life, and certain not very considerable peculiarities of body-the long, tufted external ears, for example -distinguish them in appearance. But otherwise the cat family, with its great number of species and its world-wide range, is a family with remarkable adherence to one design.

The prowling cats at present hunting in the gardens have few sympathizers, and everybody is ready to fling a stone at them. Probably, however, the town sparrow, with its rat-like powers of multiplication, its seven-month-long breeding season, and the complete security of its nestingplaces, would become a great nuisance were its cheepers not extensively thinned by feline enterprise. Already the farmers are complaining that the town sparrows visit them in vast droves in the autumn and take heavy toll of their ripening grain. 

JULY 



\section{TROUT IN ISOLATED LOCHS}

How the apples got into the dumpling was not half so much of a problem to the prince in the story as how the fish got into the lochs is to the angler who troubles his head about such subjects. Most of the upland lochs of Scotland are stocked with trout. Many of them, however, possess no practicable connection with any other trouting water. How, then, did they get stocked? To take a particular case : I have just explored, not for the first time, an elevated rocky plateau in a north-western county, on which there are seven lochs. The lowest of them-and the largest-is marked on the Ordnance Survey as standing at exactly a thousand feet elevation. The other six are from a hundred to three hundred feet higher. Of the seven, only two are connected by stream with one another, and all are drained by burns which make the whole descent of their thousand and odd feet in, at most, a couple of miles. In one case the draining burn makes a sheer fall at one point in its course of over a hundred feet; and falls far beyond the leaping powers of either trout or salmon occur on all the others. As they. are fed from above by mere rills, their isolation is complete. 
But of these seven lochs six are inhabited by a native race of brown trout, and the seventh uninhabited one differs so much in character from the others that its tenantless condition is almost certainly to be attributed to its unsuitable waters, and not to its isolation. The six fish-frequented lochs are longish rock basins, shallowed in parts with drift material, on which rushes and sedges grow thinly. The seventh has been encroached upon all round by the deep peat of the moor; and the plants of the bog-bean showing over much of its surface indicate a peaty bottom. One may, therefore, cherish a conviction that if all seven lochs were of equally good water, all seven, despite their complete detachment from any recruiting stream or lake, would be peopled with trout.

About the state of affairs on this particular plateau there is nothing whatever exceptional. It is repeated again and again all over the northwest Highlands and islands, where thousands of small, isolated lochs, fed by mere trickles and drained by small and steep burns, occur, and in the large majority of cases contain trout. Usually the isolation of the inhabitants of each loch is stamped upon them by shades of colouring and markings so distinctive, that the people of the district can tell at a glance from which of the lochs a trout has been taken.

As a rule, the people of the district carry their questionings no farther, and satisfied with the belief that when the world was created its Creator put the right fish into the right waters, they would class the efforts at explanation made by the 


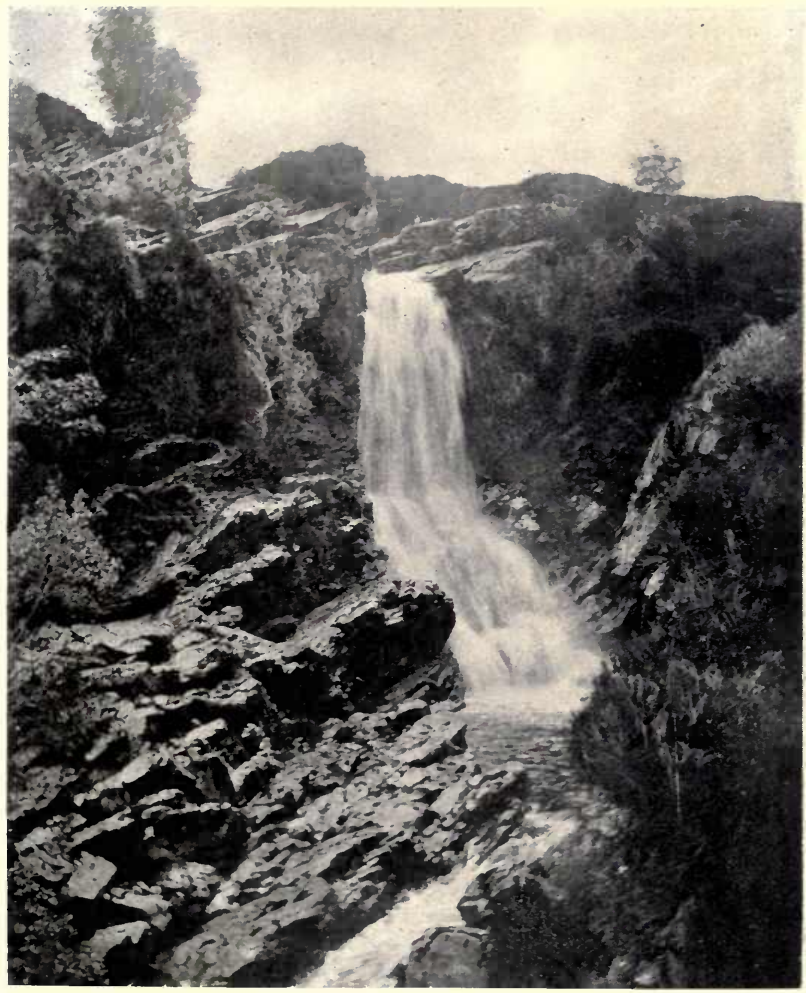

FALL ISOLATING A LOCH. 

visiting strangers among the many forms of impiety generated in the South. And impious or not, most of the explanations carry themselves with a far-fetched air. Thus Darwin, referring to freshwater productions, says that "fishes still alive are not very rarely dropped at distant points by whirlwinds," and though the old stories of "showers of frogs and fishes" are certainly not so mythical as they were once esteemed, they strain credulity when applied to the case of the thousands of hill tarns. Another explanation is that the ova may be carried from water to water adhering to the legs of wading and swimming birds. As the ova of fresh-water fish retain their vitality for a considerable time after removal from the water, this solution of the problem is not one to be instantly rejected. It has been proved in the most conclusive fashion that water-fowl do frequently carry with the mud adhering to their legs the seeds of water-plants, and newly-hatched fresh-water molluscs have been found adhering to their feet. It is also suggested that water-fowl which eat fish ova may carry some uncrushed on their beaks from water to water. But these methods, with their bare possibility, their dependence upon accident, are far from satisfying when applied to a case in which so very many accidents are required. A third solution offered by sober science repels by its sheer stupendousness. The levels of the country, we are reminded, were not always what they are to-day. Streams which now run in deep valleys have dug out those valleys for themselves, and one which to-day runs a thousand feet below 
the top waters of its petty tributaries must at one time have followed a course not much lower than theirs. It is lower to-day because its cutting and transporting power has been greater. Scotland, as one of our greatest geologists has put it, once existed as a low dome with a very gentle rise from its circumference to its crown of not more than one in a hundred. Its existing diversified features have been sculptured out of the dome by the action of its streams. But the sculpturing has been a very slow process, and if we are to get the trout from the streams to the hill lochs by harking back to the time when the connection between them was gradual and easy, we shall almost certainly reach a time before the trout, as trout, existed.

In such a case a breath of the perfectly commonplace is refreshing. Talking with an intelligent gamekeeper, I asked him how he accounted for the trout in a certain loch lying in a depression thirteen hundred feet up a western ben. " Very easily," he replied. "Thirty years ago there were no trout in that loch. The hill was then under sheep, and a shepherd named Duncan Matheson occupied a shieling beside the loch. He was very fond of fishing, and had the idea of putting fish into it. So he caught a number out of the burn in the glen and carried them up in a pail." The only thing about it that struck him as strange was that, whereas the burn trout are a dark brown and rarely exceed four ounces in weight, their descendants in the loch frequently run over the half-pound, and are a finely-coloured breed. 
Speaking on this subject, he indicated a burn wellknown to me for the size and abundance of its trout. It is formed by two small streams which issue from a great corrie on the mountain side, wanders slowly through a nearly flat piece of land below the corrie, and falls fifty feet perpendicular into a large loch. The isolation of the burn is as complete as that of any hill loch. To-day the whole area in which it runs is included in a deer forest; but less than thirty years ago the hill was sheep ground and the flat was a croft, the house of which still stands in a ruinous condition. " The crofter who lived there," my gamekeeping friend went on, "had several boys who went to. school at - (a village three miles away). They. carried their dinner with them in tin pails, and one of them got into the way of catching trout and carrying them with him in his pail to put into the burn at home. The trout in the burn are all the descendants of those he put in." And as the burn is slow and deep, and the flat land of the old croft is now an insect-haunted swamp, the trout are large beyond the generality of hillburn fish. Here, then, are two examples of artificial stocking in one district quite unconnected with the modern pisciculture, and it would be a little absurd to suppose that they stand alone. Trout in past times formed an important and easilyprocured part of the Highlander's food supplies, and it is not extravagant to suppose that the old Celt was capable of taking the very obvious steps necessary to transform sterile into productive waters. 


\section{THE BIRD OF THE BURNS}

THERE are some birds which associate themselves so closely with certain scenery that it is impossible to think of them apart from their setting. You can think of a sparrow anywhere, and of a chaffinch almost anywhere. The seagull looks about as much at home at the plough tail as on the sea, and the rook fits easily and familiarly into half a dozen different situations. But the water ouzel is a creature of a single environment, from which it will not be divorced either in imagination or reality.

When the days become warm and long a certain kind of angler, who does not take himself in that character too seriously, loves, above all things, to wander to a hill burn and ply his line for trout, which make up for not being very big by demanding little in the way of artful alluring. But with the hill-burn fisher trout are only a pretext. Consciously or unconsciously, he is in love with the burn and burn nature, and would find no sort of compensation for it in more and bigger trout taken from an artificial channel with nothing of the burn's natural variety. He finds an exquisite satisfaction looking into its deep, clear pools, watching its swirling rush among the stones, in 
the ferns and flowers that spring so fresh and verdant from the clefts of its rocky banks, and in the birds which ever and again reveal themselves to him as he passes from stream to pool and pool to stream, dropping a fly for occupation's sake on the likely places. And of all the birds of the burn the dipper is the one he is surest to see and most certain to welcome. It belongs to the place, and the place is hardly complete without it.

He turns a bend, and there it is before him. It is standing on a boulder which divides and just rises above the water. Dark brown, almost black of colour, with a pure white waistcoat, and nearly as big as a blackbird, it would claim some attention if it did nothing in particular, but its actions are arresting. As it sits on the stone it bobs up and down, "curtsies," and the action, and the upturn of the tail, suggest that it is a wren of a larger growth. It is, as a matter of fact, no sort of relative of the wren, and very unwrenlike is the next thing it does. For as the angler looks it drops plump off its stone into the water and disappears. If the watcher hides himself he may see something more of this diving faculty, so remarkable in a bird of thrush-like affinities. In a minute or so the dipper comes again to the surface and resumes its place on its stone, as dry to all appearance as when it went down. Then it makes a short, arrow-straight flight, and alights on the gravel bank just below where the watcher is ensconced. It begins to pick up minute objects between the stones, and when it reaches the edge of the stream walks right on, as if the water 
were not there. In favourable circumstances it is possible to follow its subaquatic perambulations, when it is seen to walk at the bottom of the water searching for food, to all appearance as much at home there as a blackbird under the gooseberry bushes.

There is a mystery about this submerging power of the dipper that has never been explained. Like every other live bird, it is lighter than water. How, then, does it keep itself down? The orthodox divers keep under by using the power of their propeller-like feet. In other words, their underwater course is a swimming course, and none of them walks on the bottom. That is just what the dipper does, and though it can swim in a fashion on the surface, its under-water movement is not a swim. Indeed its feet, which are the normal feet of a passerine bird, are not in the least adapted for such a performance. It is a problem, then, how it gets down, and how it keeps down once it is there. The surmise has been made that it grips the bottom with its claws, but it is not an easy surmise to prove; and I have seen a dipper walk into a pool with a smooth rock bottom and emerge a couple of yards from where it entered. There was nothing but smooth, water-worn rock for it to hold to.

The dipper's attachment to the stream is stronger than that of the angler himself, for it never leaves it. It seems to dislike flying over dry land, and in its low, rapid flights it follows the course of the stream, taking all its bends, not even lopping off a sharp one. Even when pursued by a hawk 


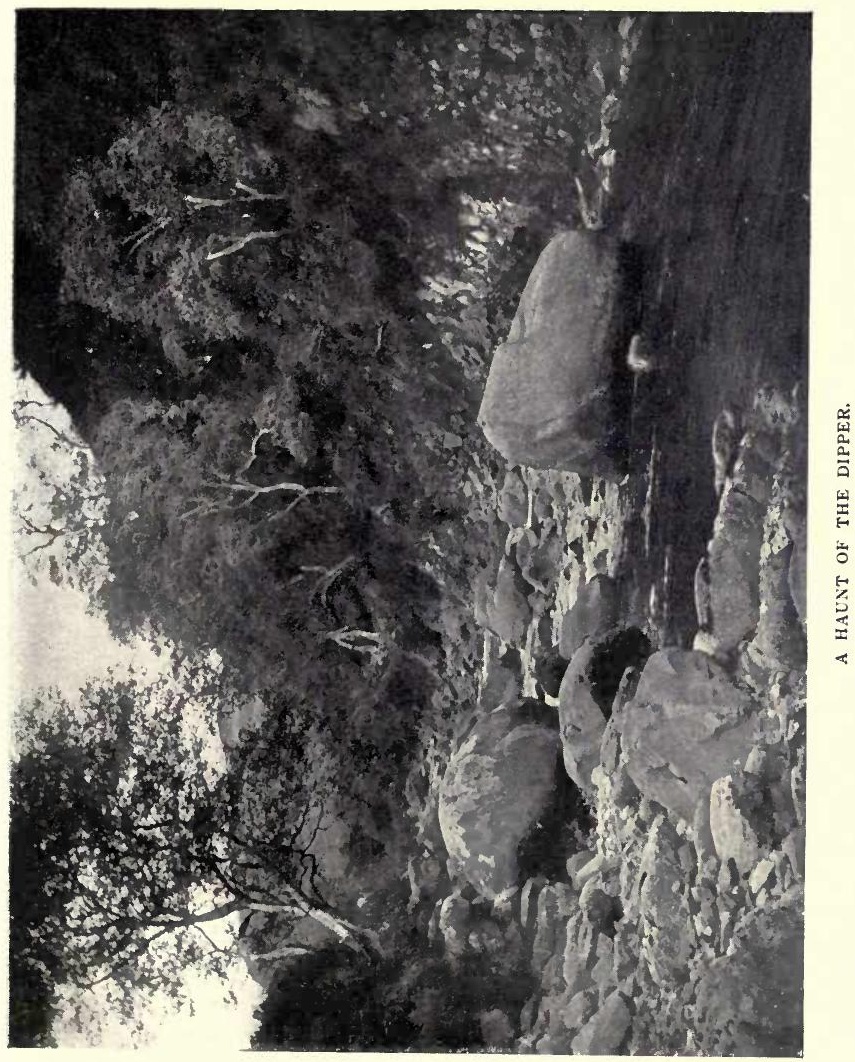



it keeps to the course of the stream, and will make in this way for some well-known shelter of the bank, though it might shorten its journey to safety by crossing the bends. Its pleasant little song is almost invariably sung when the bird is seated on a stone in the stream. In short, the channel of the stream is its whole world, and to see a dipper anywhere else is the rarest of sights. There must, it is true, be some crossing of watersheds, for the dipper raises two or three broods a year, the members of which must seek fresh quarters. But these migrations are never or hardly ever witnessed.

The nesting habits of the dipper are in harmony with its other habits. The nest, a large domed structure, resembling in this respect the nest of the wren, and adding another similarity between the two, is always built into some hole or support in the bank. A favourite place is among the large roots of trees so often exposed under an overhanging bank into which the stream is cutting. A cleft in a rock immediately above water is another favourite site, and not infrequently the nest has been built against the rock behind a small waterfall, through which the bird plunged on entering and leaving. It is a large structure, with the entrance placed rather low down, so low down at times that the eggs seem in danger of rolling: out. The eggs number five or six, and are white, and the first brood is hatched out in the spring before most birds have got well started with their courtship.

To the naturalist the dipper is interesting as 
a remarkable adaptation of habit. Its closest affinities are the members of the thrush group, not one of which in this country manifests the smallest approach to fitness for an aquatic life. But in America there are birds of the same order as the dipper which seem to exhibit a stage in the process by which its very complete water habits have been acquired. These water thrushes find their livelihood chiefly by wading in the shallow margins of streams and picking up the aquatic insects and larvæ to be found there. They, so to speak, have begun to exploit a place in nature left blank by their own kin. The dippers have gone a stage farther, exploiting the blank place more fully and making it their own. 


\section{MIDGES}

IN the Highlands the doctrine that God created all living things with a purpose in some way related to the service of man remains of unchallenged validity. The person who questions it is at once recognized as no better than he should be, and unfit for membership of the Free Kirk. I asked a pillar of that sanctuary how he disposed of the midges, but it was almost too easy a question to be worthy of so profound a theologian. Midges, he told me, like a great many other things, were brought into being to prevent us from getting too well pleased with this world. It is a vale of tears, and it is well we should not forget it. We dwell in tabernacles, and it is bad for the higher life if we take it into our heads that they are lasting dwelling-places. And much more to the same effect.

This theory has the merit that it fits all the facts contemplated by it. Life in the Highlands, particularly their more westerly and wetter parts, is not such during the winter months as to encourage the lotus-eating state of mind. But generally in early summer there falls a perfectly delightful time when the glens are good to live in, a time which, if it endured, would transform 167 
the whole character of the Gael. Then come the midges. In May there are none. About the end of the second week in June they appear in meagre companies. A week later they occupy the evening air in battalions. During July their armies grow in strength, and in August, particularly in districts where there is much swampy ground, the usual formula for atmospheric air becomes utterly inadequate, and must be supplemented by a plus midge, for they become one of its constituents. They settle upon the exposed parts of the human person in hundreds. Their mere crawling over the face and neck is an intolerable misery to most people, but crawling is the least of their offences. It is a mere preliminary to a bite, which, considering its minuteness, is astonishingly irritating. All suffer under it, repeated as it may be many hundreds of times, and some acquire bloated and swollen countenances as the result of it.

In size this biting midge of the Highlands is one of the most insignificant of insects. A tenth of an inch is rather more than its extreme length, and it takes good eyes to see the fine thread-like body of an unfed specimen between the relatively broad wings. The common dancing midge with which the Lowlander is familiar is a huge giant compared with it. But the one is a good-natured and harmless giant, and the other a virulent and poisonous pigmy. The dancing midge cannot bite, because it has not the means. Those of the minute biting midge are amazingly efficient. Just consider what they can do. In size the midge is to a man what a man is to Ben Nevis. The 
human skin is, to the midge, a far grosser defence than the skin of the rhinocerous viewed from the human standpoint. A man who had to bite through the hide of the rhinoceros for a meal would starve in the neighbourhood of plenty. But the midge alights on the (relatively to itself) much thicker human epidermis, and in about five seconds it has bored a shaft through it, and is pumping up its own fill of human gore. It is worth while watching the process out. You are seated on a rock at the loch side, and the midges are " biting bad." A score of them are operating on your hands and wrists, and you cover one of them with a lens. Under the lens you see that its body is a mere thread of transparent grey, but as you watch the colour changes to a lively red. And not only does the colour change. In about a minute and a half the thread-bodied insect becomes a corpulent and distended little sack of blood. It has had the time of its life; the time that can come to so very few of its kind.

This is one of the most puzzling of the facts about biting midges. In a non-political address a few years ago Mr. Arthur Balfour surprised some of his hearers by speaking of the human race, which has appropriated so much of the earth's surface to itself, as " a numerically insignificant species." We are in the way of thinking of the tribes of men as fairly numerous. But Mr. Balfour was right. In the district of which I write, twenty square miles of hill territory surrounding a loch, there are many times more midges than there are human beings on the whole earth. Numerically 
the tribes of men are insignificant compared with them. Around the loch they are on a mild and humid evening numerous enough to make a faint haze in the near air. But they abound on every part of the hills up to at least sixteen hundred feet, and probably farther. And every midge among those countless billions-or, to be more accurate, every female midge-is equipped with the most wonderfully complex and perfectly adapted instrument for the piercing of mammalian skins and the sucking of mammalian blood. In its microscopic proboscis there is a fret saw, with supports for boring, and a tube and pumping apparatus, and a mechanism for secreting a liquid which, mixing with the blood, renders it thin enough to be drawn through the very fine tube. It is the injection of this liquid which is supposed to make the attentions of the midge so highly irritating to the victim.

But to what an enormous extent is all this sanguinary equipment thrown away. Hardly one in a million of the midges of this district can ever taste blood. The larger animals, chiefly deer, are so rare on the ground that only careful search reveals their existence. The human inhabitants are few, and vast expanses of the hill are practically never trodden by them. In short, it is certain that all but an insignificant fringe of the numberless gnat hordes must die without ever having tasted blood, for which, to judge by their actions when the opportunity comes, they are ceaselessly. thirsty. It would be difficult to imagine a case of more prodigal waste of elaborate armature. And yet Scotland at its worst presents but a 
mild example of this phenomenon. The whole sub-Arctic belt of Europe, Asia, and America, is infested with blood-sucking members of the gnat family, and in summer in Lapland they fill the air in clouds till man and deer can hardly breathe it without inhaling them. The finest army is clumsily equipped for war compared with their equipment for boring skins and drawing blood, but the overwhelmingly great mass of them never get any blood to draw. To account for the evolution of their armature, now seen in the almost complete absence of the means of exercising it, is one of the innumerable problems on which the speculative naturalist is invited to beat his brains. 


\section{THE RED-DEER IN SUMMER}

THERE is no creature in this country which embodies so perfectly the romance of wild nature as the red-deer of the Highland hills. Its whole shape and bearing are romantic, and its action stands for the very poetry of motion. Its character, built up by a race of writers in prose and verse, is in harmony with its superbly picturesque figure. A denizen of the wild, its lithe and throbbing frame is filled with a passion of independence, and it hates man and all his ways. If you would see it you must seek it with pain and stealth in the remotest recesses of the mountains.

These are prevailing conceptions. In my own mind the wild, romantic, aloof red-deer has long, I must confess, held a place as something of a humbug. My disillusion began many years ago when visiting a Highland sheep farm in winter. I found the shepherd pronouncing himself "sair bothered " with the deer when he laid out food for his particular charges. And when I accompanied him, there they were, sure enough, hanging on his rear and actually requiring some little demonstration to drive them away. The poor creatures were hungry, snowed out of pasture, and their instinctive fear of man did not stand much 
in the way of their seeking food from his hands. At a later date I had another proof of their tameness under stress of the same teacher, when in snowy weather I accompanied a keeper with a cartload of provender for his herd. Their feeding place was on the side of a loch which bordered a " sanctuary," and where, in horrid miskeeping with the character of the animal in literature and art, feeding-troughs were laid out for their use. When the cart approached, the deer, stags and hinds, came helter-skelter out of the wood and followed it to the well-known place. And there, no more troubled by human presence than hungry sheep, they eagerly regaled themselves on a provided mess, in which the principal element was, of all incongruous things in the world, locust beans !

During the present summer (I9I I) I renewed an acquaintance with two large and important deer forests which provide in the shooting season, the one sixty and the other seventy-five stags (the numbers a shooting tenant is entitled to kill). The mountain grass was growing bravely, and the young shoots of the heather had just begun to tinge with olive green the faded browns of the hillsides. Grazing was abundant right up into the high corries, and the conditions were favourable for the development in the deer of all their natural wildness. But even thus they continued to display a disappointing tameness, refusing in the most favourable circumstances to play up to their character. Through one of the forests passes a little frequented public road, and cycling over it I came upon a herd of thirty-three, of which 
thirteen were stags with antlers of various degrees of development, but all in the velvet. The whole packet were grazing on the roadside, where, as is generally the case with moorland roads, the grass was better than elsewhere. Quite half a mile away they got my wind, and instantly stood at the gaze. And did those wild and shy creatures gallop off like the wind on detecting the approach of a human enemy? Not they. They were certainly not so stiff to move off the road as Highland cattle, but they moved reluctantly, and only when the intruder was close upon them, and at the most they did not go a couple of hundred yards away. A mile or two farther into the forest a headkeeper's house, with the usual provision of kennels and kennel courts, accommodating about a score of sporting dogs, stands in the middle of a piece of land bearing all the evidences of having once been cultivated, that is to say, a well-defined bit of grass in the midst of bracken, heather, hillrush, and moss. Grazing peacefully on this, undisturbed by the presence of half a dozen human beings engaged on various duties, were from sixty to seventy deer. As the stranger approached the dogs in the kennels barked furiously, but neither his approach nor their clamour disturbed the shy and fleeting creatures, to stalk which is a high and almost mystic art.

In the whole extent of the other deer forest alluded to, there is not so much as a yard of public road. Yet here, as on the other, I found their nerve quite untroubled by a human intrusion. To take one experience from many. Well into the 


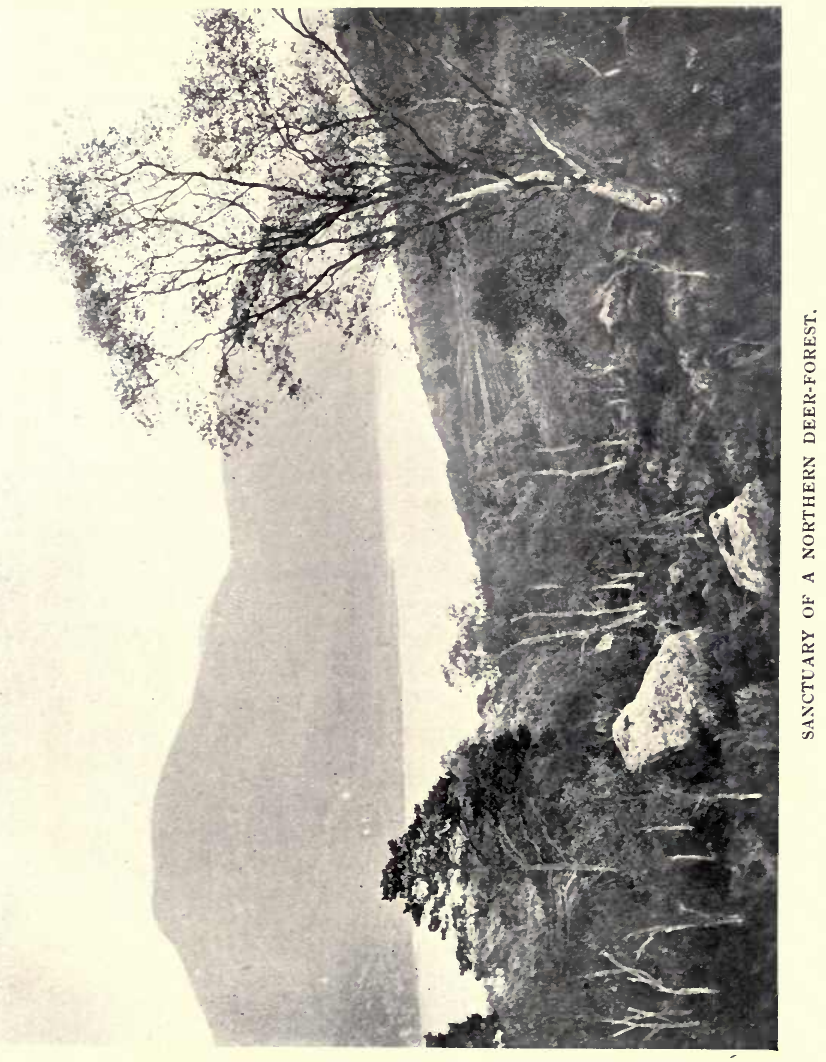



forest there is a crofter's house, with byre, kailyard, and once cultivated field enclosed in a dry stone wall. The place was occupied down till a dozen years ago, but is now a melancholy ruin, the more melancholy that traces of occupation, such as faded prints from old illustrated papers hanging half on, half off, the living room, are numerous about it. When I approached the enclosure five deer were placidly cropping the grass within it. Leaning upon the dry stone fence, I studied them a stone-throw away, and they studied me with perfect composure. When I leapt the wall and proceeded towards the house they leisurely walked away, and hopping over the enclosure with superb ease trotted at a slow pace about eighty yards up the hill which ascends steeply behind the house. But beating the stones of the wall with a walkingstick did not induce them to increase their distance, and when I left the place at one side they calmly returned to it from the other. All this in July.

The tameness of the modern wild deer is no doubt related to the fact that they are artificially fed in winter, a thing made necessary by the maintenance in most of the forests of a larger stock than they are able naturally to carry the year through. But it is all very different, one is given to understand, as the year ripens towards September. Then the wild deer becomes himself again, the creature we know in books and pictures, to approach which it is necessary to crawl for half a day with more than the care of a scout in a Fenimore Cooper novel. Well, there are various ways of approaching a red-deer, and crawling is 
one. When I pressed my friend, the keeper, to tell me, really and truly, if the very tame and trustful animals before us would become wild and watchful as grey-lag geese in the course of two months' time, he slowly dropped one eyelid, and speaking with thoughtful deliberation, said: "Gentlemen who come to the Highlands for deerstalking expect deer-stalking, and a keeper who knows his business knows very well what they are looking for. It is possible he might take them within shooting distance of a stag, with less trouble than he puts them to, but they would not think half so much of themselves. And to tell you the truth, considering what sort of shots some of our fine gentry are, the deer would not need to be a very difficult animal to approach. I would not like to tell you the number of times I have brought a sportsman within eighty yards of a stag and seen him miss it, though it gave him a mark like a barn door. As for the wild goose," he went on, "the deer-stalking sportsman who could get near enough to one to shoot it would have some reason to be proud of himself, both as a shot and as a stalker. Compared with the wild goose the deer is a stupid brute." 


\section{FOXES OF THE HILLS}

How many of the people of Scotland, urban or rural, have seen a fox at large? The answer to the question is like that to the interrogation with which mythical Scots are supposed to grace their toast, "Here's tae us ! Wha's like us?" In the English hunting counties the fox is no uncommon sight. Reynard is a brainy animal, and he has learnt that in these fair fields only one kind of danger threatens him, and that when there is no "music of the hounds" he is safe. Over the greater part of Scotland, on the contrary, the fox knows that man and all his devices are to be mistrusted, and he is constantly careful to keep out of sight. Thus, one might spend months in a hill country where foxes abound and never cast eyes upon a member of the race; and it is probable that not one in a thousand of the tourists who in the summer months explore the recesses of the mountains ever sees a hair of the largest of the surviving native carnivora of Britain. Only gamekeepers and shepherds, who wage constant war on them, know how numerous foxes still are, and even they obtain a sight of the animal by laborious and studied means.

Like the eagle, the Scottish fox in our time finds 
its most congenial ground in the deer forests, and a typical fox haunt is a rugged mountain side, well provided with "cairns," or the tumbled masses of stone that lie at the bottom of all crags. If the rock is one that weathers in small fragments it serves badly; if it breaks off in large boulders which lie upon one another at the foot of the crags in such a fashion as to leave abundant ramifying spaces between, it makes an ideal fox's home. In such a situation the fox is able to penetrate far among the stones, and its cubs, even when followed by terriers, can retreat into crannies where they are perfectly secure. With such a hold as this as a base Reynard may raise a family with perfect success, and it is a sterile country, indeed, which does not provide them with an ample livelihood.

I had, one July day, a prolonged opportunity of watching a fox family at home. The cairn in which the den was situated was among the boulders at the foot of a crag on the side of a high and narrow glen. A keeper had found it, and was returning to take offensive measures against it, and we watched it through stalking glasses from the opposite side of the glen. The vixen was at home, and lay basking in the sun on a small patch of grass and heather in front of the principal entrance. Four cubs played about her, racing round her, tumbling over her, waging mimic battles with one another, and generally behaving in the pretty manner of well-grown puppies. But there was a difference. Every now and then the old fox raised her watchful head and searched the valley 


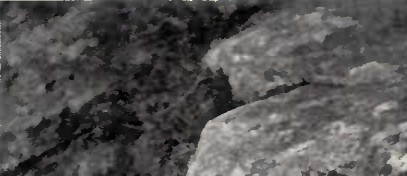

$3 . \sin ^{2}$

2.

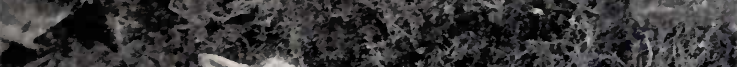
a

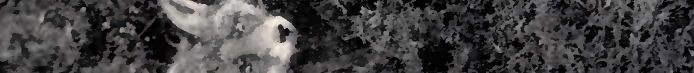

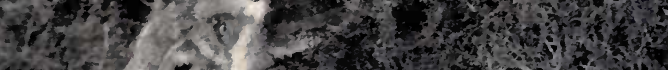
wo $x=1$ -

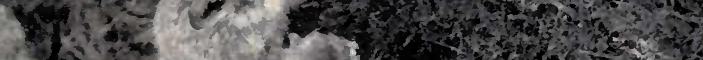
1.7.

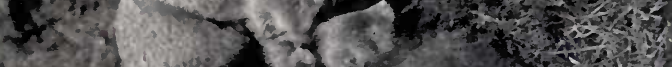

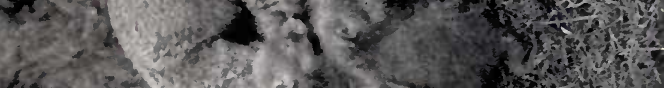

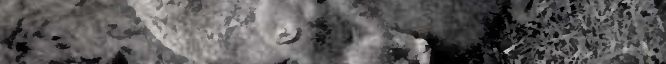

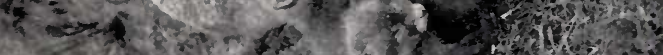

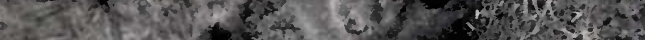

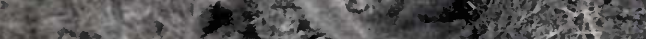

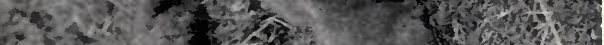
6.

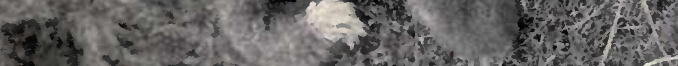

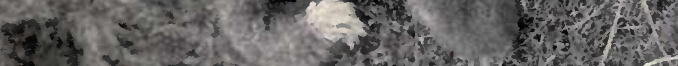

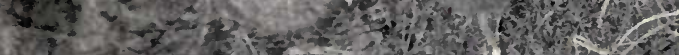

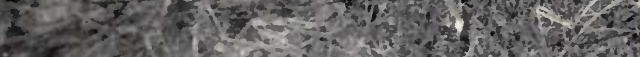

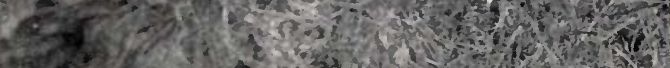

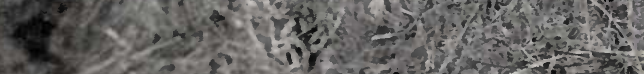
3.t.

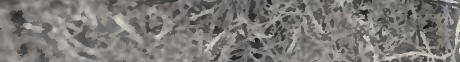

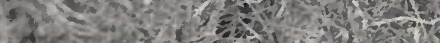

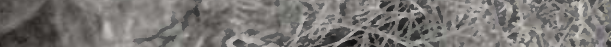

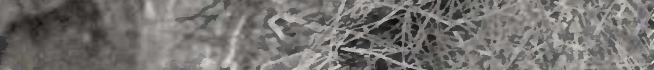

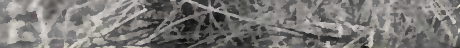



below, and every time she did so the cubs bolted into the den. After this had gone on for the better part of an hour, the vixen got up and proceeded in her stealthy way along the hill-face, and as she left them the cubs retreated to their stronghold and appeared no more. With the glass I followed the vixen on her promenade for more than half a mile to a spot, doubtless well known to her, where lay the carcase of a deer. This she began to tear with every appearance of ravenous hunger, but the keeper, who was well acquainted with foxes and their ways, assured me that in reality she was laying in a load of flesh which on her return to the den she would disgorge for the benefit of her young.

I did not see the return. An assistant keeper coming down the glen, and making straight for the den, alarmed the mother, and all prospect of coming to close quarters with her vanished till dusk, when she would attempt to reach and feed her family, even at some peril to herself. Crossing over to the den we found an interesting sight. The main entrance, where a huge boulder restec upon several smaller stones, was a considerable cavity, and within it, on well-beaten ground, which smelt vilely, lay a curious assortment of predatory evidence. There was the leg of a full-grown deer, doubtless taken from an animal which had died; the hind-quarters of a deer calf, the condition of the feet proving that it had never walked; the four feet of a lamb; the feet of a hare; many fragments of rabbits; grouse wings and feathers in abundance, and, strangest of all, a 
well-grown rat. There were also many gnawed bones of kinds not easily identified, all proving that this particular family had fared sumptuously. While we examined the antechamber of the den, three terriers were whining and barking eagerly in its recesses, but their efforts to reach the cubs were a failure.

In these circumstances it is the practice of the keepers to remain at the den till the gloaming in order to keep the parent foxes out, then to hide themselves in its immediate vicinity in order to get a shot at the animals as they try to enter at dusk. The watch has often to be maintained for two or three nights, but it is generally successful in the end, for when the young begin to cry out, as they will do after a day of hunger, the mother will brave much to get to them. There is something repugnant to ordinary human feeling in this taking advantage of the fox's best instinct for its undoing, but such a consideration presented to a gamekeeper stirs him only to an amused laugh. Occasionaly he is able to trap a fox, but it is by using its parental instincts that he is alone able to keep the tribe within bounds.

In some of the deer forests little effort is made to keep down the foxes. Indeed, there are cases in which the sentiment in favour of wild life has gone so far that every kind of wild animal and bird is tolerated; and one Highland landlord is quoted as saying that the "only vermin he objected to were sheep." The harm done by predatory beasts and birds in a deer forest is, of course, exceedingly small when stalking is the sole interest, and 
it is only when grouse form an important part of the game that vermin-killing for the sake of sport becomes imperative. But there are few parts even of the deer forest area which are far removed from sheep ground, and the sheep farmer demands a rigorous persecution of foxes as a service to which he is entitled. Where rabbits abound they form the staple article in the diet of the fox, but there is no doubt whatever that Reynard is a most persistent lamb-killer, and that if foxes are abundant they levy a heavy tax on the flocks. From this arise sharp differences of opinion as to compensation, and general charges of failure of duty on the part of the landlord to his tenants. But there is little fear of the native race of foxes being extirpated. Their number, as has been said, is greater than is generally supposed; and in the boulder-strewn glens and hillsides their hiding-places are numberless, and will never be obliterated. 


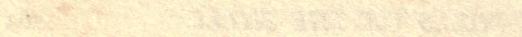

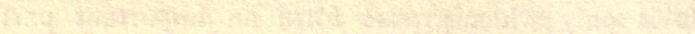

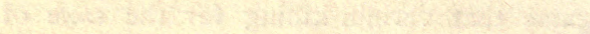

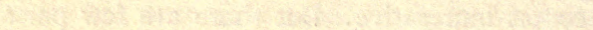

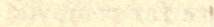

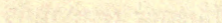

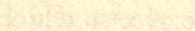
2.

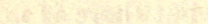


AUGUS'T 



\section{THE SLUGGARD'S MODEL}

THE wisdom and energy of the ant have been extolled since the beginning of time, and it is perhaps due to the smallness of the animal itself and the elusiveness of its habits that its example, though pointed out with first-rate authority, has had so little effect in the world of men. You must humble yourself to the ground if you would find out what ants are up to, and when you do it, it is just possible that a contingent may tell themselves off to show you how they can bite.

I have just been observing ants of set purpose for the first time. Cutting grass with a large pair of garden shears, I found that I had sliced the earthy top of a nest belonging to a community of the brown garden variety (Lasius niger). The catastrophe must have been something like an earthquake to them, and its terrible consequences were visible enough to me. Hundreds of white larvæ were exposed-known to bird fanciers as ants' eggs-and the adult members of the colony were careering about with a mighty stir. With absolute unanimity and without an instant's delay, they set themselves to the work of getting their young underground, and as long as I watched them they engaged in no other labour. It was a case 
of save the baby and let house property take its chance.

Two days later, when I next inspected the scene of the wreck, the work of restoration was complete ; the earthen roof of the nest was tolerably level amidst the grass stubble, and a number of small round holes were visible leading into an interior. Ants were moving about in all directions.

But there was a disappointing want, in the appearance of things, of that orderly industry and high intellectuality of which one finds so much in the books about ants. The vast majority of the ants were wandering about in a seemingly aimless fashion, and a map of the course of any, one of them would resemble a fallen thread.

Altogether, watching ants was such an uneventful work that I resolved to try the experimental method, so captured a caterpillar and dropped it where the crowd was thickest. Then the play brightened up. The first ant that touched the caterpillar tried to taste of it, whereupon the reptile -a green with black stripes and slightly hairy grub from a cabbage-turned sharply and tried to retaliate with its jaws. It got one of the ant's. legs in its mouth, and was having distinctly the better of the fight when a second ant took a taste in the neighbourhood of its tail, and the caterpillar turned with a convulsive jerk to inspect the new sore place. Then the first assailant attacked it again. Soon a dozen or more ants were engaged fiercely in the assault, and the contortions of their large prey indicated that even a caterpillar can 
give way to rage. But of real material damage he appeared to suffer none at all, and examining the struggle with a large reading-glass, I came to the conclusion that the ants never managed to do more than bite and pull his hairs. Therefore I rescued him from torment, and went in search of something more vulnerable.

A perfectly smooth green cabbage caterpillar was my next martyr, and his fate soon proved the value of hairs to creatures which have occasion to crawl where ants abound. On the smooth caterpillar the ants threw themselves with the same courage that animated them in attacking the hairy one, and in five minutes the caterpillar was dead and exuding moisture from every segment.

The scene that followed was highly interesting. Having killed their game, the ants proceeded to take it home, and it was like African pigmies attempting the transport of a dead elephant. As many of them as could find standing room around it bore a hand at the great work, and though as many more stood upon the body it was actually with minute jerks moved along. The nearest entrance to the nest was three inches away, and in the course of a quarter of an hour the carcase was actually at the door. But here a great problem arose. The caterpillar's body was thicker than the entrance to the nest was wide, and when his head had been jerked, pushed, and pulled into it further movement seemed impossible. And unfortunately, whether ant ingenuity was equal to the engineering problem presented I am unable to say. As long as I watched, the triumphant 
tribe continued to run over, round, and under the body of their quarry, but no advance to a solution was made. Next day, however, the caterpillar's body was away.

Proceeding with experiment, but this time giving deference to the dictates of humanity, I offered the little people the body of a large moth which had been dead for at least a year, which time it had passed impaled on a pin. It was as dry a piece of pemmican as ever teeth were tried on, and I expected the ants would turn from it in disdain. But no. They swarmed over it in the highest excitement, tried their jaws upon it, and swiftly came to the conclusion that it was a great treasure sent by the gods. Probably the experts announced that, though dry, the magnificent carcase was rich in proteids, and therefore excellent for sausages, so they determined to get it home. The most admirable efforts were put forth, but after, half an hour of feverish industry the labourers had succeeded in doing no more than turning the gigantic body round. Then they changed their tactics, and showed that ant intelligence is equal to devising two ways of facing a difficulty.

"We cannot get this magnificent mine of wealth home in a lump," they seemed to say, " so we must take it home in bits." Working on this bright idea, they began to bite off the legs of the moth, and one by one succeeded in detaching them. As each was severed it was hauled along in triumph to one of the doorways, down which it rapidly disappeared. Six legs of moth were thus deposited in the larder. Next the ants assailed the wings, 
and, though it was a prolonged and difficult job, succeeded in getting all four of them off. It might be supposed that they would treat these as mere useless lumber, whose removal was necessary merely to facilitate the transport of the body. Not so, thought the ants. Each wing was borne along to the entrance of the nest, and cut into fragments small enough to be pulled inside. For what purpose they were put in store some great authority on formic economy may be able to say. Despoiled of its legs and wings, the body of the moth was successfully hauled along, but when darkness put observation to an end it was still blocking up the door.

Bates, in his book on the Amazon, writes of the terror with which a moving column of ants fills every sort of creeping thing. The common little garden ant wields something of the same power. A worm is a very leisurely performer as a general thing, but drop one among a company of ants and the speed with which he will make for a safe place gives a new impression of his motor powers. A long-winged and very lethargic fly abounds just now on sunflowers, and it is so lazy that it will allow itself to be pushed off, and will fall to the ground without trying to save itself. I dropped one of these among the ants, and the effect upon it was that of an electric shock. It ran from the scene with every gesture of frantic alarm. 


\section{ROBBER BEES}

THE bees have a fine reputation-one, indeed, of which any insect might be proud. They gather honey all the day, as the poem has it, and in virtue of this praiseworthy habit are given an honoured place among the good honest workers of the world. But that, though the foundation of their reputation, is far from being the full structure of their. merit. As every schoolboy knows in these days of widely diffused scientific erudition, they play a powerful and indispensable part in the economy of the vegetable world. They are the matrimonial agents of the flowers. When a bee sticks its head into the heart of a flower it has a purely selfish purpose. It is either collecting pollen with which to feed the grubs or floral nectar for storage as honey. In either case it is equally useful to the flower, for the pollen adheres to its head and thorax, and some of it is left on the stigma of the next flower it visits. Thus the flowers are cross-fertilized, and the seeds resulting from cross-fertilization are both more numerous and stronger than those resulting from selffertilization.

But sometimes things do not follow quite this order. Some flowers are so shaped that only bees 
with a long proboscis can reach the honey in them; and unless this particular bee comes along that flower is not cross-fertilized. It might be supposed, then, that these flowers are the reserve of the kind of insect that is equipped to reach their nectar, and that all the other kinds are tantalizingly excluded from it. But that is to assume that bees are both honest and unresourceful. The other day my attention was arrested by the ongoings of a bee which was busily engaged working the beautiful blue flowers of a long spike of delphinium. The delphinium carries its honey at the bottom of a long spur formed by the prolongation of the upper petal, and presumably only a bee with a considerable length of proboscis could get at it. Whether the bee before me was of that breed, I could not say. It was of the kind known in the simple classification of youth as a bumbee-a hairy person with a coat predominantly black, pleasingly varied with old gold. For the time being the point of interest about it was that it did not enter a single flower or attempt an entry, but went straight to the bottom of the spur on the outside. On investigation, every spur was found to be pierced about a quarter of an inch from its extremity, and the bee was extracting the honey burglariously without making the usual payment of service.

I continued to keep an eye on the delphinium, and found that all the bees that came to it-the hive bee and two or more species of Bombus were among the visitors-went straight to the back door. One began by going in the right way, but 
it only did this in a single flower. All the other flowers on the spike visited by her were explored at the felonious entrance. The inference is that when once a honey-thief has pierced an easy entrance to the nectary of a flower, even the honestest bee will prefer the easy way.

It is an old story now how when first the agriculturist of New Zealand introduced red clover they failed to get seed off it. The crop grew splendidly, but the flowers never matured, and for each succeeding season the farmer had to get seed imported from Europe. When the matter was investigated it was found that none of the native insects of New Zealand was qualified to fertilize red clover. The honey in the flower of the red clover is secreted at the base of the stamens, and lies at the bottom of a tube from 9 to $10 \mathrm{~mm}$. long. In order to reach this honey in the legitimate way, an insect must have a proboscis of the same or greater length, and several of the humble-bees are suitably equipped for the job. After these had been imported and established in the country, red clover did as well in New Zealand as in any other land.

It seems, however, that all the Bombi are not equally useful. In two species of the family the proboscis is less than $9 \mathrm{~mm}$. long, and they are unable to reach the honey of red clover legitimately. In strict honesty they should refrain from visiting clover-fields and stick to flowers that suit their size. But clover is one of the very finest of honey flowers, and when it is to be had at all it is generally in vast abundance. It follows that 


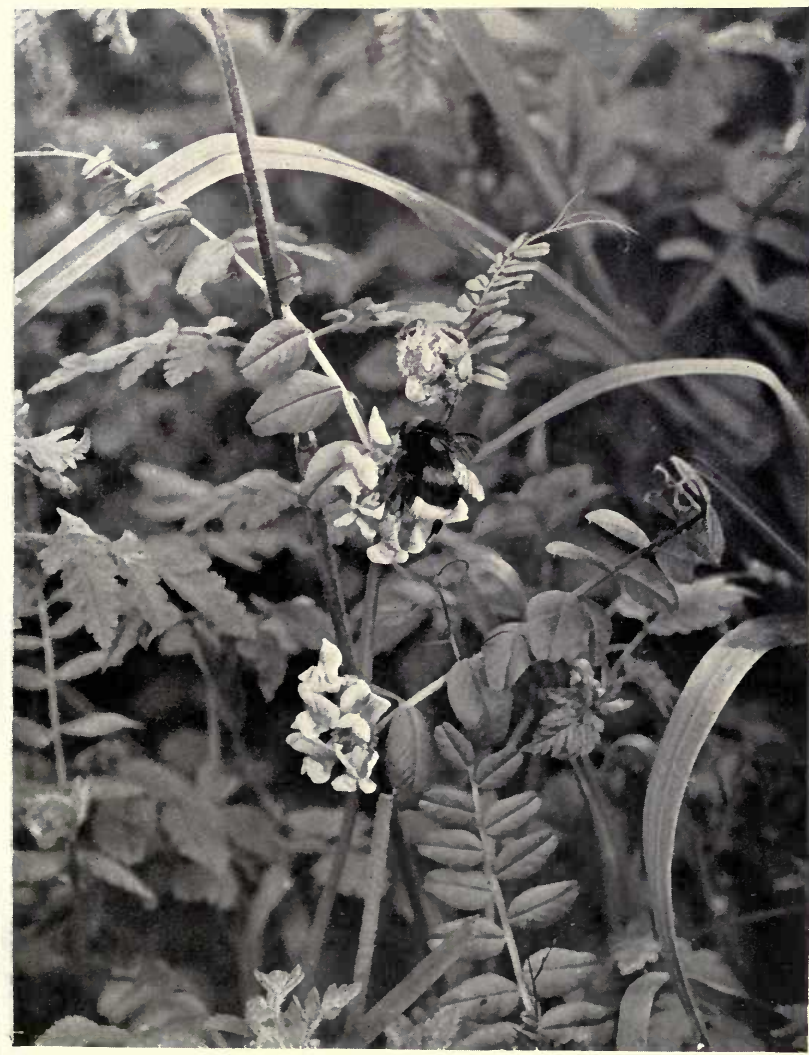

THE ROBBER BEE,

I., R. F. IIorn. 

the bee which cannot negotiate the $9 \mathrm{~mm}$. tube suffers a serious deprivation. Imagine the case of such a Bombus coming for the first time upon a field of red clover in flower. The whole air simply smells of honey, and the odour, as is well known, excites a bee as the smell of warm bread excites a hungry boy. Bombus with the short proboscis throws herself at the first flower in sight, and plunges her nose into one of its many florets, only to make the horrid discovery that she cannot reach the nectar, though she can get within the breadth of a finger-nail of it. Bees have short tempers, and with a bombian gesture of irritation she withdraws from the first floret and tries another. The result is the same, and half a dozen trials find her in a towering rage. To make matters worse, she sees another Bombus, not a bit higher in the scale of being than herself, only longer in the nose, which detracts rather than otherwise from her beauty, absorbing honey to her heart's content.

It is more than the short-nosed Bombus can stand. She must liberate her angry feelings on something or somebody, and she flies at the clover again and bites it viciously. And then a queer thing happens; she finds that it is quite easy to bite through the tube, so she bites and drinks and bites and drinks again. Perhaps, as a matter of fact, this discovery of the short-nosed bee was not made on clover. Many of the other flowers of the same pea order store their honey at the bottom of a long tube, and the bee which would get at it honestly must have strength and skill to pull the wings and keel of the flower apart, 
a process which causes the anthers and stigma to emerge, and length of proboscis to reach the far extremity of the flower after it has pushed past the organs, fertilizing them in the by-going. All these the short-nosed bees get at by biting a hole through the protecting petal close to the point where the honey is stored. Where the bees known to science as Bombus orrestris and B. pratorum abound it will be found that a large proportion of the flowers of peas and beans have been pierced in this fashion. As most of the flowers, nevertheless, set seed it is to be presumed that honest bees played their part before the robber came upon the scene, or perhaps failing to notice that she had opened an easy.way, after her.

If you are growing food plants it is a very important matter that the flowers should be properly fertilized by the bees. If, on the other hand, you are merely growing flowers for their own sake as flowers, a visit from the bees is of no value, and is even undesirable. A flower which is fertilized has a shorter life as a flower than one which is not. The moment a flower has been fertilized its purpose in the life-history of the plant has been served. It has the double purpose of protecting the essential organs and attracting the bees to them; and when fertilization has taken place with the deposit of pollen on the stigma no more attention from the bees is wanted, and in a very few hours the protection of the organs ceases to be essential. In the flowergarden, therefore, the robber bee plays no bad part. 


\section{THE GLORIOUS TWELFTH}

THE very true remark has been made that the shooting of grouse is not the whole of grouseshooting. It is merely, so to speak, the title element in a festival which derives extraordinary favour from the fact that it follows a prolonged fast. There are, no doubt, many of those who, on the I th of August, step out upon the springy purple heather to whom the pursuit of the red grouse is merely one in a ceaseless succession of sports in which salmon, trout, grouse, deer, pheasant, and salmon again are the quarry. But to the great majority of grouse-shooters the Twelfth is the beginning of the abrupt and pleasant change from labour in the Senate, in the Law Courts, and in the office, which thins the blood and dulls the eye, to the irresponsible contact with Nature, which is the supreme restorer of vitality to tired tissues. Hence its favour. If partridge-shooting began on the Twelfth and grouse-shooting on the Ist of September, the Twelfth would still be the great day, though perhaps not quite the great day that it is. For who will dispute that the virtue of contact with Nature is a more potent virtue on a far-stretching moorland than on a well-shaven stubble? In the 
scheme of recuperation turnip-tops compete indifferently with bog-myrtle.

Most of us are the bondservants of purpose even in our pleasures, and the slaying of the little red bird is the purpose that takes thousands to the hills. But even those who seek no more than the little red bird find more than they seekrefreshment of blood in the strong air of the mountains, refreshment of vision in their colour, tone in a thousand unconscious impressions. Millais likened Scotland in the richness of its colouring to a wet pebble, and at no time does it glow with a splendour greater than that of August. At all seasons there are purples on the hills, but they are the purples of atmosphere, which vanish in the sunshine. The purple that comes upon hill and moor in the second week of August is a material reality whose richness is only enhanced with the full light. With the moorland greens and olives of rush and fern, of bog-myrtle and horsetail, which make with it the perfect harmony, it forms the colour impression that dominates the festival of the day. The day has its sound impressions, which dwell no less persistently in the memory. The silence of the hills has many voices, and it would be a less impressive silence than it is, were it unbroken by the sad notes of curlew and plover, true children of Nature's own domain-such domain, that is to say, as Nature is permitted in a land like ours.

For no sport, not even that of grouse-shooting, is wholly favourable to the retention of the land surface in the state of Nature. A careful but 


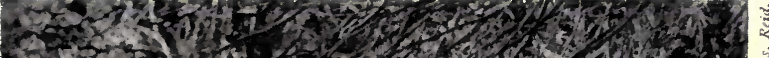

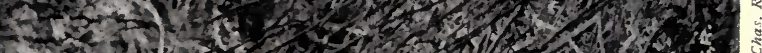

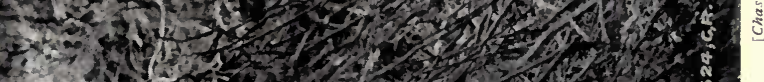

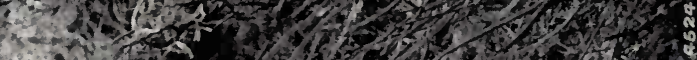

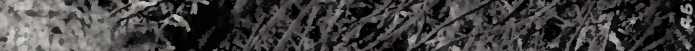

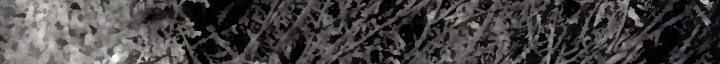

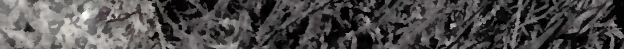

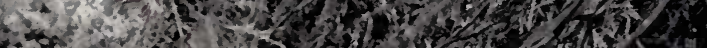

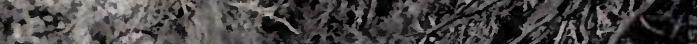

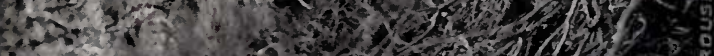

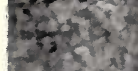

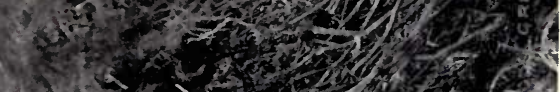

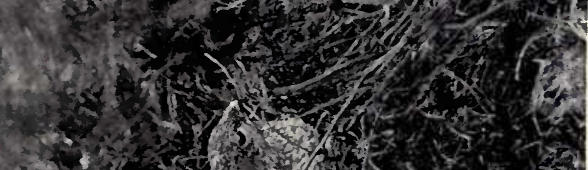

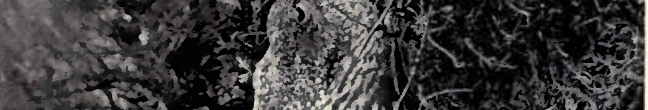

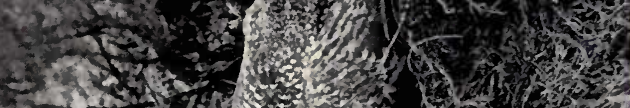

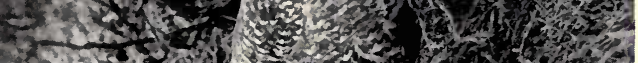

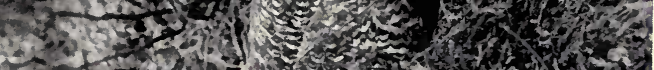

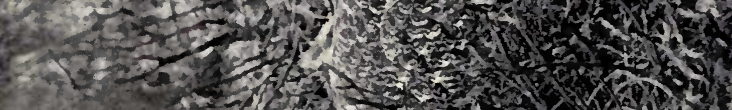

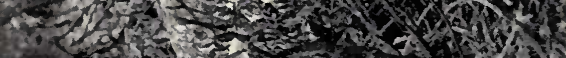

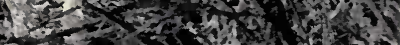

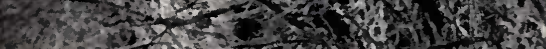

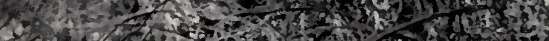

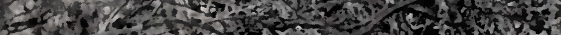

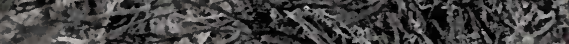

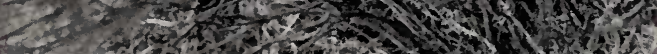

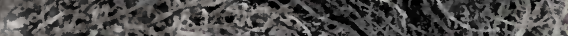

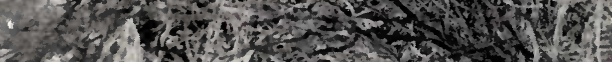

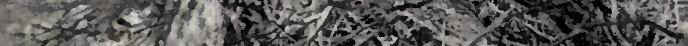

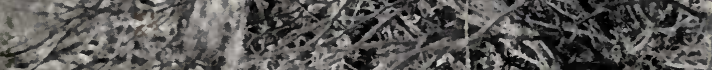

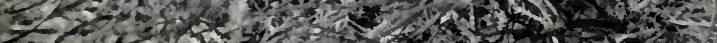

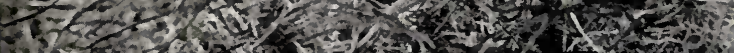

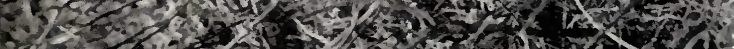

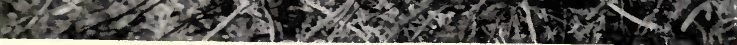



never obtrusive system of drainage has greatly changed the proportions of the plant population of probably every moor and mountain-side in Scotland. A very large proportion of every natural moorland and wet hillside is occupied by various species of rushes, of which there are a score or more in the British flora; and their vivid green suggests a succulent pasturage, which, however, would serve but poorly for the fattening of sheep or cattle. Drainage has reduced their area and given it over to heather. But the changes of surface effected in the course of grouse-preservation are small compared with those brought about by the effort to better adapt the land to deer. While the grouse-preserver wishes to promote the growth of heather, the deer-preserver wishes to eliminate the plant, and in many of the forests, by persistent burning, he has succeeded to such an extent that an old inhabitant would hardly know the country. Where there were vast slopes of brown and purple heath the yellowish-green mountain grasses extend themselves, and the crofter on some of these districts finds difficulty, in what once was the land of heather, in getting enough of it to thatch his barn.

Even the natural breeds of bird and beast are not what they were. With the object of increasing size, many owners have introduced park deer from England, and some have experimented with even more remote strains of the red-deer from abroad. If it be true, as it is probable, that a wandering deer might make its way from Cape Wrath to the Mull of Cantyre, it is unlikely that the alien elements have remained in the districts to which they were brought. It is less generally known, 
however, that an analogous process has been at work modifying the grouse, yet such is the case. The real old red grouse of the Highlands, the bird which the old Highlanders called Coilleach ruadh, or red cock, is now rather rare, and, according to Mr. Harvie-Brown, may only be found in the Outer Hebrides and in some isolated localities in the west of the mainland, the predominant bird of the day being, in his opinion, the result of innumerable introductions of new blood and mixing up of types. Other influences, such as change of living conditions, the breeding of a far larger stock than the land would naturally carry, the destruction of natural enemies, and the substitution for their selective work of the systematic but non-selective operations of the sportsman, have possibly modified the grouse to such an extent that if Fergus Vich Ian Vhor were to revisit his hunting-grounds he would hardly recognize it.

When all this has been said, however, the grouse remains the grouse and Britain's distinctive bird. Every other bird in our avi-fauna (perhaps we should except the St. Kilda wren) may be found on the European continent, but the grouse is our own. The real old Coilleach ruadh was not a distinct species, but merely a strain distinct enough to form a recognizable variety; and the man in the butts, or the man who prefers to follow the game behind a brace of good dogs, may bring his bird down with a feeling that his quarry is substantially the same as that which his ancestor, the ancient Briton, in a different way hunted for. the pot. 



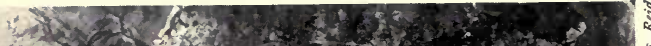

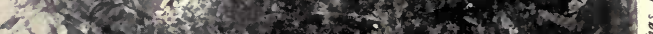

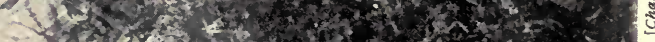

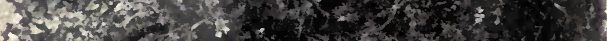
of

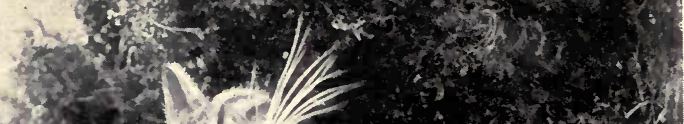

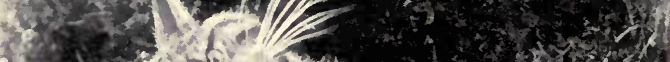

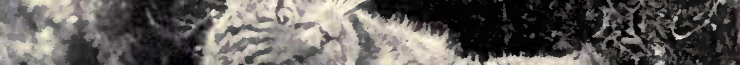

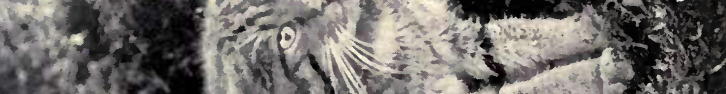

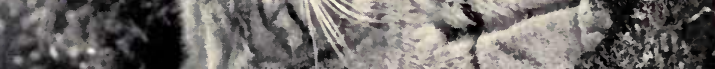
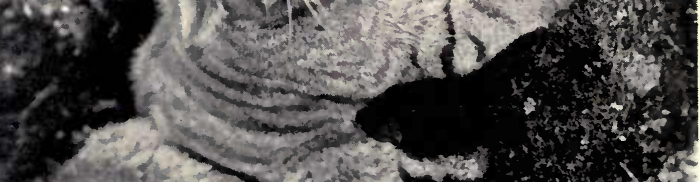

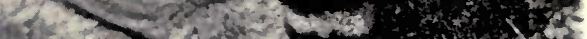

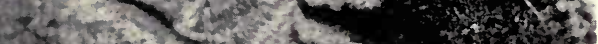

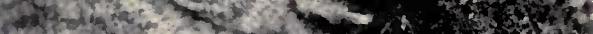

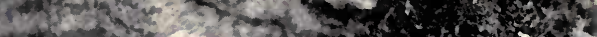

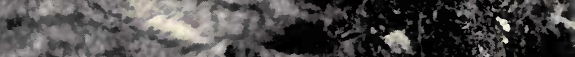

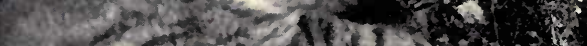

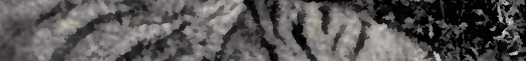

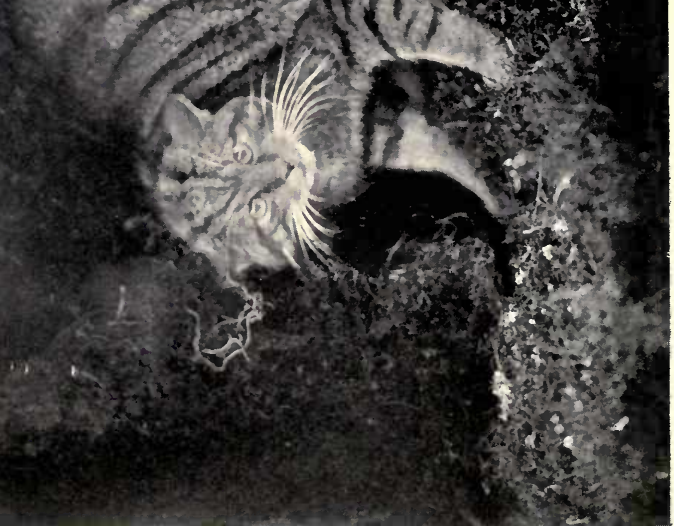

 


\section{ARE WILD CATS SCARCE?}

Sometimes one is assailed with a doubt whether animals generally supposed to be rare are actually as rare as they are reputed to be. When, for example, the badger is written about it is usually represented as an animal verging towards extinction. But occasionally one comes upon a credible authority on such subjects who declares that it is by no means scarce, though it is rarely seen. Strictly nocturnal in its habits, it never will be seen as one of the chance sights of the countryside; and even in the days of its greatest abundance it was seen in its own haunts only by the people who specially sought for it and dug it out. At that time it was the object of a barbarous sport, now no longer indulged unless it be in secret, and there was a purpose in seeking it. Now even the game-preserver feels little urged to persecute it, for, despite its strength, size, and undoubted carnivorous affinities, it is generally recognized that it is hardly worth considering as an enemy of game.

The rarity of the true wild cat is even more a matter of common belief, and about three times a year the newspapers contain a paragraph recording the capture of one and setting forth its 
dimensions and weight. The paragraph is written because the writer believes the animal to be very uncommon, and for the same reason it is given prominence in the papers. During a visit made this summer to the head keeper on one of the large northern estates-a man of high intelligence and great experience-I asked his opinion on the subject, mentioning that the reports of the killing of wild cats were rare, whatever might be the case with the creatures themselves. His reply was interesting and characteristic. "I'll tell you what is scarce," he said. "In the parts of the country where there are wild cats, men who write to the papers are scarce. When you see a report that in such-and-such a place in the Highlands a wild cat has been captured, you must not suppose that wild cats are more abundant there than elsewhere. It simply means that there is a man there who writes to the papers."

He took down his vermin book and went on. "Here," he said, "we are a good bit from anywhere, and have even to row across the loch to reach the nearest public road. Nobody but gamekeepers live in the neighbourhood, and they would as soon think of writing to the police as to the papers about a wild cat. It follows that any number of wild cats might be taken here, and nobody but ourselves would know anything about it. Now I find that, as a matter of fact, we got eleven wild cats last year, and that does not look as if they were very scarce. If we had tried particularly we might have got more." He went on to relate with great amusement how he had sent a live 
"Tom" to a great authority on sport, who had asked him for the first he got. What his correspondent wanted was the body of the first "Tom " captured for setting-up purposes, and great was the embarrassment caused at a certain town office when an animal with the temper of a tiger arrived in a box which nobody dared to open.

On the adjoining forest, almost identical in character, some further light was thrown on the subject, though the story told was different. I asked the keeper if he often got wild cats, and the reply was that they very rarely saw them. " That," I said, " is rather strange, for I have just been told that at L_- they got no fewer than eleven last year." "It is not so strange as you would think," the keeper explained. "Down at L_- where they always grow some oats and turnips, they trap a great many rabbits, and all those wild cats are taken in the rabbit-traps. They don't try particularly to get cats, but the cats come after the rabbits and get into the traps set for them. Then they are killed, partly because it's an old habit with gamekeepers to kill them, and partly because it's a most ticklish job to take a wild cat out of a trap alive. Here we shoot a good many rabbits, but never trap them, and that's the reason why we never get any cats. But though we never see cats here, I have no doubt they are as numerous here as at the other end of the loch. In the winter-time we often see their tracks in the snow, and could get them if we had any object, but in a deer forest they do no sort of harm whatever. We do not count their work among the 
rabbits harm, for ,if they were more abundant than they are they would be a nuisance."

Talking about reports of the killing of wild cats, this keeper, like his neighbour down the loch, said that those who most often got cats never thought of " putting it in the papers." "But," he went on, "I remember one in this district that was put in the papers. It was captured by the hotel people. They were bothered by some animal killing their hens, and thought it was a fox. So traps were set, and the very next morning a big wild cat was found with its fore-feet in one and its hind-feet in another. It was taken into the kitchen, held at both ends with the cords of the traps; but even in that state it nearly frightened the girls out of their wits with its ferocious ways. We carried it over and threw it into the kennel to try the dogs on it, but, notwithstanding the traps, it left its mark on them before they killed it."

Wild cats may abound in a wild bit of country and never be seen even by those whose business it is to daily perambulate the ground. They keep to their lair among the rocks and bracken during most of the day, and do their hunting at night and in the morning and evening twilight. Even if they do happen to be abroad in daylight, their movements are so stealthy that they are with difficulty observed, and in their natural surroundings their colouration is protective in a marked degree. In this latter respect they are strikingly different from the fox, which inhabits the same kind of country, and whose bright yellow coat is in almost startling contrast with the dark rocks and heather. 


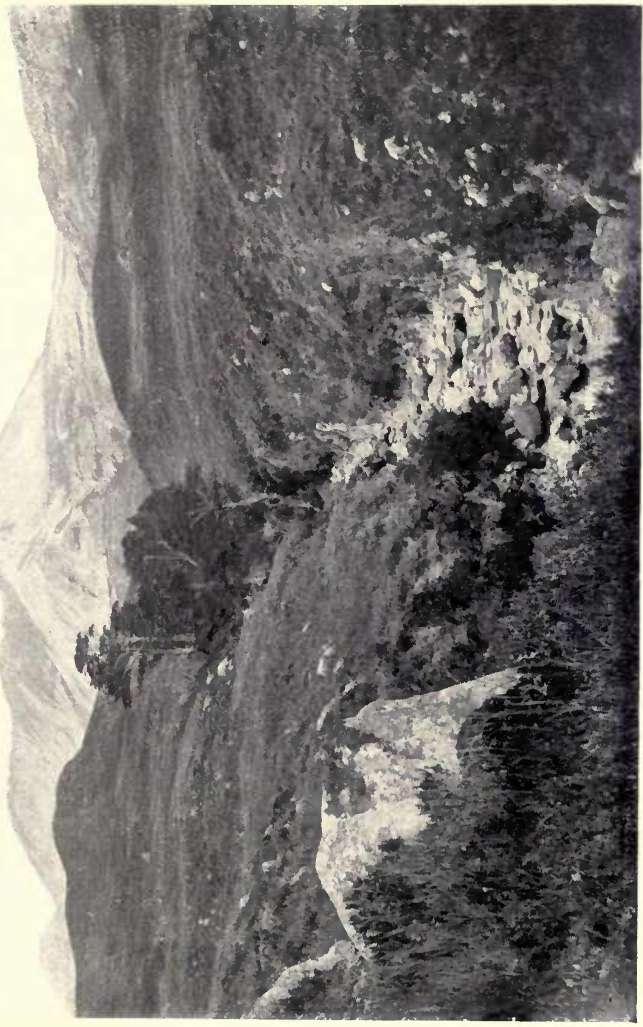

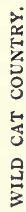



But while the fox is an extremely difficult animal to trap (or, despite his conspicuousness, to see), the cat is one of the easiest to capture if its presence is suspected and an effort is made to get it. Setting traps for a fox is almost a high art. A single trap beside a bait Reynard is quite sure to detect, no matter how skilfully it may be concealed; and if he is taken in this way at all it is by means of a second or third trap, into which he puts a paw after his abundant suspicions have been lulled by his discovery of the other two. The cat, on the other hand, will walk into a trap if it is not in sight, and the same amount of art that suffices for the capture of a rabbit will suffice for the capture of the rabbit's great enemy. The meaning of this great difference is, of course, that the fox observes the world chiefly through his nose, and uses his eyes as auxiliaries to that organ, whereas the cat depends chiefly on its senses of sight and hearing. And, as the instruments of cunning, ears and eyes are not to be compared with a thoroughly efficient organ of smell. 


\section{WASP PLAGUES}

IT is rarely that in any part of Scotland wasps become numerous enough to constitute a plague. They are not scarce by any means, but they do not take possession of the countryside. In the South of England, on the other hand, a wasp plague is a frequent occurrence of the autumn, and if one may judge from what is said in the papers, such a plague is in full blast just now (I 9 I I ). Once I made acquaintance with the wasp in plague numbers. Entering a hostelry in a western corner of Middlesex, I found every inmate bearing large and visible traces of combat. There were bandaged hands and bandaged faces. In reply to the question, "Been to the wars?" the lady of the establishment said that the "wasps were terrible bad," and pointed to the window and sundry saucers of beer arranged in conspicuous places around the room. In the window wasps were buzzing in dozens against the glass. In the beer saucers they lay in scores dead or dead-drunk. And all around others were freely indulging"tasting," as they say in the Highlands-till, tasting too deeply, they tumbled in and died. For the wasp is a bibulous creature, and likes liquid bread and plenty of it. 
There are various views of wasps' character. Some say that wasps will not touch people who leave them alone, others that they are of a perpetually angry temper and as ready to take offence as a Corsican. Myself, I can say that I have never been stung except when carrying out operations of a distinctly provocative kind. Once a small boy requested me to poke a fishing-rod into a hole in the edge of a thatched roof because his " ba' was stuck in it." The poke was administered, the deceptive urchin ran away, and at the same moment a swarm of wasps emerged and threw themselves at the innocent disturber like angry projectiles. Four stings on the face and two on the hands made up the casualty list. But I have never been stung when merely watching at close enough quarters to hear the grinding of their jaws. Nevertheless, the wasp is an animal to be treated with respect, and she knows it- " she," for, as is the case with bees, only the female carries a sting.

The question is often asked why wasps are so much more numerous in the autumn than at any other time of the year, and the answer involves some little knowledge of vespian economy. Of the social wasps, only the fertilized female or queen survives the winter. On the approach of cold weather she seizes a fibre in some sheltered nook, and, hanging by the jaw, sleeps the cold months away. When aroused by returning warmth, she begins at once to make a nest, underground or suspended from a branch of a tree or shrub, according to the species, the material being 
a kind of paper made by chewing woody fibre. In the nest is a small comb containing at first four and later about thirty cells, and in each cell an egg is laid. When the eggs are hatched the queen does all the work of feeding the grubs, which, in about a month's time, develop into worker wasps. Almost as soon as these have dried their wings they commence the labour of enlarging the nest, and henceforth the queen confines herself to the one function of egg-laying. In this way the wasps' nest grows throughout the summer, and one which began by being as large as a golf ball may end by being six inches in diameter and more than a foot in length, with a population many thousands strong.

Perhaps the best way of acquiring a little knowledge of wasp habits is to watch the arrivals at the nest, noting what they bring home with them. They neither store nor make honey, and in their anatomy there is nothing corresponding to the pollen-basket of the bees. A very brief vigil at the nest will show that they are beasts of prey. Every arrival takes something with her of an animal nature. The most frequent captive is the aphis or green fly, enormous numbers of which fall a prey to the wasps. But the wasp does not specialize. If she finds fly-maggots she takes them home; flies themselves serve her turn, and spiders have no terrors for her. When she has flies to carry she generally cuts off the wings and legs for the simplification of transit, and to see her at the process is almost to be compelled to have views on the subject of insect intelligence. 
A wasp has been seen to struggle against the wind with a fly, and, finding that its wings caught the breeze, to descend and shave them off in the most knowing fashion. It may thus be said that, as a fly and maggot and aphis destroyer, the wasp plays a useful part in the world to set against its depredations in the orchard when fruit-time comes round and the occasional poisoned daggerwork it carries out on the human cuticle.

It must not be assumed, however, that the wasp, as wasp, is a carnivorous animal, for it is not. The grubs are carnivorous, and all the bodies of aphides and flies brought to the nest are for them. Inside they are torn up and administered to the occupants of the cells, which are as voracious as young cuckoos. If a nest is broken up and a comb containing live grubs is secured, the grubs may be fed with fragments of meat and the keenness of their appetite realized. This gross taste disappears when the young wasp has passed through the pupa stage and reaches developed insecthood. Though it then hunts for flesh for the use of its younger brethren, it finds its own sustenance mainly, like the bees, from flowers, till the fruit is ripe, when it concentrates its attention on the sweetest it can find, preferably plums and pears. At this stage in its life-story the wasp generally gives up the labour of keeping the community going, knowing, perhaps, that the first October frost will bring the whole enterprise to an end; and when ripe pears are falling from the tree, there may the marauders be found in numbers all day long. 
It is an interesting sight to watch them when thus engaged. They prefer to operate on a pear from which a blackbird or starling has taken a beakful, and it is no uncommon thing to find them eat out the entire inside of the fruit, leaving the skin intact, save for the original bird-made entrance hole. When thus employed they fight fierce battles with one another, grappling and savagely biting, but apparently never using the sting. That seems to be reserved for enemies of another race. Bluebottle-flies have also a fancy for ripe pears, and it is amusing to note the hasty way in which one of them abandons a fruit when a wasp comes to take possession. When wasps are engaged on ripe pears, so greedily engrossed do they become that it is a perfectly easy thing to seize one by the wings for examination. Its rage when so seized is great, and frantic efforts are made to sting, but when liberated it will generally be found to make straight again for the pear. A little earlier in the season a wasp, taken liberties with in this way, would put aside every other thought in favour of revenge. 


\section{SEPTEMBER}




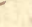




\section{THE BUSY BEE}

IN these autumn days the garden, unless the succession of flowers has been very knowingly arranged, acquires a rather bedraggled and empty look. The summer blooms are all past their best, and the autumn glory is still to unfold itself. But sunflowers of all sorts make a very glowing display, even if they are rather full blown, and where sunflowers are, there may be found the busy bee. When, however, I examine the bees in my sunflowers, I am forced to the ungenerous thought that business is not their distinguishing trait.

Here, for example, is a black "bumbee." It rests on the disc of a ripe sunflower, so ripe that it has curled into the similitude of what a female person calls an iron-holder. About the bee there is a strange and uncharacteristic leisureness. It has tarried on this bloom, to my knowledge, for half an hour, and to say that it is gathering honey all the day is an exaggeration of politeness. It makes just enough movement to show that it is alive. At long intervals it withdraws its proboscis from one full-blown floret and thrusts it into another, but the whole action is performed with airs of boundless time to spare. Perhaps this bee is a bad character, a shirker among a busy 
tribe, a person without respect for the glorious traditions of the apian race. But no; I turn to the other sunflowers and find that each has its bee, some two, and that all the bees are behaving in substantially the same way. There has evidently been a complete break up of the moral foundations of the bee world.

The case must be investigated, so with a pencil I touch the first bee-prod him in the ribs, so to speak. Generally speaking, the action of a bee which is prodded in the ribs may be predicted. It utters a fierce buzz, rises on speedy wing, flies bang into the face of the author of the outrage, and stings. It will not have liberties taken with it, will a bee. But the behaviour of the animal on the sunflower is not modelled on the conventional bee tradition even in this respect. A large, well-developed, and muscular bee, with great breadth of beam, it seems pre-eminently adapted for belligerency, but when pushed in its hairy side the most it does is to feebly raise one leg and wave it in the air. There is a weak sputter of bee-noise, and noise and action together say quite plainly, "Go 'way." The bee does not withdraw its proboscis from the floret. I push it more energetically, and it responds by waving two legs, but still sticks determinedly to the business of suction. Apparently the nectar in the sunflower is extraordinarily seductive, so good, in fact, that while it flows down the bee's throat every passion but that of indulgence goes into retirement.

The investigation must be pushed further. We 
shall see how the bee behaves separated from this delicious fluid, so I knock it completely off its sunflower. To such treatment a volcanic outburst of rage would be the right response, but nothing of the sort takes place. The bee has landed on its back, and so it lies, buzzing weakly and waving its feet in the air. An active imagination might detect in its song the words, "We won't go home till morning," and there is a distinct leer in its large eye. A few ribald remarks follow, not fit for publication, and finally the bee goes to sleep. In half an hour it bestirs itself, stretches its legs, and manages with an effort to get right side up. Then with a prodigious expenditure of energy and output of noise it manages to launch itself into the air, and after one turn round it plunges right into the heart of the sunflower once again.

By this time it is what policemen call a clear case. The bee is a drunkard, and the sunflower is its favourite " pub." When it first opens shop and puts out its yellow sign, the sunflower is a temperance establishment-none more respectable. It opens two or three hundred barrels filled with a perfectly innocent beverage, and invites bees to come and drink. The bees come-worthy, industrious, law-abiding creatures, who extract the nectar and go home with it, and deposit it in the honeycomb. But gradually a change comes over the character of the sunflower. Its nectar ferments, and from being a temperance-house it becomes a shebeen. It is then no place for respectable bees. And, as a matter of fact, those bees of which I have 
been writing are not, and never have been, entitled to the name. They are drones.

There is a tragedy in drone life, and it is being worked out just now, though in no very tragic spirit. Throughout the long summer the drone had a glorious time of it. When the sun shone he moved from flower to flower, sipping nectar all the day, and never bothering to take any home. That was the work of the female in the bee community. When it rained he stayed in the hive, and there was always a little drop o' summat on the chimney-piece to which he could put his lips when so dispoged. Probably he looked with lordly scorn upon the drudgeful female working bees, with their engaged and over-anxious ways. But all the time those ladies had an eye upon him. Perhaps they communed with one another about him and his idle, wasteful habits, nodding the while and saying, "Wait, you, till we have no more use for him." The moment when they had no more use for him came, and they bundled him out-of-doors, and if he returned they stung him to death. Most of the drones did not try to return; they knew better. Down in the mouth, they flew to the nearest sunflower " pub." to drown their sorrows in drink, and their last days are those of the sot. In the cold of the night-time they become numb and three-fourths dead, and when the sun rises it thaws them out and they resume their course of tippling. At noon they are tolerably competent, " a little rocky about the feet," yet able to move from shebeen to shebeen. By four o'clock they are blind fou. 
One cold night a touch of frost will settle their case, and they will pass away with alcoholic dreams.

The drone is a great deceiver of human kind. $\mathrm{He}$ is of more robust build and altogether of more dread-inspiring aspect than the worker bees, and ninety-nine people out of the hundred treat him with respect. But he is no more able to inflict punishment than a bluebottle fly. $\mathrm{He}$ is, in fact, a pure humbug, for, knowing himself unarmed, he carries himself with all the terrifying airs of a gladiator. Capture him and he will raise his abdomen with the same threatening gesture as the sting-bearing worker; blow smoke upon him and he will erect his hair and execute a series of menacing movements, all carried out with such verisimilitude as to overawe even knowledge of his helplessness. In short, he trades upon the real terrors of the ladies of the hives.

How, then, it will be asked, can one distinguish in order to give respect only where respect is due? The correct way is to approach your bee, magnifying-glass in hand. Concentrate attention upon the two upper segments of its hind leg. If these, the tibia and the first tarsal joint, are found to be broadened out and fringed with hairs, leave that bee alone, for it is a female and bears a sting, and the appearances alluded to constitute its pollen-brush and corbiculum or bread-basket. If the corbiculum is absent the bee is a drone, and you can afford to be bloody, bold, and resolute. 


\section{THE SPARROW'S HOLIDAY}

THE sparrow's points of contact with humanity are, as everybody knows who has studied his ways, very numerous. $\mathrm{He}$ has adopted our dwellings as his own. He has so nicely adjusted himself to human economy that we have, in no fanciful sense, become his servants and providers. A creature of urban civilization, he is as familiar with the dangers of the streets as a gamin, and makes as little of them. He knows our ways and our weaknesses, and takes full advantage of both. His latest tribute to humanity is the adoption of our habit of treating ourselves to a summer holiday.

I am the happy possessor of a bit of ivycovered wall, which is the happy home of a goodly sparrow company. There they nightly go to rest before darkness sets in-their one thoroughly respectable trait. For quarter of an hour their squabble for the best sleeping-perches makes a quiet corner clamorous, and fills with futile longing the pussy cat which is the latest addition to my live stock. They do not manœuvre for position; there is no finessing about sparrows. They simply plunge in among the ivy leaves and elbow vigorously for places, scolding in real backyard 
style as they do it. This had so long been a regular nightly performance that the cat counted upon it as an excitement with a reliable place in his daily programme.

Quite suddenly one night in August the performance did not take place. Pussy was in his place, waiting for the excitement. Thinking that the show was over for the day, and wishing to gratify him by renewing it, I flung a stone into the ivy, expecting to see the sparrows come out. This had been done before, with success gratifying to the feline spectator. On these occasions the sleepers had always emerged with a rush, settled on a neighbouring pear-tree, and after debate, couched in tones of high resentment, had dropped back to their places one by one and settled down, after the inevitable amount of shoving, for the night. But on this occasion nothing followed the flinging of the stone, and when darkness fell not a sparrow had taken its place. Next night it was the same, and it became evident that my fifty feathered tenants has deserted me. How was this strange behaviour to be accounted for? I was certainly not to blame. True, in seed-time I had tried hard to capture and kill, as an example, some members of the flock, then very active working havoc in the seed plots. But if that manifestation of hostility was resented at the time, it had long been forgiven and forgotten. Perhaps some owl had taken up his quarters in the ivy, and rendered it untenable as a dormitory for small birds.

That that was not the explanation was made 
clear when one night the whole flock reappeared on their old ground, and resumed their old habits with all the old airs of confidence and ownership. And then, of course, the whole mystery was plain as print. They had been away for their holiday, and, plebeian birds though they are, had chosen for it the aristocratic holidaymaking-time of the year. Just about the date when the grouseshooters were making for the moors, to drive the town vapours from their lungs by copious inhalation of ozone and the scent of blooming heather, the town sparrows shook the dust of the streets from their wings and made for the fields. Perhaps they held a parliament of their own on the peartree, and discussed the cause and cure of that "tired feeling" and speculated on the benefits of country air and food. Mrs. Sparrow may have remarked that caterpillars were getting too big and gross on the urban cabbage-patches, and that now the family was up and doing for itself they might all indulge in a little change. Mrs. Sparrow may have thought that a short experience of the simple life, a few weeks " back to Nature" before facing the winter, would set them all up and save doctors' bills. Whatever they may have thought, off they all went ; and now back they all are, looking brown and fit, chirping with the heartiness of birds which have done themselves well, and ready to declare that, though the country is all very fine for a spell, after all the town's the place.

The farmers, especially those whose holdings lie within eight or ten miles of a large town, 
know all about this autumn visit of the city sparrows to the country. All the year round the country population of sparrows is not very great. In an average rural square mile there are more sparrows than chaffinches, than buntings, than greenfinches, than larks, blackbirds, or thrushes. But there are not more sparrows than all of these put together. Just when the corn is ripening, however, there is a sudden and prodigious accession to the sparrow flocks, which have hitherto found the roads and farmyards their chief huntinggrounds, and the little brown-grey scallywags outnumber all other small birds put together. And the chance deposits of semi-digested grain on the highway no longer interest them. They take to the standing corn, and the sight of them in full operation is one to fill the agricultural heart with rage.

Here is a wheat-field with a line of ash-trees around its edges. The heads are full and turning yellow. Passing along on a bicycle-it is wonderful how generally the birds have learnt to look upon a man on a bicycle as safe-you notice perhaps a dozen sparrows hanging on to the grain. Ride on and they will take no notice of you, but confine their attention to the business in hand, which is the consumption of untaxed corn. But dismount at the nearest point to them, and-_ I A dozen sparrows, said you? A couple of hundreds or more instantly rise from the corn, with'a unanimous chirping clamour and a noise which would not discredit a covey of grouse. They make for a tree at a safe distance, and converse volubly 
on the situation. If the watcher moves slowly away, still keeping an eye on them, he will find before he has gone fifty paces that first one of the marauders drops down among the corn in the old place, then three, then five, then the whole flock; and before he has gone a hundred yards they are all feeding as greedily again as if they had been on short-commons for a month. If, on the other hand, the enemy looks like making a stay, they will without much loss of time shift their quarters, and begin operations on another part of the field at a safe distance away.

The sparrows' digestion of grain must be enormously rapid, for such is their dexterity in stripping a head of wheat or oats that they seem capable of eating in a quarter of an hour as much as should stuff tight their little insides. Yet they are at the job the greater part of the day. There is a period, usually about midday, when they leave off for a considerable spell. Then it is their joy to assemble in, for choice, a hawthorn-tree, which has a great abundance of little branches adapted to the size of sparrows' feet, for a real good gossip. To the ear of flesh they seem all to say the same thing, and to say it in one word repeated a million times. But the ear of the imagination readily detects that the conversation is both animated and varied. It is in praise of corn and the delights of eating one's fill again and again. How glorious it is to be nearly choked a dozen times a day with sheer abundance, after picking up a living which hardly suffices to keep one's feathers tight through ten months of the year! 
And what a delightful atmosphere they keep in the country! And how pleasantly few are the human bipeds to the square mile-those worries of the sparrow life of the towns. Sometimes a farmer stalks the hawthorn-tree, with a gun well loaded with scattering shot; and if he gets within forty yards-well, it is not nice to be shot. It is not even nice, though not by any means so sore, to have some of your relatives and friends shot. But as a matter of reassuring fact-so a philosophical sparrow would proceed-it most providentially happens that farmers are exceedingly busy just when the corn is ripe, and have little time to fool about with guns. And if the farmer should be so malicious that he will go gunning in sparrow holiday-time, sparrows have still a very good chance of coming out of the ordeal all right. They know how to look about them, and it is a poor flock which cannot keep an eye on more than fifty yards. 


\section{A GENTLEMAN IN VELVET}

ONCE upon a time in the ages before work began I read in a boys' paper an article telling " How to become a Taxidermist," and straightway proceeded to become one. The first thing to be done was to compound a wonderful preparation for use in skin-curing, and in defiance of the loudly expressed protests of a family which took no delight in evil smells, about enough of the stuff was made to treat the hide of a horse. The next thing was to find a subject, and to that end I sallied forth. During an eager hour the blackbirds and thrushes of the vicinity ran all the risks of war, but escaped all its penalties. They were too nimble for a very indifferent marksman. Next the squirrels experienced all the excitement of pursuit without being a penny the worse. But at last a victim was found to the lust of youthful experiment in a "black water-rat."

A water-rat is a bad or a good object on which to practise the art of taxidermy, just as you look at it. The creature is endowed by nature with about as much figure as a potato, with the result that when it is set up it may fail to satisfy the cravings of the æsthetic eye. On the other hand, no matter how bad your taxidermy may be, your 
setting up of a water-rat is bound to be something of a success. Therefore it is a good beast for a beginner to begin with.

This reminiscence is set down here merely to enable me to express the wish that the enemies of the water-rat were limited to the taxidermists of tender years, for there is every reason to think that a very innocent little animal is suffering for sins not its own. On the brookside where I slew my victim twenty years ago, I could count any summer evening on seeing a dozen of them, looking like miniature beavers, on a hundred yards of bank. On a recent evening I searched a mile of it and saw not one. They have been extirpated. And why? Chiefly because in popular nomenclature they share the use of a name which for the best of reasons is in much disrepute; and as at the present time an anti-rat crusade is in full swing, they are likely to suffer even more than in the past.

The first thing to learn about the water-rat is, that it is not a rat at all. It has the dimensions and some of the outward semblance of a rat, but it is merely a vole, and there is no vice in it. It has not even a nasty tail, an appendage which, in its scaly forbiddingness, counts for much in the rat's unpopularity.

The bank of a stream half choked with vegetation and a June evening are the time and place to study the water-vole. You move cautiously along with an eye on the off-side, and, if the rat-exterminator has not been at work, should soon catch a glimpse of the martyr to mistaken identity. Probably he will be attending to his toilet, an 
office to which he devotes great attention. Sitting on his haunches like a little black or brown bear, he carefully combs the fur of his face and head with his fore-paws. This smoothed out to his satisfaction, he surveys the surrounding vegetation and tries his teeth on the top of a tall grass, holding it with both " hands" with a squirrel-like air. But grass is not much to his taste, and presently he plunges into the water in search of better fare. Swimming under the water, his resemblance to the rat is complete enough to ensure him the compliment of a stone from almost any human creature who, seeing him, can lay hands on one. But if no stone is flung he is soon on the bank again with a piece of iris leaf or root, which he evidently regards " a bit of all right"; but almost any kind of water-growing plant satisfies his sober taste. Barring alarms, this is his inoffensive programme all day.

It would be difficult to name a creature more absolutely harmless than the water-vole. Its relative the field-vole, as often designated a mouse as the water-vole is a rat, is not harmless by any means. When circumstances favour it, it multiplies at a prodigious rate, and has been known to ruin vast areas of pasture, not because it eats the verdure up, as is sometimes thought, but because it cuts out for itself a most lavish provision of galleries at the roots of the grass, and thereby destroys an amount of herbage out of all proportion to its size. Those galleries are made for the purpose of concealed movement, field-voles having learnt in the course of their long history 


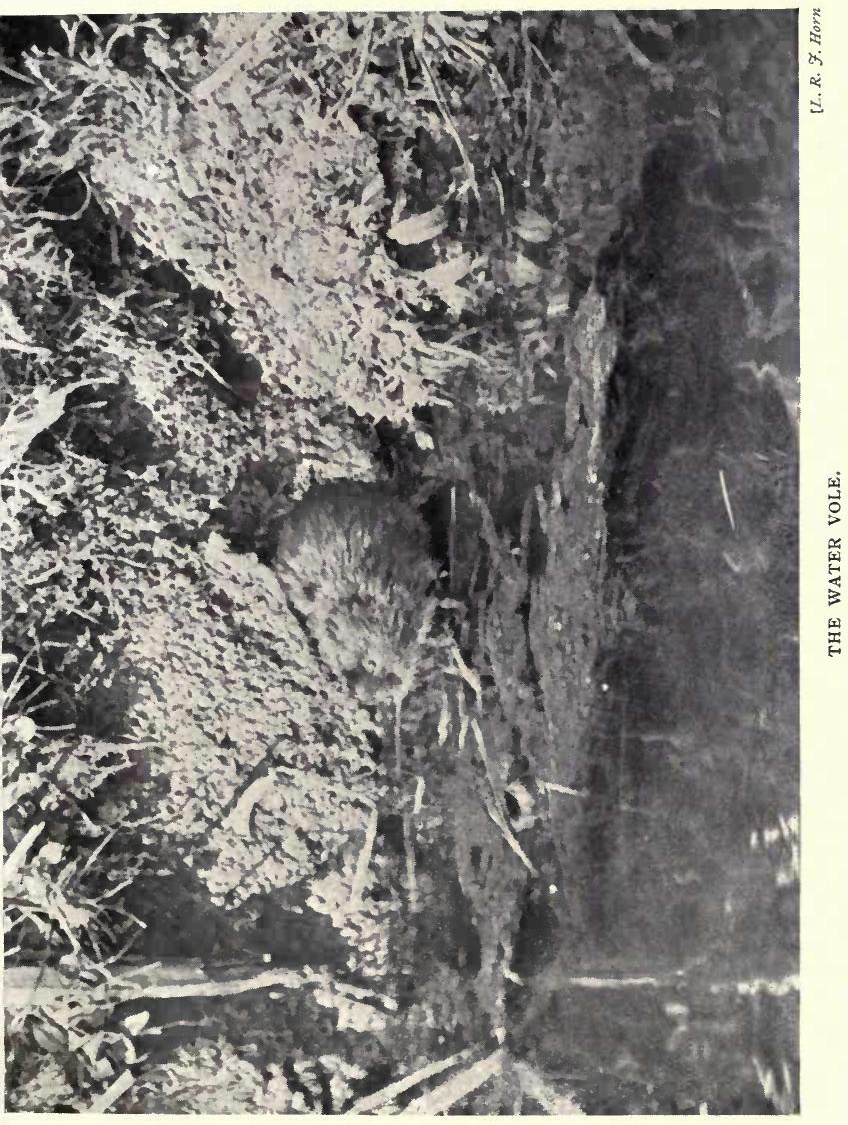



that their fat little bodies are loved to an embarrassing extent by hawk and owl. And when industriously seeking the pleasures of obscure security they give no thought to the interest of the sheep-farmer, who is a much later comer on the surface of the earth than themselves.

But the water-vole plays none of these pranks. If a great congress of the species had been held to consider ways of living inoffensive to the tyrant man, it could hardly have devised a better programme. It eats none of his crops. It injures none of his property. It is scrupulously clean in its habits, and as it does not tolerate fleas, like the rat, to act as disease-germ disseminators, it would work him little or no sanitary mischief, even if it frequented his dwellings. But it never goes near them. Add to its negative virtues that it does not touch fish or fish ova, or even fish food in the form of larvæ and insects, and it will be admitted that it is wonderfully successful in the avoidance of offence. Its positive virtues are less notable, consisting as they do in the one fact that it eats up vegetation which tends to choke watercourses. But then his one positive virtue is worked hard all day. long, and may be held as good as half a dozen which are brought only occasionally into play. The solitary fact brought against an otherwise blameless character is that it digs holes in the banks of streams, but as the holes are not frequent, and as the vole always selects for them a bank of reliable consistency where they can do no harm, this as an indictment is mere carping. 
And yet with all its innocence the water-vole leads a persecuted life. It might say, with Stevenson's pirate, "I never knew good come out o' goodness." When it sallies forth for its blameless supper worthy of an anchorite, a supper of herbs and water, it steps into the trap set for its feet. When it sits up in conscious rectitude on the bank in broad daylight to do its back hair the passing ploughman or fisher heaves a rock at it, and it succumbs to a touch which would hardly inconvenience the tougher sinner who has cursed it with its name. The prime mistake of its evolution was in the adoption of its shape. Perhaps it made an honest effort to achieve distinction when it adopted a short tail. But, alas $!$ it hides this testifying feature away, and it is rarely seen by the enemy till the owner is dead. In these days, when the real black rat has all but disappeared from the land, the colour of the watervole, a jet and glossy black, or sometimes a very dark brown, might save it; but it doesn't. It merely makes it a black rat to the majority. 


\section{THE ANTLERS OF THE RED-DEER}

\section{ORNAMENTS OR WEAPONS?}

A GREAT many fine heads have fallen in the Highlands during the past month, which in due course will take their place as decorative elements in the homes of Britain. In what light should their owners regard them? Are they defensive weapons like the horns of the buffalo, or decorative equipment like the tail coverts of the peacock? Curiously enough the question is not so easily answered as it seems.

It can be said confidently, however, that the horns of the deer are not in the same category with the horns of the buffalo or of any other ruminant, while it is highly probable that their history in the development of the race is as different from these as it certainly is in the history of the individual. The horns of all the other ruminants are permanent, and they are present on both sexes. This means that they are defensive weapons in the fullest sense. Those of all the deer, with the single exception of the reindeer, are confined to the male sex, and they are shed annually. The winter, too, is the season when they are absent. Now, most deer are natives of 
countries of which wolves also are, or were, indigenous inhabitants, and the winter is the season when wolves pack and become particularly dangerous enemies of deer. From this it would follow that the antlers of the deer have not been developed as weapons of defence, for if that were their character they would be possessed by both sexes, and would last throughout the year. What, then, is their function and history?

If nothing were known of them beyond the facts briefly stated above, the naturalist would feel justified in including the deer antlers in his list of " secondary sexual characters" ; but a great deal is known besides which definitely relates them to sex. Thus if either by accident or purposive mutilation a stag is desexed, very remarkable consequences follow to his antler development. Should the operation be carried out when he is without antlers he will never renew them. Should it be carried out when he is adorned with antlers he will never cast them. This means that the whole set of physiological processes which in normal circumstances produce the annual growth and shedding of the antlers is a sex process, and that it is permanently arrested at the moment when sex is destroyed. The association is even more marked if the act is performed at any of the intermediate periods. When the antlers of a deer are growing they are soft and tender, richly supplied with blood-vessels, and covered with a velvety skin which is cast when the horns reach their full size. Should the stag by accident or design be desexed when its antlers are "in the 
velvet," their growth stops from that day and the velvet is never cast. It dries up, but adheres hard to the horn.

Another curious fact marks the sex character of the grand armature of the deer. Antlers on a female deer are about as rare as a beard on a woman, but old hinds supposed to be past the fertile period of life have been known to produce them. Something of an analogous nature has been seen in the human species, and it is far from uncommon in the case of fowls. In these days of scientific poultry-rearing and marketing, few fowls are ever permitted to attain old age, but in former days it was common farmyard knowledge that hens allowed to live beyond the laying period tended to develop wattles, and even spurs, and to crow like cocks.

There is accordingly no doubt that the antlers of the deers are sexual characters, and that their evolution is more akin to that of the peacock's tail coverts than to that of the purely defensive of offensive weapons of the other ruminants. But the question remains, Have they been developed as sex weapons, like the spurs of the polygamous fowls, or as ornaments, like the wattles and finer plumage of the cock? It looks like a question which answers itself, and yet the answer is not so certain as it seems. Most naturalists are agreed that, especially in the case of polygamous animals, both ornament and fighting capacity play a great part in enabling the males to secure the large harem which they all aim at, and the antlers of the deer are both ornamental and warlike. 
Deer fight with their horns and occasionally with their feet, and nothing in the whole field of animal belligerency could seem fiercer or more determined than their combats. But even in their fiercest enounters there is a good deal of make-believe. They try to terrify one another like those soldiers of France who practised the art of looking fierce in their drill-yards. Their challenge is loud and long, and when they come to close quarters the clash and clang of their antlers is awesome to listen to. But in the great majority of cases the fight consists in nothing more than the dashing of one bony mass against another with prodigious noise. Cases are known in which the antlers of the fighters have become interlocked, with fatal results for both; and cases are far from uncommon in which one of the fighters receives wounds from which he dies. But usually weight carries the day, and the battle ends without either of the combatants breaking the other's skin. The defeated stag has simply been overawed by resounding clash, and there is at least one case on record of a hornless stag forming a harem and keeping all rivals at bay. This would suggest that deer can fight successfully without horns, and that horns are menacers in the main.

A not uncommon sight in the Highlands during late October or early November disposes those who witness it to look upon the stag, while not disputing his real courage in the lists of love, as a great posturer. Trampers in the hills occasionally come upon patches where over a space of several square yards the heather, and even the 
peaty soil below, is all torn up. If you were within sight when the heather and turf-tearing was done, this is what you would see : on the grazing-ground there is a stag jealously herding the company of hinds he has been able to gather for himself. On the eminence is another stag trying the effect of terrifying tactics on the more successful rival below. He lifts up his head and roars. He swings his head about and tears up the turf with his horns. There is a prodigious show of power, and generally a suggestion that he has more than half a mind to go down and tear the other fellow into shreds. Some of the hinds are manifestly impressed, and show a disposition to move away and join the prepossessing young buck on the ridge. But the old stag rounds them up with many a disciplinary shove, and that is generally all he does. Generally, too, menacing is all that the buck on the ridge does. $\mathrm{He}$ is in hope that the stag below will take fright and run away. This is a performance that usually takes place after the more real fights which, at an earlier stage, have determined the question of which stags are to possess a harem of hinds. When the harem has actually been formed a wise stag pays little attention to challenges. He knows precisely what their value is, and possibly he knows, too, what will happen if a multiplex husband gets into a scrap. What takes place when an unwise stag leaves his herd to beat off an encroaching rival has often been witnessed. A third stag promptly appears upon the scene, and attempts, sometimes successfully, to carry a cluster of the ladies away. 
It is often said in these days that the antlers of the present race of red-deer in Scotland are diminishing in size, and the owners of many deer forests, believing this to be true, take special pains to repair the defect. To this end they from time to time introduce park deer from England and from European countries, like Hungary, where the breed runs to greater weight than with us. Some of them, believing that big heads go with good feeding-to which alone the superior heads of the park deer are attributed-provide their herds with ample winter supplies.

That on a long view the antlers of deer show a great reduction in size there is no doubt whatever. The antlers and skeletons of stags have been recovered from the peat mosses of Scotland immensely larger than any that have ever been seen on living red-deer, and modern records bear out strongly the belief that the process is going on. But there are several reasons why we should account it strange were it otherwise. The first was pointed out by Darwin half a century ago, when he said that the practice of the Scottish sportsman of steadily killing the finest stags must inevitably cause the whole race to degenerate-a practice, by the way, which, as Darwin noted, is exactly the reverse of that followed by the Incas of Peru. It is true that deer have been hunted in this country ever since it had human inhabitants. But down to the era of the rifle the hunter's power of selecting the best was very limited. He had generally to take what he could get rather than what he would like, and as the deer-stalker till 


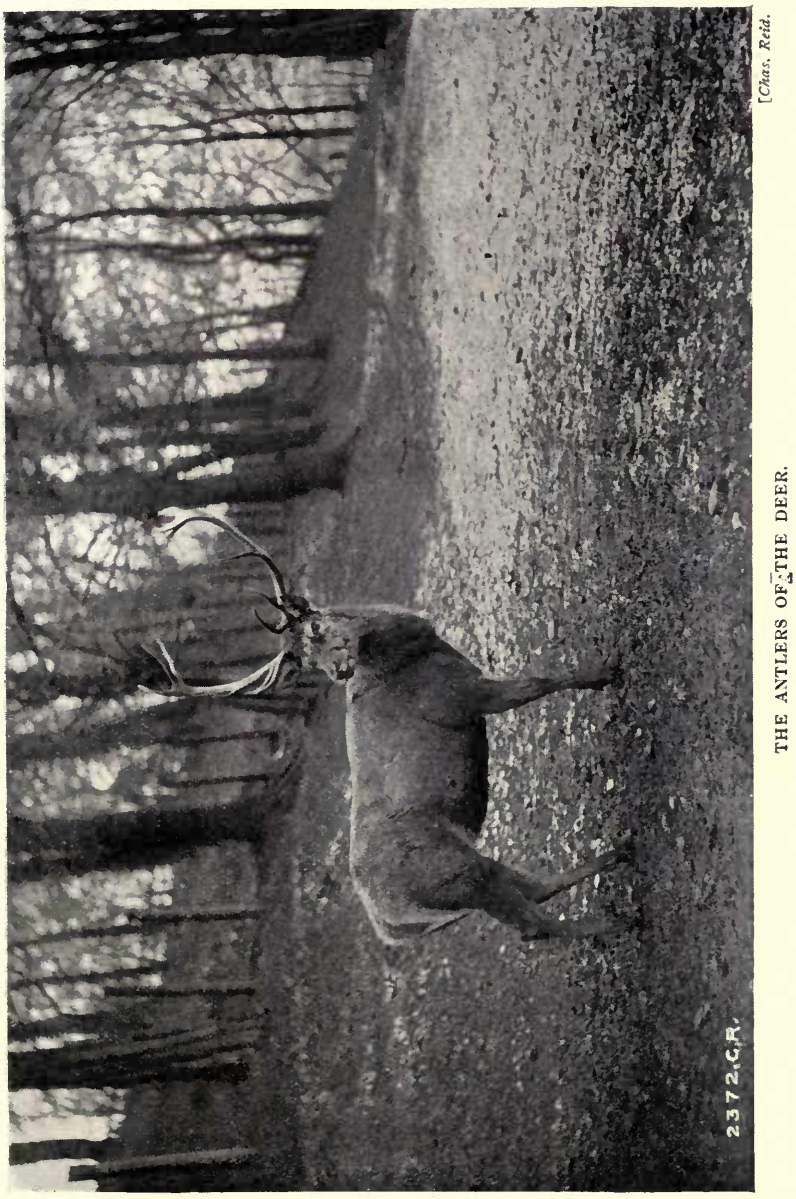



less than a century ago was after venison rather than a trophy, it did not matter to him very much what sort of head he got. To-day the deerstalker is after trophies all the time, and the modern rifle vastly increases his power of selecting what he wants. This selection of the great heads is more likely to affect the stock in the case of deer than the selection of the best individuals in almost any other species of animal ; for, thanks to the deer's polygamous habits, a stag is for all practical purposes prevented from perpetuating himself till he has acquired his great head. The general result is that one can never read a review of a stalking-season in these times without finding the shooting of a stag with a head of long and thick beam and tine, dark-coloured and rough, recorded as a rarity - " the typical old Highland stag not often met with now, when horns are more generally light in colour and smooth in tex"ture." The roughness of the deer's antler is merely the record of the network of blood-vessels, which built it up when it was soft and growing, and a smooth horn denotes a deficient blood supply.

This "elimination of the fittest" would account for almost any amount of reduction in the antlers of the deer, but there is another considerable probable cause. In our time the deer population of Scotland is almost confined to the hill country, so much so that many people think of the mountains and moorlands as the animal's proper and chosen habitat. That, however, is a mistake. Throughout its range, which extends over tem- 
perate Europe and Asia, the red-deer is much more of a forest than a hill animal, and in the past it ranged over the whole of the British Isles. It happens that the less valuable ground to which it is now (putting parks aside) almost confined is the most markedly deficient in the plant life and mineral constituents necessary for the formation of bone. That deficiency does not affect carnivorous animals, or, indeed, animals on which the bone-making demands are normal, but those of the stag are abnormal in a high degree. A full-grown stag sometimes carries twelve or thirteen pounds of bone on its head (the forest deer of Europe carry much more). The massing of bony material here is not to be compared with that on the brow of the Cape buffalo, but the buffalo does not cast its horns from year to year. It adds continually to their size. The red deer, on the other hand-a much smaller animal-builds up a new set every summer, so that a fourteenpointer, presumably fourteen years old, might in the course of his life have produced and cast away as much as a hundred pounds of bone. How the vast expenditure is sustained is a puzzle.

The scarcity of lime and salts, the materials of which bone is formed, is believed to account for some curious deer forest phenomena. Many thousands of antlers are cast in the Highlands every year, but it is rare indeed for a set to be found. Keepers occasionally find a set, but those found do not represent one in a hundred of those shed. What becomes of them? There is no doubt whatever that they are eaten by the deer them- 
selves. Whether the stags ever participate in this strange food is doubted, but that the hinds eat them is beyond dispute. They have been seen at it. When a herd of hinds find a horn one gnaws at it till she is tired, and when she abandons it another takes it up. There is a case on record of a hind found dead with a part of a chewed antler sticking in its throat, and another case of a deer shot the tips of whose antlers had been gnawed on his living head. Though entire antlers are so rarely discovered, the basal bosses of antlers are a common enough find, and in these cases the thin end is always gnawed.

But stag horns are not the only objects capable of gratifying this curious appetite of the deer. Any kind of bone left exposed on a moor or hill inhabited by them quickly vanishes, and there is a Hebridean case of the skeleton of a horse being completely consumed by deer in a few months. Probably the skeletons of dead deer vanish in the same way. Every one familiar with deer-forest exploration have observed the abundance of dead deer and the rarity of skeletons. I have happened upon as many as a dozen dead deer in a day. The fresher of them bore evidence of the recent attention of foxes and crows, and the oldest were still providing food for maggots. But clean skeletons hardly ever occur. If we assume that the ribs and the bones of the legs have been gnawed by the deer themselves, the burial of the rest by vegetation would be a simple affair. In justice to the deer, however, it must be said that this taste for bones is not peculiar to them. Other 
animals which graze on the hills share it, and Highland cattle have been seen greedily chewing at the skeleton of a dead sheep hardly past the carrion stage.

The production of antlers year by year must be of some use to the species which produces them, but the case of some extinct deer suggests that a point may be reached when whatever advantage big horns bring is more than counterbalanced by the drain of producing and the labour of carrying them. In the case of the Irish elk-which was not an elk at all, but a true deer-the antlers frequently measured nine feet across, and weighed as much as from eighty to ninety pounds. When one thinks that this "mighty mass of osseous matter" was thrown out in the course of a few months every summer and discarded every winter, one can readily believe that the sheer uneconomy of it contributed heavily to the fate which befel the animal. 


\section{THE FAIRY RING}

THE warm humidity of the past week or two has proved very favourable to fungoid growths of all sorts. On tree-trunks, on decaying woodwork, and, above all, on old grasslands the proverbial swift maturity of the mushroom family has been claiming the attention of even incurious eyes. On the grass plot beside the door you find in the morning a little forest of brown and forbidding-looking agarics, and could swear there was no sign of them the night before. The golfer, making his morning round, practises driving on the temptingly poised umbrella-heads, and leaves not one in his wake. But next day there are plenty more. He may even find a whole ring of them, many yards in circumference, perfect in its circular drawing, which seems to have come into being by the magic art of some dark agency of the night.

The fairy mushroom ring has puzzled mankind from the earliest times, and it remains in many ways the most interesting of fungus phenomena in this country. At all seasons of the year it is easy to discover on any piece of well-cropped permanent pasture a circular patch well marked off from the rest by its colour. The circle may 
be anything from a yard or less to a hundred yards in diameter, and not infrequently it is broken by what seems to be, and, in fact, is, its coalescence with another ring. Throughout the greater part of its extent the ring is occupied by grass much greener and more vigorous than that of the rest of the pasture, but generally on its outer edges the grass is brown, feeble, and occasionally quite dead. Then at a favourable season, like the present, around the extreme outside edge of this brown part there comes into being, with the most startling suddenness, a circle of mushrooms, growing side by side with a strangely artificial-looking regularity. The pileus, or cap, of each at first is of a brownish ochre in colour, becomes paler with age, and fades to a rich cream before it finally dies away.

How account for a vegetable family endowed with so curious a geometrical habit? How the ancestral wisdom explained it, every child of, at any rate, the last generation knew perfectly. The fairies who lived in subterranean dwellings had certain well-marked habits. On moonlight nights they issued forth and engaged in dances on the green, linking hand-in-hand and tripping it round a circle. Very naturally, indeed, the grass refused to grow on a circle trodden by such elfish feet, and no less naturally a plant which formed the favourite throne of the elf-a plant itself of elfish nature, since it grew without seed-selected that particular place for its development. In short, the ring mushrooms grew out of the footprints of the circle-dancing fairies. Thus the brown 
ring of withered grass and the ring of fungi were both explained in the most satisfactory way, and nothing remained to account for but the verdure of the grass enclosed in the space within. And what more simple? All dumb animals have a special knowledge of, and a deep respect for, the denizens of the nether world ; and the sheep, recognizing the ground which the fairies had traced out as their own, took great care not to trespass upon it. Thus everything was clear.

The humdrum botanist, dissatisfied with these explanations, has formulated certain others of his own, and if you care to believe him the mystery is accounted for in a way something like this : The fairy ring mushroom, which he prefers to know as Marasmius oreades, is, like all others of its kind, parasitic in its nature. It cannot extract from the soil or the air the material necessary for its existence, so it gets what it requires from the decaying substance of other forms of vegetation. Also, like others of its kind, it shows above ground only its spore-bearing parts, the equally or more important part of its body, the mycelium, remaining out of sight. Now, suppose that a Marasmius has begun to grow from a spore suitably placed in meadows or pasture soil. Its first growth is a small circular patch of mycelium, which closely invests the roots of the grass, and these, as a consequence, either become very unhealthy or die. In due time, what is popularly known as a mushroom grows from the mycelium and sheds its spores abroad. This is the beginning of the fairy ring. Its subsequent 
development is just an extension of the process: The mycelium exhausts the ground which it occupies, and therefore its further growth must be outward. It follows that in its second stage there is a small circular patch of exhausted ground surrounded by an outward-growing circle of living mycelius. This in turn exhausts its grounds, and continues to grow from its outside edge into the unexhausted soil without. The circle of growing mushrooms and the circle of withered grass are therefore explained, and all that remains to account for is the verdure within. And this is explained by the fact that the outward-growing mycelium, developing from its outside edge, must always leave behind it a mass of mushroom substance, which, since it has nothing to live on, dies and decays. Thus the mushroom, which begins by impoverishing the ground it occupies, ends by enriching it with a manure opulent in the most valuable nitrogenous properties.

It will be seen from this that the fairy ring is a growth-it may, be a growth of many years' endurance; and sometimes the green circle becomes so extensive that, if placed on a hillside, it may be picked out at a great distance. But the circular form is not always observed. Sometimes, as has been said, two growing circles meet, and as they cannot extend into the ground exhausted of mushroom food by each other, they coalesce and form a figure eight. Where the ground is particularly favourable many rings may thus meet and produce an outline of undulating curves. Again, a growing ring may meet an 
obstacle, such as a stone, and a break in the continuity occurs which is perpetuated in the subsequent growth. Hence the very common occurrence of partial rings or segments.

In this country practically only one mushroom is eaten (Agaricus campestris), but a great many others are equally good as food, some a great deal better; and, strange to say, our favourite is on the Continent no favourite at all, and the Italians, who are the greatest fungi-eaters in the world, refuse to look at it. Among the neglected, but edible, British species is the Fairy Ring mushroom. One of the greatest authorities on the subject says that "when of a good size and quickly grown it is perhaps the best of all fungi for the table, whether carefully fried or stewed with an admixture of finely minced herbs and a minute portion of garlic. It is, at the same time, tender and easy of digestion, and when once its use is known and its character ascertained no species may be used with less fear." The champignon, as the French know it, can be dried and the caps strung on a thread, when the mushrooms remain available for use for a considerable time. But few are those who ever care to make alimentary experiments with mushrooms, and when it is known how closely the good are resembled by the bad, the prevailing reluctance cannot be pronounced either absurd or unwholesome. 

OCTOBER 



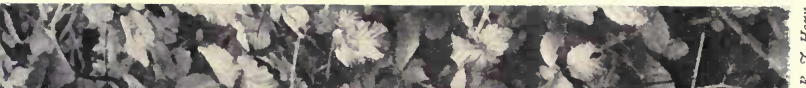

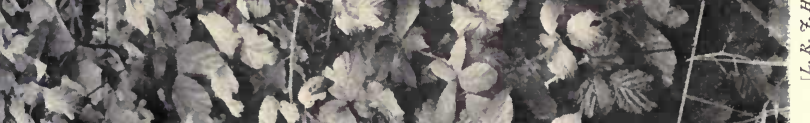

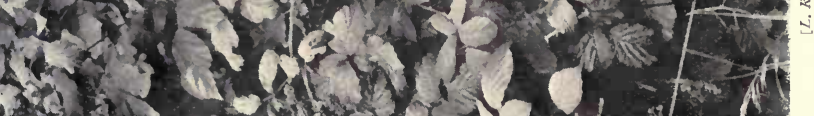

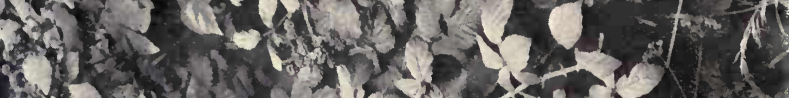
and $7 x$

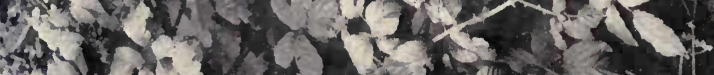

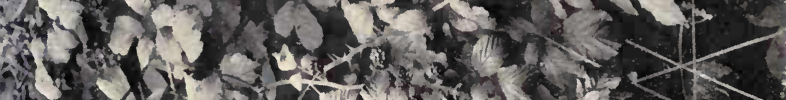

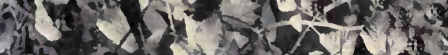

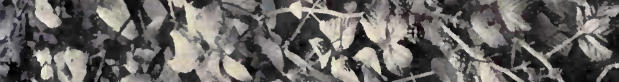

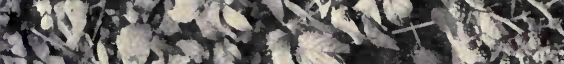

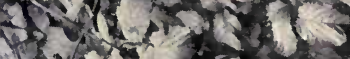

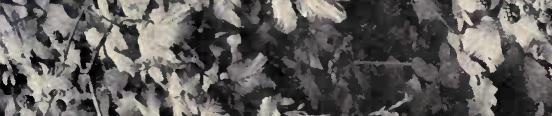

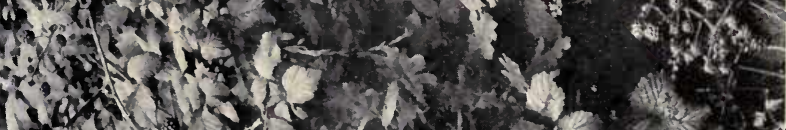

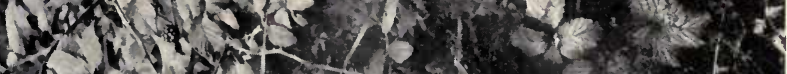

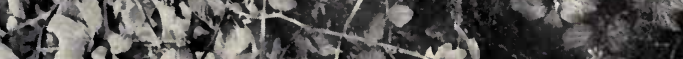

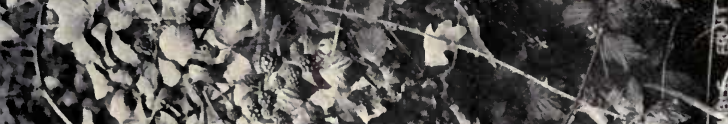
Non,

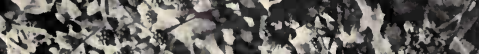
a 17 a.

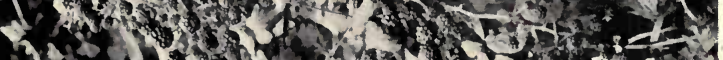

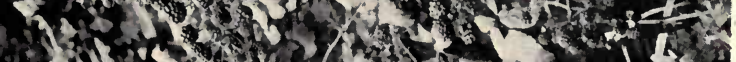

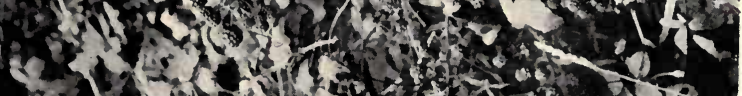

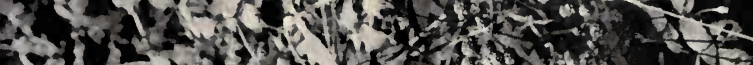
-3) 


\section{THE BRAMBLE}

\section{The Latest Small Fruit}

To mention the bramble is to set up a related order of ideas which vary with the circumstances in which the name is introduced. In rhetoric, and particularly in sermons, the bramble is a symbol of the desolate place, pilgrimage in which is misery. It goes with thorns and briars - the trio of Godforsaken regions. Outside rhetoric all three enjoy quite another reputation. The thorn becomes the hawthorn, a very pleasant shrub whether in flower or fruit, and not at all partial to really desolate places. Briar becomes wild rose, the adornment of the hedges, ready to spring on the margins of rich land spared by the farmer. More than the other two the bramble makes a shape of growing on desolate wastes, but that merely means that it can grow nearly anywhere. The desolate place is not its own choice; it is the place in which we tolerate it most. The places that I associate with brambles are among the pleasantest places I know. Here is one : a road runs almost due north and south, and on its eastern side there is a beech wood. On the westward side the land slopes away from it for about a dozen feet, and 
at the bottom of the slope is a dry stone wall about four feet in height. But you have to look for the wall, for it is completely buried in brambles rooted on both sides of it, and trailing over it. There, facing the afternoon sun, the brambles luxuriate, and are good to look at in all seasons of the year.

In July this bramble-hedge is full of white blossom, but its midsummer appearance is its least attractive. For, though the bramble flower is a rose, it is a poor specimen of a rose, with petals which never quite fill their place, and sex organs which seem to overfill theirs. Late in August it becomes more attractive. Then it shows fruit at all stages of growth, a few rich and luscious black berries, many more a strong, brownish red, still more green, and among them, even at this stage, flowers not a few. It reaches its best about the last week of a bright September, when most of the fruit is ripe and conspicuous. At this stage the berry-picking boys and girls come upon the scene and make the kind of scene dear to Birket Foster's heart, and though blackberrying is not exactly a thing of yesterday with me, I could still enjoy taking a place in the picture on a sunny afternoon. And the charm of the bramble hedge is not all gone when the brambles are picked. The bramble retains a considerable proportion of its leaves throughout the winter, and some of them turn a bright red, and others a vivid yellow. These, with the long red and green stems, make a fine picture against the snow when it comes.

The manner of life of the bramble is not such 
as to supply pleasing analogies for the human moralist. Except when attacked by the human being armed with a spade and bill, it is a success in life, but it succeeds like those people who get on in the world by creeping over the shoulders of their fellows. It has long and tough stems, but they have not the power of standing erect. Therefore, the bramble gets on best when there are either hedges or walls to support it. It has the power of germinating and growing in very poorly lit places, and a common starting-point with it is the shadowy bottom of a hedge. There it sends up its young stem among the hedge twigs, hooking itself on to them by means of its strong barbs. These prevent it from falling back, and in the course of a month or two it reaches the top. Once there it sprawls over the hedge and enjoys the best of the light that falls upon it. Usually there are four or five branches coming from one root, and when they all get to the top of the hedge that part of the hedge is predominantly bramble. But this is only the beginning of the career of a bramble. Its shoots may sprawl for twenty or thirty feet over the hedge, and sooner or later their tips are pretty certain to reach the ground again. When that takes place a strange thing happens. The growing end undergoes a complete change. The leafy growth at the tip vanishes; the tip itself becomes thick, and seems to be pushing itself into the earth. If it is pulled out while the process is still young, it will be found to be sending down roots, and in a few weeks it will be as firmly rooted at this end as at its point of origin. From this new point of attachment with the earth the 
bramble sends out new shoots, which in their turn sprawl over the hedge, and again form new startingpoints. By this manner of growth it often happens that what looks like a great mass of brambles covering a hedge or a wall may be, in strict truth, no more than a single plant. Though many kinds of branches do on occasion root themselves in contact with moist ground, no other British plant has the regularly established habit of spreading itself in this way. Some, however, have methods not very unlike it. The strawberry, for example, sends out its runners, on which quasi-independent plants with both leaves and roots arise, capable of establishing an independent existence. Many others have far-travelling underground stems, which at intervals send down roots and up vegetative shoots. When the underground stem is cut between these, each section goes on as a separate plant. But the bramble carries out the plan in a bold, grasping, and, literally, over-reaching fashion.

Common people speak of "the" bramble, but many botanists would not permit the use of the singular. Some of them have divided the British brambles into about a hundred species, each with its strong point of specific difference from the others in habit, foliage, flower, or fruit. Some of the differences are visible to the most ordinary observation; thus brambles with pink instead of the usual white flowers are common. But most of the differences are slight, and many of them are doubtless the product of the varying conditions in which the plant finds itself, rather than of variation established in the plant itself. Some 
botanists, however, not chargeable with the speciesmaking mania-Hooker, for instance-have admitted seventeen varieties of the British bramble, all well marked and breeding true-that is, retaining their characteristics in changed conditions. It all means that the bramble is a plant of flexible constitution-a fact which should commend it to a greater share of the attention of the horticulturist than it has received in this country. For when you get a plant with a plastic constitution it means that it is one of those that present openings to the improver. The fruit of the bramble is almost universally appreciated, and it comes at a time when small fruits are scarce or wholly absent. Yet, strangely enough, we depend almost entirely upon the wild supply, and a cultivated bramble of any kind is a rarity. There is no reasonable ground for doubting that if the improver took the plant in hand he could, by choosing the best of its natural varieties, by crossing them, and by selection of the individual plants in the progeny showing desirable points, greatly improve it, and make of it a most desirable garden-plant. The bramble has already been hybridized with the rasp, the product of the union being the loganberry, which is larger than the parents, but in other respects not so good a fruit as either. An improved bramble, larger in fruit, tidier of habit, and carrying more fruit in relation to its size, is a much greater desideratum. In America much attention has already been paid to this subject, and several varieties of bramble native to the North American continent have been improved, and have a recognized place in the fruit-garden. 


\section{SEED DISPERSAL}

WE have our seed-time and harvest, but Nature does not so divide the year. She sows her seed as soon as they are ripe, and is doing it now in the most prodigal fashion. A great deal has been written about the ingenuity of the devices she has evolved for the more effective accomplishment of the function, and they are wonderful, indeed, both in their cunning and variety. For the scattering of its seeds the vegetable world has enlisted the services of the animal world. Cherries, apples, pears, plums, berries of every sort are all but so many bribes offered to animal nature as an inducement to perform the service of carrying the seeds. Birds eat berries, and the seeds pass through their intestines uninjured. They are thus carried far and wide. Almost all the fruits which, in popular language, go by that name, have hard or bitter seeds, which the eater rejects; and the service of diffusion is performed for the reward offered. In less pleasant ways animals are impressed in this service. Hooked seeds, of which there are many, attach themselves to hair, and stop there till the outer cover with its attachments is reduced to dust, when the true seed falls 
to the ground, and perchance finds a fit place to germinate.

Many of the devices of mechanics have been anticipated by plants in their efforts to spread their seeds. The dandelion and many of its relatives have invented the parachute, perfect in form, efficient in performance, and by means of it sail their seeds down the wind in the search for new grounds to occupy. Maple, ash, and lime have devised divers shaped aeroplanes by which their seeds are carried, even in still weather, well beyond the shade of the tree that bore them. In the tension produced in the drying pod of broom or furze, and many others of their order, there is a catapult which pitches seeds many yards from the plant on which they grew. Some plants, like the wall toad-flax, have actually evolved methods of planting their own seeds. When the seeds are ripe the fruit stalk moves away from the light, and in this way searches out the shady crevices in walls and rocks, there depositing the seeds in the position best suited for their germination. And so one might go on enumerating devices through many pages.

But when everything has been said about the "cleverness" of plants in providing for the placing of their children in the world, the fact remains that they put their chief dependence on prodigality. Seeds are produced in boundless profusion in order that, peradventure, one may survive. In a season like the present, which has been as favourable to wild fruits as it has been unfavourable to those of the garden, some aspects of this sub- 
ject are forced on one's attention as one walks abroad. The rowans have been particularly beautiful. Many trees have shown red from crown to lowest branch. Probably nobody ever tried to count the berries on a rowan-tree, but it is well within the mark to say that they often run in numbers into the hundreds of thousands. Yet the rowan is quite a third-rate success in spreading itself, and it is doubtful if any particular rowantree has a progeny of one in half a century. In that time it has produced millions of seed, provided the means of covering each with an alluring pulpy flesh, all to this little end. It is difficult to resist the opinion that it would have done as well if it had practised the hardest economy, and thrown all its seeds from it naked and unadorned.

And the rowan is only exceptional in its conspicuousness. I have just been through a little wood of alders skirting a river. The undergrowth is heavy, its most notable components being plants of the umbel family, particularly cow parsley. In a narrow quarter of a mile the plants of this class are many thousand strong, each thrusting up its tall stalk headed with seed. Passing along you can fill both hands with seed at every step, and are tempted to play the part of the sower. If all the united seed produced in this little strip of ground were collected, it would suffice to sow cow parsley over a whole county. But it is a practical certainty that not one seed in this mighty provision will ever get beyond the wood in which it has been produced, and that there will be no more umbels next year than there have been this year. 
The feeling is not easily forced down that the umbels overdo it. Then here is a healthy plant of the humble chickweed. Some one has taken the trouble to estimate its latent progeny, and has concluded that if all its seeds grew up and their progeny were in turn equally successful for just three years, the family of the single original plant would cover all the land space of the globe. Yet chickweed is not much of a success, and would be even less of a success than it is if gardening and agriculture had never been invented. For, though the gardener is its greatest enemy, it makes but a poor show of it where he or the farmer have not prepared the ground.

With all their prodigality and all their clever devices, the flowering plants are not by any means such successful seed scatterers as the ferns which in the modern world they have so nearly superseded. It is probably no exaggeration to say that there are fern spores everywhere. Microscopic in size, they fall in millions from the back of every fertile fern frond, float in the air, and form a part of the impalpable dust which just becomes visible in an isolated sunbeam. In time they reach the earth, and only wait the suitable conditions to germinate. But the conditions suitable to fern germination are relatively rare, and the fern's plan for reaching them is to powder the whole world. Thus if there are only half a dozen spots in a country suitable for a particular fern, that fern will be found in those places (or would if collectors had never been permitted to wander at large). From this it may be inferred that 
in the success of the flowering plants the essential element is not their ingenious ways of securing seed dispersal, for the relatively unsuccessful ferns manage it better, and not the number of the seeds they produce, for, great though that number often is, it is still insignificant compared with the number of the fern's spores. They succeed better than the ferns, chiefly because they send forth their seeds, each provided with a food supply on which the young plant can live during its tenderest infant days. To begin development the fern spore must fall on a damp place. The place, moreover, must be so conditioned that the infant plant, microscopic in size, can almost from its first cell-division draw the material of growth from the environment. At a later stage exceptional conditions are necessary before the conjunction of the sexual elements necessary to start the growth of the true fern from the prothallus, which has developed from the spore, can take place. All those difficulties the flowering plant overcomes by giving its seeds something to start life upon, and during its early days every such plant lives not by its own exertions, but on its inheritance. Thus love of offspring may be said to have had its first hint of a beginning in the flowering plants, and their great success is their reward for inventing it. 


\section{MASCULINE FEMININES}

THE difference between " maleness" and "femaleness" is a subject on which the biologists have long been beating their brains, and the literature of it would almost make a library by itself; but in these days it is open knowledge that the female may develop a good deal of the male. To the naturalist this potency is no new thing. I had the pleasure of examining this week a hen capercaillie shot in Forfarshire which exhibited the almost complete plumage of the cock. But for its smaller size it would have passed for a cock, and only a sportsman quite familiar with the species would have noticed that his quarry was a hen.

This power of the female to develop the secondary male attributes, though usually rare enough to excite interest and surprise, is as widespread as sex dimorphism itself. That is to say, in all species in which the sexes are markedly different, individual females have been found which have assumed the marks of the male. In the days before scientific poultry-raising had been heard of, the phenomenon was common enough in the farmyard to form the basis of a proverb. The henwife cherished some particular hen for a real or imaginary grace of character, and it escaped the 
pot till an advanced age. One morning its mistress was scandalized to hear it crow. If she spared it till after its next moult she found it to assume cock's feathers, and probably wattles as well. Waterton gives a curious case of a hen which assumed not only the plumage, voice, and spurs, but also the warlike disposition of the cock, and which, when opposed to an enemy, would erect her hackles and show fight. The order of birds to which the domestic fowl and the game birds belong is rich in sexual dimorphism. In every one of its species which is polygamous, and that is the large majority, the cock has a much more ornamental plumage than the hen; and in nearly every such case hens have been found manifesting these attributes of the cocks. In the case of the capercaillie, according to Millais, there is one such hen in every two or three hundred killed, but such frequency of occurrence as this is probably rare. It is possible, however, that many cases pass unnoticed. If the male and the female are about the same in size it would be rather remarkable if a case were detected in which the hen had developed a complete male dress, and in most of the cases on record the assumption of male plumage was short enough of complete to attract attention. The difference in size between the capercaillie sexes makes discovery easy, and perhaps accounts for the large proportion of females with male attributes found.

On somewhat similar grounds we may probably account for the fact that it is this order of birds 


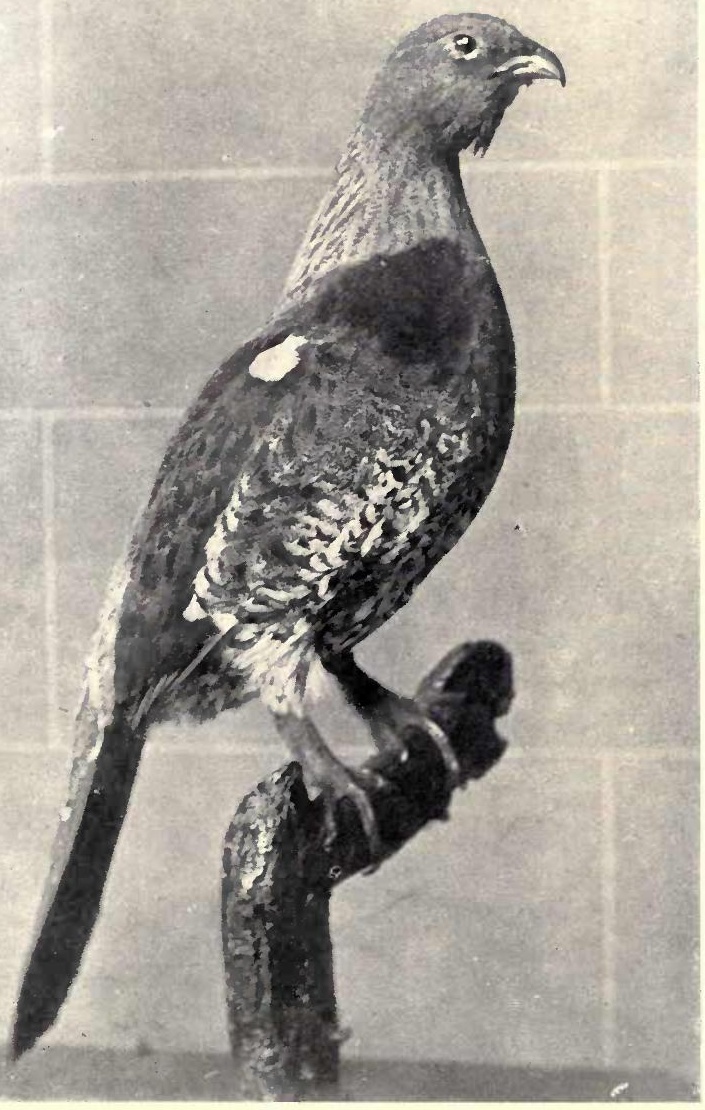

HEN CAPERCAILIE ASSUMING MALE PLUMAGE. 

which has yielded the great majority of examples of females assuming the characters of the male. It happens that the birds of this order, being the best of all food birds, are the most frequently handled; whereas in a dimorphic species which is rarely or never handled, it would be strange if the occurrence were detected. A female chaffinch or bullfinch, for example, might assume male plumage; but if it did not happen to be in captivity, the change could never be observed. But it is certain that the development of maleness in females is not confined to the gallinaceous birds, for a ten-year-old duck has been known to assume both the perfect winter and summer plumage of the drake. Nor is it confined to birds. In at least two species of deer, hinds have been known to grow antlers, and, as everybody knows, something analogous occurs in the human species itself, varying in notableness from the development of masculine mental attributes to the development of so unmistakably masculine an attribute as a moustache or beard, or both.

Occurrences of this sort are of high scientific interest for the light they throw on the problem of sex and sex inheritance. In every investigated case it has been found that the development of secondary sexual male characters by the female is associated either with age or with injury to the primary sex characters. The barn-door hens which assume cocks' plumage are almost invariably old birds which are past laying. In many other examples subjected to examination it is found that the fertility of the ovaries has been destroyed 
by disease or direct injury, and the appearance of the secondary male characters after the ruin of female characters has some important implications.

There is no subject in natural history on which greater battles of theory have been fought than the development of the ornamental and other secondary sex characters of the males of dimorphic species. Darwin explains them by his famous theory of sexual selection, which, in the case of birds, attributes to the female an rsthetic sense which the male must satisfy. By the constant selection of the males best capable of gratifying this sense, the gorgeous tails of the peacock and argus pheasant have been built up. In this theory the characters are developed in the male alone, for in him alone is there a call for them. Another theory which has somewhat more favour to-day assumes that the male of, say, peacock or pheasant represents the normal race development which would have resulted in equally beautiful members of both sexes but for some inhibitory force operating on the female alone. The inhibitory power is a variation which natural selection has fixed in the females by eliminating those that did not possess it-conspicuous females falling easy victims to enemies when tied to the nest by the duty of incubation. In support of this explanation it is possible to cite many examples, all to the purpose that the birds in which high beauty is confined to the male are open nesters; whereas in the case of hidden nesters-the kingfisher is a case in point-both male and female have evolved in beauty equal in extent and kind. 
The bearing of this theory on cases like that of our masculine-feminine capercaillie is obvious enough. These cases show that the secondary male characters are undoubtedly transmitted to both sexes, that they exist latent in the plain female and may begin to develop any day. So long as the creature remains a full female they remain latent, but whenever her "femaleness," either by accident, injury, or original sterility, becomes incomplete, the latent begins to make itself patent. There is experimental proof, however, that by certain means not involving direct sex injury the latent qualities can be stimulated to activity. Dr. Archdall Reid mentions certain emulsions which, when injected into hens, supply the necessary stimulus, and cause them to develop the combs, wattles, and warlike disposition of cocks. He does not mention how their laying powers are affected. The broad fact is that in nature, when a female begins to assume the attributes of the male, she has ceased to be a female in the complete sense. 


\section{THE SWALLOWS}

By this time of the year the vast majority of the birds have completed their family business, and many of them have even begun to flock. That means that their summer economy is at an end, and though possibly the best of the summer is still to come, that their winter economy has begun. They are seeking food and keeping company in the way they will adhere to till spring again arouses in them the instinct which breaks the flocks up into pairs. But while this is true of starlings, pigeons, some finches, and many wildfowl, it is easy to observe that the swallows are still as busy with family-rearing cares as they were in the month of June. Find the nest of a house-martin under the eaves of some cottage, and half a minute's watch will prove that the birds are still coming and going with their characteristically impetuous rush of wing, bringing insects to feed a brood of young. They are at it all day, and their energy is unabated after months of toil.

Swallows raise two broods every season, and it is, of course, the second brood that is engaging their attention just now. But why should they take so long about it? Many birds raise two 


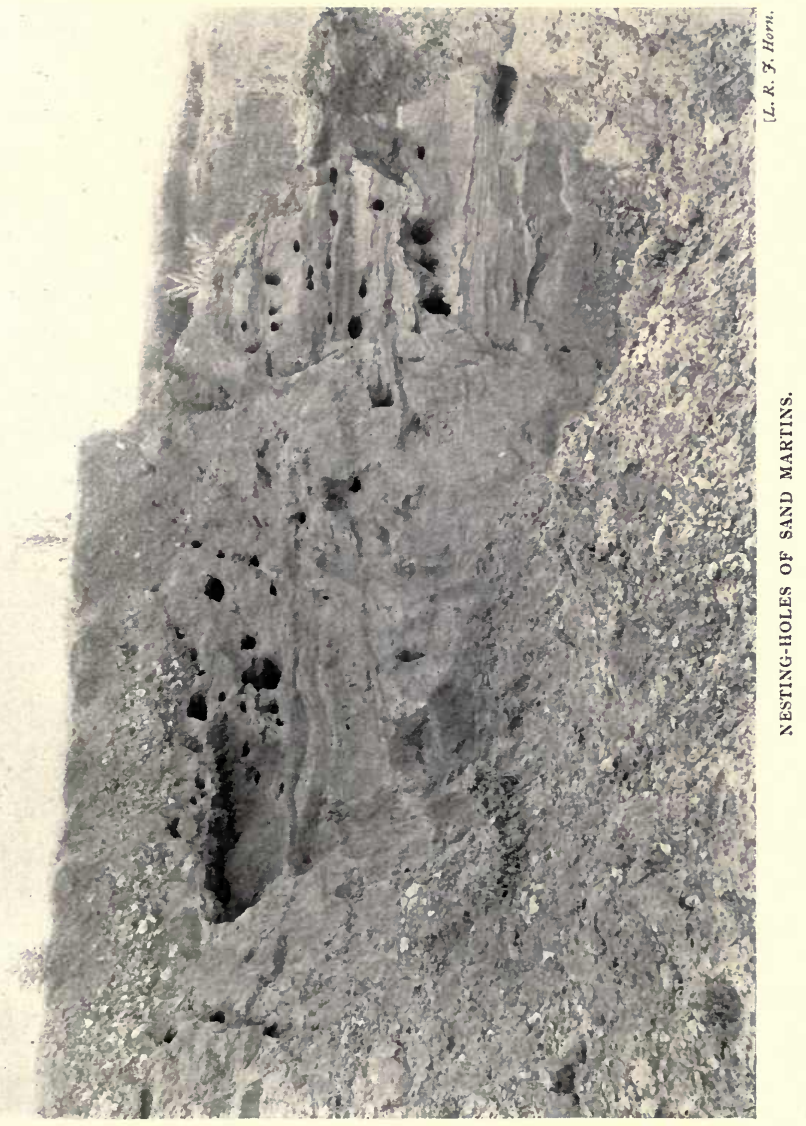



broods and have the whole process completed before August begins, while it is no uncommon thing for swallows to be hard at work right up to the end of September. Sometimes, indeed, the second brood is unfledged when the time for the migration comes round, and in such a case as that the old birds have been known to go with their kind, leaving the young to die of starvation in the nest. The fact gives one a vivid sense of the impelling character of the instinct which can overcome even that of parental affection, so very strong in all birds; but the prolongation of the nesting season remains unexplained.

It has been suggested that the explanation may be found in the fact that the nest-making process in all three species of swallow is a very prolonged and elaborate affair. This is true. The sandmartin, the weakest of them all, drives a tunnel often four or five feet long into banks of sand sometimes approaching rock in its compactness. When it is remembered that all this is accomplished with the soft and short beak of an insect-eating bird as the only tool, it is possible to realize the magnitude of the labour. Nor is the driving of the tunnel the whole work, for at the end of it the martin builds a nest which, though not an elaborate piece of architecture, contains a large mass of fibrous and feathery material which takes time to collect.

The nests of the swallow and the house-martin are of a totally, different design from that of the sand-martin, but each in its building takes up much time. Both the saucer-shaped nest of the 
swallow and the sphere-shaped nest of the housemartin are composed of finely worked mud or clay. This clay the bird collects in suitable places in mouthfuls and kneads into cohesiveness with its own saliva. From the very nature of the case it is impossible that much of the building can be advanced at one time. The foundation layer is attached to wall or beam by nothing but its own cohesiveness, and till it is rigidly hard and dry no more can be done. It is the same with every successive layer; it must dry before the next can be attached to it, otherwise the whole fabric would be brought to the ground by its own weight. In moist weather the drying process must be slow, and in the best of conditions it cannot be fast. But, then, it must be remembered, a very large proportion of swallows of both sorts do not build their nest every year. They merely repair the old ones, and if they were as speedy brood-rearers as some of our native birds, the double brood of these at least would be already on the wing. But a house-martin's nest, which I have under observation just now, was found by the tenants on their arrival in an almost perfect state-so far, at any rate, as the external masonry was concerned-and, nevertheless, the second brood is not yet far advanced.

Few of us in these days have ever an opportunity of seeing the nest of either the house-martin or the swallow in what may be called their natural conditions, and for the very good reason that the vast majority of them have adopted conditions which, whatever the birds themselves may think 



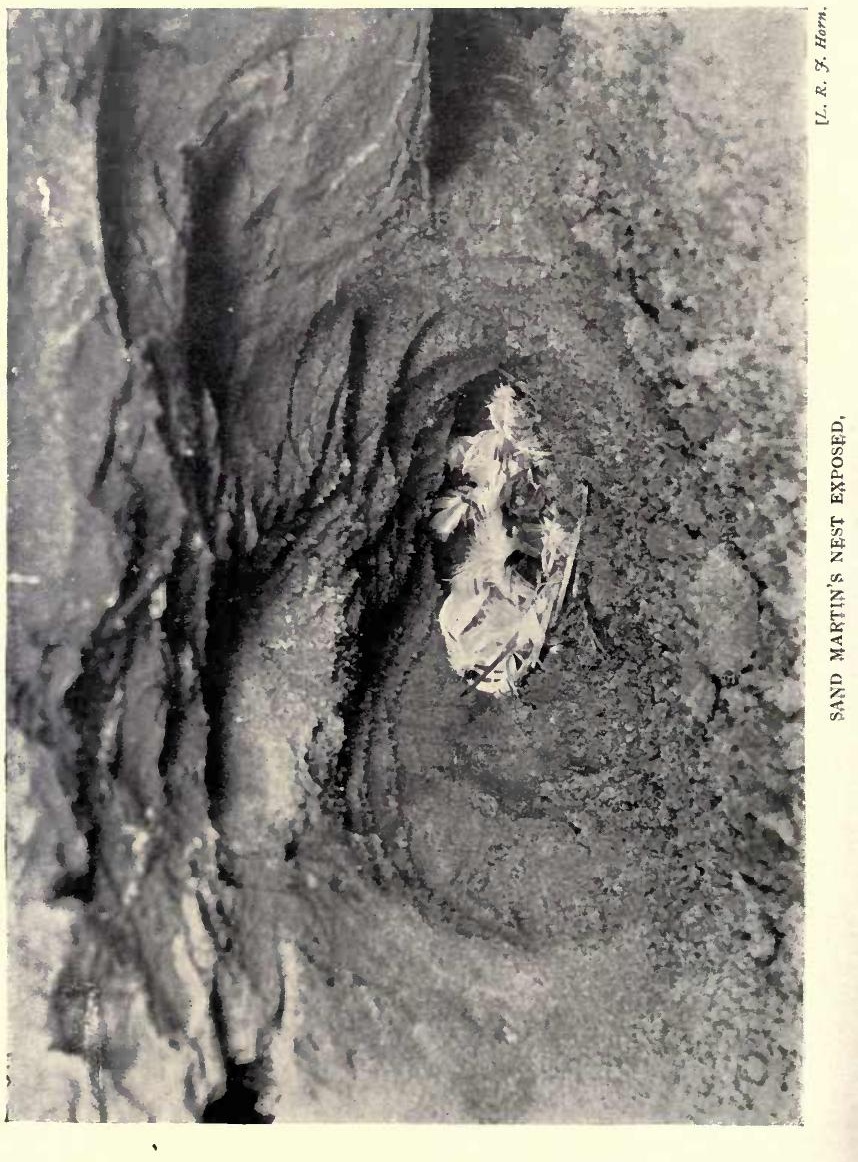


of them, are to us artificial. But it adds wonderfully to one's interest in the birds to find their nests built as they must have been during the long ages before human dwellings dotted the land, and I happen to be very familiar with a piece of coastline on which the sight may be witnessed summer after summer. It is a cliff on the northern shore of a sea loch, blessed therefore with a southern exposure, and penetrated by half a dozen considerable caves. These were hollowed out by the sea in a past age, but an uprise of the land has lifted them about forty feet above sea-level, and interposed between the cliff-foot and the beach a broad strip of dry. land cumbered with fallen rocks. The swallows build in the caves, attaching their clay structures to the roofs, and in the case of at least one large and vaulted cavern it is possible to believe that they were tenants of these roof-sites when the floor was used as the dwelling of primitive man. On the face of the cliff outside a much more numerous colony of house-martins have their abodes, their globe-like nest being attached to the under angles of the ledges.

But the chief interest of these neighbouring colonies resides in the illustration they afford of the swallow mind and its power of recognizing essentials. In the course of its long evolution the swallow formed the habit of nesting in caves, but when it found the first open barn it was able to recognize that here were all the essentials of a cave. So now we have swallows using every manmade cave to which they can find access. Barns with open doors, grain lofts with a broken win- 
dow, old mills with the rafters conveniently exposed-they are all caves to the swallow, giving the needed elements of a roof overhead, with convenient irregularities for the attachment of nests where cats and other creeping quadrupeds cannot approach. And as the interior of a building is a cave to the swallow, the wall of a building is $a_{4}$ cliff to the house-martin, and the overhang of the roof or the corner of an elevated window represents the ledges.

There can be no doubt that the power of recognizing that a made interior is as good as a cave, and that a wall is as good as a cliff, has proved of the greatest utility to these two members of the swallow family. Over the greater part of Britain natural cliffs are of rare occurrence, and natural caves, even if we include great hollows in trees, are rarer still. If, therefore, the housemartin and the swallow were confined to them for nesting sites, both species would be of exceedingly local distribution. As it is, they occur in practically every district of the country, except in the high altitudes. It may be said, then, that the human settlement of the country has been the occasion of a great expansion of the numbers of the swallow tribes-one point to set on the credit side of our account with nature and against the bill of extermination for which our responsibility cannot be denied. 


\section{THE STARLING IN AUTUMN}

AMONG the many characteristic things about the starling nothing is more characteristic than his feeding manners and customs. A blackbird feeds like a conscious pilferer. Even when he is innocently looking for slugs among the gooseberry bushes he dodges in and out in a furtive fashion, and is off at the first alarm. The sparrow has no doubt whatever that he is a thief, and glories in his shame. But the starling has a large and homely confidence that all sorts of food are meant for him.

One best sees this trait of starling nature in the winter, when playing the charitable part to the birds. There are all manners of approach to the spread feast-the swift come and the swift go of the mavis, the reconnoitringly managed side approach of the chaffinch, the studied stage by stage advance of the greenfinch. The starling's manner is to walk right up with a "thank-goodness-breakfast-at-last" sort of expression, and begin without any airs or graces to tuck in. He is not quarrelsome, and does not deny other birds a share, but, nevertheless, he is very sure that the deposit laid down is meant for him. And 
when he gets his upper mandible over a fragment of desirable substance-well, the fragment is his.

At present little flocks of starlings are feeding on the fruit of the elderberry tree, and it requires a bird of the starling's serenity of assurance about his place in the world to do justice to such a feast. The cymes of elderberries are always placed on the extremity of branches, which are usually slender and often pendulous. In fact, they form the extreme outer surface of the mass of the tree. It follows from this disposition of the fruit that it is not very easily got at. It extends beyond all the good perching branches, and as the berries have to be picked off one by one the job of clearing them is one of time and detail. The starling manages it with much wing work. He descends on the tree with a splash, and after much floundering gets a hold on among the leaf-stalks. As he feeds his footing is constantly giving way, and before a cluster is cleared he may be resting on outspread wings, deliberately using them as supporting limbs. A dozen starlings feeding in this way in an elder-tree make as much noise as a cat among the ivy, and if there is a cat in the neighbourhood he finds the watching of them a frightfully exciting thing. The starlings are always falling and always recovering themselves, and pussy is plainly filled with a hope, against her better judgment, that one of them will fall right down. But, of course, one never does.

It is part of the starling's great confidence as a feeder that he is almost the only bird in this country which has the audacity to descend upon 
the backs of sheep and cattle in search of food. Two or three of them may often be seen at one time on the back of a cow searching the hide with great care from head to tail, and picking up many trifles of insect-life which the cow is well pleased to part with. Sheep appear to provide even better fare, no doubt because they afford better cover for game, and the starling goes about the business of hunting with a thoroughness all his own. He prefers sheep lying down, but if the animal rises while the bird is still at work the starling does not fly away. $\mathrm{He}$ assumes a balancing attitude, like a boy in a cart which has begun to move, and then resumes operations when the sheep comes to a standstill.

Most birds mix up their feeding and their playing, and are at both nearly all day. Like the human animal, the starling keeps the two functions quite apart. He has his working hours and his hours of recreation, and that is perhaps the reason why, when he is at work, he makes such a serious business of it. At present in his daily programme work is intermitted for at least two hours every afternoon, and these he devotes to improving conversation and music. One of these starling conversaziones is as worthy of study as any function of bird-life. The birds seem to talk and to take great pleasure in one another's company. I have been watching one such gathering in a half-bare pear-tree, and without the aid of a glass it is possible to see that the feathers of the throat of every bird are in motion. With a glass one sees that the birds are going through all the motions 
of quite ecstatic song. The head is thrown up with the gesture of a prima donna, it moves from side to side, and the bill opens and shuts with the play that should attend copious utterance. Yet not a sound is heard. Get a little nearer and you seem to be approaching a concert in which castanets are the only instruments employed. The noise is caused by the rapid opening and shutting of many bills. A little nearer still and you get within musical range, and find that the starling is quite a fine musician in intention, though his powers of execution are small. $\mathrm{He}$ has a good ear and a fine sense of rhythm, and, in fact, everything that goes to the making of a first-class singing bird, except size of voice. The voice is hardly larger than that of a competent cricket, and a whole flock cannot make so much sound as one little wren. But, then, the song of the wren is a marvel in the magnitude of its outburst, even if it were not contrasted with the tininess of the bird.

There is, however, one very wonderful thing about the starling's song. As you listen to it, many of the notes and phrases seem familiar in a faraway fashion. One of the performers has got the notes of a blackbird, and he goes over them again and again. If the listener knows bird notes well he can pick out in the concert those of almost every songster of the grove, but always uttered as if the performer, in the language of the nursery, were "saying it little to himself." The truth is, the starling is a conscious mimic. He has notions about music, listens appreciatively to the song of 
other birds, and in his home-parties tries to reproduce them, and with remarkable success in everything but volume. He does not even confine his mimicry to the songsters of the grove, for he tackles such a sound as the cry of the curlew, and at ten yards his effort distinctly suggests a curlew half a mile away.

But to a great extent these afternoon assemblies seem to be devoted to gossip. Seated among the branches, the birds appear to talk to one another in a fashion which might be pronounced quite decorously polite, so low are the tones, were it not for the fact that they all talk together. And the idea that they are conversing receives rather a rude shock at times. What looks like conversation when the talkers are informally grouped among the branches looks like something quite different when, as sometimes happen, they select as the scene of their gathering the telegraph wires. Here they sit in rows, with gaps separating little groups, and almost always with the heads looking one way. In its general appearance an assembly so perched suggests a comic artist's effort to caricature a piece of music, and especially is this the case when there are four or five wires. But the birds go through the same performance as on the tree, chattering away as fast as they can find utterance, but obviously not chattering anything in particular to one another. Like mankind when they have nothing to do, they like to do it in company, yet each individual does it as if he were alone. 


\section{A BEAUTIFUL CHARACTER}

IN the article on earwigs in the Encyclopadia Britannica it is stated that scarcely any naturalists have made the insect the object of study. If, therefore, you wish to seek renown in a virgin field, here you are. Go in and find out all about it. I have made an effort myself, without, however, finding out enough to discourage anybody. I attempted to tame an earwig (by the kindness method, of course), but found him strangely unresponsive to affection. In fact, but for one crowded minute of glorious life he sulked during the three whole months I held him in captivity.

The episode alluded to occurred when, with the idea of cheering the captive up, I introduced a spider to his domicile. I hoped that they might take to one another and be friends, but from the first they regarded each other with settled suspicion. The spider, a fine hearty specimen of the domestic variety, with good muscular development, settled down at once to work out an enveloping movement. With a sidelong gait suggestive of a high-spirited horse, he moved around the earwig, which at the same time rotated on its axis. Once or twice the newcomer threw out a 
silken lasso, which the earwig cleverly avoided, and soon it became evident that there was to be a wrestling match under catch-as-catch-can rules. The end came with lightning speed. While the spider was still making pretty prancing motions, the earwig rushed in, seized him in a half-Nelson clasp, and, doubling up his own abdominal region, scorpion fashion, administered three swift and deadly crunches with his anal pincers, and it was all over.

As I am easily discouraged this display of ferocity on the part of my pet brought my taming experiment to an end. To another, as Don Quixote says, is reserved this great achievement, though I dare say I can claim to be the first since Adam to try if the thing could be done. Nor was the experiment altogether without results, since it proved that the earwig's pincers are not, as some naturalists allege, mere ornamental terrifiers, but genuine and even formidable weapons of offence.

If any one wants to go in for earwig-taming, now is the time. Lion-taming is sort of played out, and besides lions are not easily got. With earwigs it is otherwise. Take the bark off any paling post at this season, and you may capture a score. Shake a sunflower and out they will drop by the half-dozen. Above all, look in unprotected dahlias, and you will find the game abundant and strong on foot. For the earwig is as dainty a feeder as the object of a poet's vision. As long as he can get flowers he will have nothing else. In his own way he is a downright æsthete.

It will no doubt be said that the earwig is a 
repulsive, abominable creeping thing, and that its ugliness sufficiently explains its neglect by the naturalists. But that is all a mistake. It is not half so repulsive as the cockroach, which has received any amount of attention and is invariably presented to beginners in the science of entomology ; and besides-and this may be said to be its trump card-it has a beautiful character. When a man says that he married his wife for her beauty of character, it is generally surmised that the lady is plain. The earwig undeniably is plain, though it has its points of prettiness. Its wings, for example-which so few suspect, tucked tightly as they are under their little coversare both delicate and beautiful. But its moral charm is its real strength.

The vast majority of insects have not the rudiments of a moral character, which, the psychologists are agreed, arises out of the maternal instinct. They drop their eggs in more or less appropriate places, and let their offspring look after themselves. Chuck and chance it is their motto. Ants and bees furnish a doubtful exception to the rule, for though they take great care of their young, the ants and bees that do the caring are not the parents of the young they look after. What they. exhibit is indeed not the maternal instinct, but the social and economic instinct, and their care is not affection but interest. The earwig, on the other hand, goes into the business of maternity with all the beautiful solicitousness of a bird. She broods over her own eggs, and if they are disturbed she will collect them and stand on the defensive with 
a courage equal to that of the barn-door fowl. When the young are hatched she tends them and leads them in the way earwigs should go.

Now this is surely a point of contact for the sympathetic and all who like to encourage virtue, and one fitted to diminish prejudice. Other positive virtues will almost certainly reveal themselves to research, for it is impossible to believe that the good mother is good in no other respect. At present, the earwig's other virtues remain uncatalogued. It feeds robins, but it doesn't do it willingly; and centipedes which have not yet revealed a single good quality do as much. But if the catalogue of merits is short it may be said that the earwig's demerits are in the main mythical.

The first is its plainness, and many people who would not themselves do much in a beauty competition would crush it for its appearance. But it must be confessed an animal is just as ugly as it looks, and the earwig is deficient both in line and colour. The second demerit is that it enters people's ears, but how this story originated is one of the mysteries. There is absolutely not one authenticated case of the slandered insect having invaded the human ear. If an earwig were to find itself on the side of a human face, disliking bright light as it does, it would make for the nearest cover, and it might enter the aperture of the ear, which from its point of view would seem to be a kind of cavern. But earwigs do not get upon people's faces, and their strongest instinct is to keep out of the way.

So completely has the search for evidence of 18 
an earwigging propensity broken down that some naturalists have tried to explain the name as a corrupted form of earwing. The wing of the earwig is approximately ear-shaped, and fits into the explanation very well. But, unfortunately for the theory, the name occurs in languages in which the confusion of terms is impossible and so remote in their locus that they cannot have copied one another. Thus in Latin it is Auricularia, in modern European languages it is Perce-oreille, Ohrwurm, Oorblazer, Ormask, Oerentvist, Gusano del oido, etc., while in Armenian it is a word meaning ear-enterer. The inference is that somebody who lived before the building of Babel had an earwigging experience which is commemorated in world-wide nomenclature. Possibly it was Eve. No garden has ever been free from earwigs, and doubtless they had their place in Eden. Eve, moreover, was full of curiosity, and brought worse than earwigs upon her head. If she was the person who had the experience she would, as a matter of course, tell Adam all about it and make the most of it, and probably more than the little incident was worth. He would be glad to hear about it, for it is on record that he named all the beasts, and he must have been hard put to to get distinctive appellations for the insect hosts.

It is worth mentioning that, though nobody has ever been found who had an earwig in his ear, the remedy for the emergency is ready and easily applied. It is only necessary to blow tobacco smoke into the cavity, and the earwig will come out. The experiment may be made on a dahlia 
or a sunflower, and if there is an earwig lurking in the recesses he will emerge with a haste which bears eloquent testimony to a sense of smell cultivated on nothing grosser than floral perfumes. 



\section{NOVEMBER}





\section{A QUESTION OF CHOICE}

THERE is a very laconic entry in Gilbert White's Nature calendar to the effect that in November "bucks grunt." Any one who has the privilege of exploring a deer forest at this season will admit that bucks do grunt, and a good deal more, for they roar and bellow in a fashion which may be a little disturbing to weak nerves. The truth is, the great heart of the stag is just now filled with love, which, as is common with male animals all the world over, manifests itself first in a prodigious passion of hatred directed against all of his own sex.

It is not the love of the stag, however, so much as the love of the hind that I am moved to write about just now. I have just been reading a book by a lady who traces most of the evils of our evil world back to the fact, real or assumed, that the human female has been deprived of her right to choose her mate-a right enjoyed by the female of all the higher animal races. She took deer as a type, and her view of the case is that the males fight furiously, and that the females who have been spectators of the combat and judges of it choose the better fighter as consort and king. Thus the high quality of the breed is maintained, 
thanks to the good sense and fine judgment freely exercised by the hinds.

But is this what really happens? I have no very exhaustive personal knowledge of deer forests in November, but recently I had some talk with one who knows them all the year round, and his views and those of the lady do not harmonize. In November stags begin to collect hinds, and those graceful ladies are not allowed much choice in the matter. When a stag has buffeted a few of them into his train, and still wants more, he casts his eye on the bevy of beauty another stag: has gathered and fights him for them. If he gets the better of it in the fight, he drives the beaten stag away and takes possession of his wives. Their leave is not asked. If they show a disposition to follow the beaten husband, the victor simply jostles them into his train and shepherds them with jealous eye. In this way a first-rate fighter gathers a fine harem; and ought to be happy; but he is not.

"Of all the miserable animals in the world," says my friend, " a stag which has gathered a large harem of hinds is the most wretched." Let us suppose that his collection is complete. His success means that a great many other stagsmettlesome creatures, but younger and lighter-are left in desolate bachelor state. But they do not accept that condition as inevitable. They hover near the coveted collection and keep its owner in perpetual hot water. One of those interested onlookers appears on a neighbouring eminence and utters a challenging roar. He comes nearer, and, 
by way of defiance, sweeps his antlers scythe-wise through the heather in front of him, leaving a mark in torn-up heath and peat which survives the season. When this insolence becomes unendurable the master of the herd rushes out to punish it. There may be a fight. In any case, his eyes are for some minutes off his charges while he is engaged chasing the intruder away, and in those minutes complications arise.

Another young stag has been watching events from the opposite side, and as soon as the attention of the dominant one is diverted he approaches, bold as brass. If there is a fight going ahead he descends upon the packet of hinds and begins to cut out a few for himself. It commonly happens that they are by no means loth to go, and when the lord of the lot returns it is to find two or three of his wives trotting away with a four-legged Jock o' Hazeldean. With a roar he rushes after them, and probably the thievish young male bolts with all possible speed. If he stays to make a fight for it the ladies will wait for the upshot, and only accompany the victorious old stag when he indignantly prods them back to join his other wives. They go, in deference to superior force, casting long, longing looks after the younger stag the while.

This encounter over, this infidelity punished, the stag in possession returns, only to find another episode of the same sort in progress. An interloper, perhaps two of them, are among his wives inciting them to elopement. His rage flares up again, and he dashes at them and after them and 
drives them forth; and when he returns, weary and moist with sweat, though he may have the finest head in the forest, he is not the prettiest stag. He holds his harem as an Arab chief does his-by prowess, and not by consent. For many days he is kept trotting round his hinds, warning off rivals, and not till he has beaten all the bachelor stags in his district does he get anything like peace. Even then he is rather more of an angry shepherd than a husband. The envious ones will keep showing themselves. The light-headed feminines will keep looking longingly at their trim figures, and if they were not watched it would be "o'er the border and awa" " with some of them. Long before the time arrives for the breaking up of the association the great stag is worn to a shadow, largely by the furious labour required of him to beat off encroachments from without and to repress infidelity within.

The whole theory of female choice in the animal world has fallen a good deal into disrepute, and, if it were well established, would not afford a very good basis for an argument positing its superiority. For it will be noted that most of the cases on which it rests are cases of polygamous animals. Five-sixths of the cases on which it rests are taken from the order of the game birds, which, from the peacock to the blackcock, make great courtship displays before the females, who are supposed to choose the male with the finest plumage show, or the best dancing style, or the finest gift of strutting. If they do make the choice, it can hardly be called 
a good one when so many of them settle upon the same mate. In fact, the theory makes polygamy a feminine invention. It shows the feminines so determined to have the best that they sink every other consideration. They would rather have a twelfth share of the best than a monopoly of a second-rater. "But the facts of the deer forest suggest that if the ladies of the herd had their own way they would spread their favours much better, and, instead of crowding upon the best fighter, would show their appreciation of other qualities. 


\section{BIRDS AND STORM}

ON days of high and blustering wind most of the birds disappear, and it would be a puzzle to the most competent of field naturalists to say where they have gone to. He can do little more than suppose that they are sheltering themselves in their roosting-places, and as a rule these are very hard to discover. There may be little or no concealment about them, but, like most other living creatures, birds become wonderfully near to invisible when they remain still. A dozen birds in a leafless tree can easily evade even a searching eye by remaining motionless, and what is true of birds in trees is still more true (if that is an allowable expression) of birds on the ground. There even large birds, and birds which would be pronounced conspicuous, merge into their surroundings in a way which usually astonishes those who discover without rousing them. Thus I recall how on one occasion when walking through a wood, a friend pointed out a small object and asked what it was. It was actually the eye of a sitting hen pheasant, which he was looking at without seeing. Most animals, birds excepted, know, or act as if they knew, this secret of invisibility. Thanks to their flying powers, which can so swiftly 
take them out of the way of most of the natural dangers, birds put their dependence rather upon their mobility than upon the concealment they could effect by keeping still. But in stormy weather they keep to one place, and profit by the fact that when still they vanish.

There are two or three groups of birds, however, to which nothing of this can be said to apply. The gulls and the members of the wading tribe which frequent the shore do not retire to roostingplaces in stormy weather, and some of their most interesting motions can then be observed. To take a familiar example from among the last, the flocks of ringed plovers, popularly called sandlarks, keep the shore in all weathers, and some of their actions in high wind are curious and interesting to watch. At such a time it is an easy matter to approach a flock feeding on the flat sand left by the tide to within a dozen yards. When a human intruder upon their domain comes within that distance of them, the flock of little bullet-headed birds, as if moved by one will, will turn and run down the wind with amazing speed, and at the end of a dozen yards more will wheel with a simultaneity and precision never equalled by troops on parade. In the curious, swift run, in which the legs are hardly seen, and in which no motion is visible but the rapid forward motion of the body, and still more in the abrupt wheel round to the wind, with which it ends, these little plovers irresistibly suggest the action of certain mechanical toys. All animal motions are in a sense mechanical, but I can think 
of no motion which is so completely machinelike as this one. It is only to be seen in a fairly strong wind. At all times the ringed plover is a fast runner, but its speed is greatly accelerated when it runs down the wind, and the swift turn at the end of the run is, of course, meant to bring the lie of the feathers round to the wind before they are ruffled. For this same reason the birds always feed up the wind.

Some of the most beautiful of the flight motions of the gulls, particularly of the larger species, are seen in wind. For long spells they can be observed apparently enjoying their powers as aeroplanes with no other purpose than enjoyment. Facing the wind, with the wings raised to a slight inclination, they will make an effortless ascent into the air. On these occasions there is no flight motion in the wings, no motion of any sort save a just perceptible quiver, of the tips of the quill feathers, which probably assists in the balancing. Now and again a jerky downward move of the whole body indicates that for an instant the balance has been disturbed. After a spell of this windsustained hovering, the gull, turns and sails swiftly down the wind, then turns again and repeats the upward gliding performance. Strong gusts give every kind of variety to the planing, and in abrupt surprise gusts the birds often shoot into the air on an almost vertical line. But they never, like the airman, lose control and come to grief with a fatal downward plunge.

It is not all aeroplaning with the gulls in stormy weather. In all states of the weather they have 
a habit of resorting to some bare spot, such as the highest part of a grass or stubble field, and preening their feathers there in very quiet and undemonstrative company. When the wind is very high, these chosen spots are never without their congregation. Hundreds of gulls may be seen in such a place sitting absolutely motionless for hours on end, with all their beaks pointing as accurately in one direction as if they were so many magnets drawn to a pole. In very windy weather there is no doubt that gulls, in 'common with all shore birds, have to get along on seriously diminished fare. Their best feeding-ground is the strip of shore just uncovered by the tide, on which small crustacean life is yet unhidden. When the waves are dashing savagely on the strand, and racing far up it with every fall, every condition is against successful hunting.

One of the popular names of the missel-thrush is the stormcock, and it has received it in deference, it is said, to the fact that, unlike the other birds of its family, it sings in winter, and is not silenced by stormy weather. There is a courageous robustness about every action of the missel-thrush which claims admiration, but I rather suspect that it does not sing very often in storm. At any rate, I have never heard it. It is called missel-thrush because it feeds on the mistletoe berries. There are, however, large parts of Britain-Scotland among them-where the mistletoe is never seen save as an import, and there the familiar name itself is a misnomer. In stormy weather those three familiar birds of the garden-the missel- 
thrush, blackbird, and mavis-can generally be found skulking in sheltered places, such as the leeside of walls, searching for the elusive worm, but when the high wind is accompanied by rain they vanish like the lesser feathered people. The smallest of British birds is the least depressed of all by bad weather. On a day of hard frost and nipping wind the little wren will suddenly emerge from a heap of brushwood, and, sitting on its topmost twig, pour out a burst of song which would be considered splendid in volume if it came from a bird ten times the performer in weight. But wee Mr. Wren is also the greatest skulker of all. Nearly all his time is passed creeping about sheltered places looking for the small game fit for his small crop, and his emergences into the open rarely last for more than half a minute at a time. He appears to feel it incumbent on him to let the world know at intervals that he is not a mouse, much though he may look like one creeping about the roots of the hedge. 


\section{THE FLOCKING OF THE BIRDS}

THE passionate devotion of birds to their young and the intensity of the maternal instinct make a favourite theme of the sentimental writers on natural history, and one not despised by writers who keep their sentiment well in check. Curiously, little seems to have been written on the related subject of its speedy and complete inversion. When incubating, birds notorious for their shyness will stick to their nest till actually touched by the hand of their most dreaded enemy-Man. Others, like members of the plover family, which in normal circumstances can only with difficulty be approached within gunshot, will, when they have young in their charge, abandon every fear and strike with angry wing at the head of any intruder on their domain. Their chicks are the objects of an overwhelming and passionate solicitude. Yet in a few brief weeks the whole of this wonderfully absorbing devotion dries up and vanishes, and in many cases its place is taken by a positive and active driving-out hatred.

The driving-out instinct is illustrated best in the case of eagles, such hawks as adopt a definite district as their own-the buzzard is a case-and the raven and its relatives the crows. All are good 
and affectionate parents, unremitting in the laborious work of finding plenty of food for their broods. Most of them are daring in their defence, and will fearlessly encounter the risk of death in order to save them from attack, the eagle, strange to say, being a decided exception. But take the case of the raven. The young ones are still quite callow, and follow their parents in the search for food. They are able to find for themselves, but are not above flapping their wings petted-ways and begging when the old birds discover something good. But one fine morning, while the youngsters are still in the mood to be led and catered for, old-man raven looks upon them with a cold and strangely altered eye. They annoy him, though yesterday they were the joy of his heart. The mood swiftly strengthens into aversion, and he attacks them with a fury which fills them with surprise and pain. He drives them and buffets them right out of his territory. They return, sure that it was all a hideous mistake, only to get buffeted again. And very soon they accept the situation, and they and their parents are strangers ever after.

With the smaller birds the driving-out instinct is less markedly displayed, but it is there all the same. Very early after the fledging of the brood, the blackbirds and thrushes dissolve the family partnership more completely even than the eagles and ravens, which maintain the marriage-tie. The blackbird very calmly looks his wife in the face and says, "I don't know you," and proceeds to live strictly for himself alone. Should any of 
his progeny follow him and claim relationship, he will fight. In the case of the mavis, the mother bird seems to take an interest in her young for some days after her lord and master has resumed his bachelorhood; but very soon the members of the family party wander off in various ways, and know one another no more. Within a week of the fledging, all the members of the household are established on an individual basis. Of the small birds, the tits seem to be alone in maintaining a family party for any length of time, but even with them the institution of the family flock is in its endurance a thing merely of days.

It is questionable if any British bird is entitled to the epithet "Socialist," and the vast majority of them are individualists of the most absolute kind. At present many of them have flocked, but the flock is not a society. There is no sort of co-operation, unless it be in the avoidance of danger, every bird searching for and consuming food strictly " on his own." And most of the flocks that frequent stackyards in the winter-time are composite. Larks, linnets, corn-buntings, yellow-hammers, greenfinches, chaffinches, bramblings are all mingled together, and when the bird-catcher nets them he generally gets specimens of all these, and sometimes other species as well. In some of their actions they seem to be animated by a spirit in common. The suddenness with which hundreds of birds will take to flight at the same instant on some real or fancied alarm has suggested the conjecture that they possess a sixth sense of which we know nothing. One 
cannot watch for any length of time a composite flock of birds in a stackyard without being struck by this peculiarity of conduct. They are all feeding absorbedly. Suddenly, with a simultaneous rush of wings, they are off in a compact body to the bare branches of the nearest tree, from which they drop back in singles and groups as their fears subside. The same thing occurs again and again at intervals throughout the feeding-hours, and generally a visible or audible cause of the movement is searched for in vain. It is much easier, however, to suggest a cause-there are usually rats moving about-than to explain the simultaneousness of the flight that makes the flock move as if animated by an impulse from a single mind. But all this is not social action; and, indeed, it is questionable if the flocking habit of the birds that make up the winter farmyard flocks is a natural habit and not a by-product of man-made conditions. One thing is certain : all the members of the species which contribute to these assemblies do not flock, for throughout the winter plenty of single foragers of all of them, may be found about the fields and hedgerows and in the gardens. Thus the congregating of the birds may mean nothing more than a recognition on their part of the massing in set places of food supplies. It takes an effort to realize how greatly human operations have modified the natural conditions of the wild inhabitants of a country like Britain, their proportions and their relations to one another. To the lark, for example, we present great continuous areas of land perfectly adapted 
to the needs of the bird, and make vast numbers of larks possible. In winter we concentrate on set places the food for which, in a natural state, larks would have to search over a wide area. Thus large flocks may be said to be directly a product of cultivation, and without cultivation the lark flock would be impossible. The bird which, of all others in the British list, comes nearest to forming a society is the rook. Rooks build in company, and, if all tales be true, make love to one another's wives. They go out to feed in company, and, there is some reason to believe, set aside certain of their number to keep a watch -a more truly communal trait than simple association. But the feeding habits of the rook are in every detail adapted to cultivation, and in a country without cultivation their regimented methods of feeding could not be carried out. It may be said that flocking among many birds which most conspicuously display the habit is not brought about by the desire for society, but by a uniform competence in discovering the best places for finding food. Those birds like the crows, whose food is rarely or never to be found assembled in one place, as the food of the rooks is assembled in a ploughed field, are solitary in habit; but in countries where garbage and carrion abound about the habitations of men, even the crows present the semblance of social birds. 


\section{HAWKS IN TOWN}

IT is common knowledge that in the recent period bird-life has become greatly more abundant in towns than used to be the case. In the main, we are for the change indebted to suburbia. The great extension during the second half of the nineteenth century of the kind of dwelling-gardensurrounded, with abundance of trees and shrubbery -to which the business man betakes himself has provided safe harbourage for birds of many kinds, where their only enemy is the prowling cat. In these they have learnt the relatively great security of town life, and to-day gardens in the very heart of large cities have their bird population. It is hardly too much to say that for a very considerable number of bird species suburbia is a true sanctuary, from which the bird-nesting boy and the man with a gun are alike excluded.

In one sense it is strange, though in another perhaps it is not, that in these circumstances the hawks have not come to town. It is one of the most unfailing of the laws of Nature that when a food supply becomes abundant the creatures served by it correspondingly increase in numbers. When there is a vole plague the owls of an incredibly wide area find it out and flock to the 
place, and the smaller hawks are attracted in the same way. Now, here we have in the towns a great supply of the smaller birds, on which the sparrow-hawk and the kestrel habitually prey. But how often is either of them seen within the borders of a town? They might hunt with impunity, and the sparrows are so abundant that nobody would lament if an enemy would appear, capable of thinning their ranks. But the enemy does not come. Doubtless the reason is that the gamekeeper has most effectually reduced their numbers and imbued the survivors with such a fear of mankind that even the best of good hunting cannot induce them to take up their quarters where human beings abound.

But twice within the last month (November, 1912) I have had the pleasure of seeing a hawk -the same hawk, I believe-in town. On the first occasion it appeared and disappeared so suddenly that I could not decide whether it was a kestrel or sparrow-hawk, for though their colouration is very distinct, the bird was between me and the light, and I saw it all dark. It came like a stone from above, picked up a hedge. sparrow, and next moment was gone among the trees of a neighbouring garden. On the next occasion-the 8th of November-I saw it in the air, hovering over a piece of swampy ground surrounded by tall grass. It was at a height of about two hundred feet, and showed itself at a glance to be a kestrel by its manner on the wing. The folk-name of the kestrel is the wind-hover, and this one might have been bent on proving 
the appropriateness of the appellation. I pointed it out to a friend, and we stood watching it together. For exactly seventeen, minutes it kept the same position, almost as steadily as if it had been suspended by a string from above. Occasionally it made very slight movements with the wings, but these never amounted to even a halfbeat. After watching the bird for about five minutes, my friend denied that it was a bird. No bird could keep a place in the air like that, and he was quite sure it was a kind of boy's kite cut out in the shape of a bird. He was still searching the vicinity for the boy who held the string when the kestrel dropped down on a very steep slope into one of the trees on the bank. Five minutes later it ascended again, and began hovering at the same height a little farther to the west, soon, however, to drop down with the wind to its old post over the swamp. In all probability it reckoned this bit good for a mouse. But it did not get one, and after another ten minutes of hovering it moved away in a leisurely fashion in the direction of a neighbouring wooded hill.

This particular kestrel, I have said, hardly moved its wings as it hovered. At the time a steady and pretty strong breeze was blowing from the west, and this, of course, helped it to maintain its position without wing-work. But the kestrel will hover in a dead calm, and when, to maintain its position, it has to beat its wings with great speed. This is its habitual way of searching the ground, and it is doubtless an adaptation to the habits of the kind of prey it chiefly hunts. 
The sparrow-hawk is the great hunter of small birds, and in search of them it flies slowly and with pauses along the edge of woods and over the hedges. Its relative, the kestrel, also takes small birds. But it is pre-eminently a hunter of groundgame of the smaller sort-that is to say, field mice, young rats, and voles. And it is not too proud to stoop to beetles. Quarry of this kind could rarely be detected by a hawk which hunted in the manner of the sparrow-hawk. The ground has to be painstakingly searched from above, and the searcher must maintain herself so steadily over the spot she is examining that the smallest movement in the grass will be seen. Of the two hawks, it will be seen, the sparrow-hawk would prove the better adapted to town life, where small birds abound but small ground-animals are scarce. But I have never seen a sparrow-hawk in town.

It is not altogether improbable, however, that we may see both of them yet. It has been a terribly difficult business to teach the gamekeepers of Britain that every hawk is not his natural and inevitable enemy. Since modern game-preservation began, it has been the habit of the keeper to shoot and destroy the nests of every bird of prey, hawk or owl. The naturalist bitterly resents the idea that an interesting bird may rightly be exterminated merely because it preys (like the sportsman) on game birds, but his resentment has counted for little. Very slowly, however, he has managed to persuade a proportion of gamepreservers and their servants that there are great differences of character among birds of prey, and 
that the damage to game done by some of them is either nothing or negligible. Among the most innocent in this sense are the owls, and next to them come the buzzards and the almost extinct kite, while hardly more injurious to game than these are the kestrel and sparrow-hawk. The kestrel, on the other hand, as a great vole and field-mouse destroyer, is an eminently useful bird. As a result of the spread of this knowledge, there is somewhat more toleration of the lesser hawks than there used to be, and in some parts of the country they are increasingly common. 


\section{DECEMBER}





\section{A WINTER SLEEPER}

THE idea of lifelessness which inevitably associates itself with the winter aspect of field, wood, and garden is, of course, one that will not survive a second thought. There is, as a matter of fact, only a little less life in the ground in winter than there is on and over the ground in summer. All the floral life of the summer is there, latent in seeds innumerable and in the roots of the biennial and perennial plants. Most of the insect-life of the summer is there in the form of hibernating insects, of larvæ or of pupæ. Countless numbers of the unobstrusive little mammals which we know to be about and active in summer-time, though we rarely see them, are snugly tucked away in burrows and crannies, sleeping through the dead days, destined to emerge and resume the state of activity in the spring. But the impression of deadness is so masterful that it is only when chance brings us upon some of the sleeping inhabitants of the soil that it is temporarily overcome.

And, though one ought to know that they are there, it is always with a little shock of surprise that one comes upon them. The other day I addressed myself to the task of breaking up the roots and replanting some delphiniums, and with 
the first big spadeful of roots and earth out came a queen humble-bee. Her sleeping-quarters were wrecked and ruined beyond recognition as the earth fell away from the spade, but the lady herself was most wonderfully fresh and clean. There was not a stain on her velvet, and not a suggestion of damp. For ten seconds she lay perfectly still on her back, then her legs began slowly to move, and in a minute's time she was sufficiently awake to grasp a straw. But the most wonderful thing about her was her power of affecting the spectator with surprise. In all their associations the humblebees suggest glorious summer weather in the height of July. They are seen, it is true, in May, but they are not numerous then. In August they are getting scarce again. July is pre-eminently their time, when Nature is revealing herself in her most opulent guise and the sun is flooding the world with light and warmth. Then the great droning, velvet-clad insects add a note to the summer day, so peculiar to itself that the sound, well imitated, is capable of calling up visions of lush vegetation quivering in a heat haze. And here was one actually buzzing on its back on the chill earth on a December afternoon. One felt for a moment that a trick had been played with the grand order of things, or that there is something of a trick or a deception in the order itself. I made a nest for the disturbed sleeper, put her into it, and buried her up, and only hope she will get out when the right time for waking up comes round.

Hibernation is very exceptional among the mature insects as a way of getting through the 
cold season. In the case of most insects the life of the species is carried over this season in the larval form or in the form of pupæ, and in not a few the chasm of winter is bridged by the wellprotected egg. Some of the butterflies, however, hibernate, though they do not risk the fate of the species upon it, for the main current of life is carried in the chrysalides either buried in the ground or safely hung up in sheltered nooks. With the humble-bees and the social wasps hibernation by the fertilized queens is the only plan, and just now countless thousands of these are sleeping away the months either in little cells dug out by themselves in the earth or in nests at the bottom of thick moss. It is a very rare thing to find one of the sleepers. Those that pass the winter in the earth very generally choose a spot for their little burrow close to the root of a tree, and such spots are rarely disturbed by spade or plough. Those that blanket themselves in moss are equally safe, for the existence of thick moss means that the place is left untouched from year to year. Yet, despite all this, such is our sense of the delicacy of insects in the mature state, that it is difficult to overcome the feeling that in trusting to a successful winter sleep they are trusting to a very precarious plan.

It would be a little difficult to justify the feeling. A very large proportion of insects fulfil the whole purpose of their existence in the summer and die with the first frosts. But the insect organization is not on this account to be taken as peculiarly incapable of resisting cold. Many larvæ can survive the ordeal of being frozen hard, 
and some mature insects as well. The death of so many at the end of the summer rather implies senility and the exhaustion of function than simple inability to resist cold. Insects which have not completed their functions often experience sharper night colds in the summer than suffice to kill them in the autumn, but, though they become torpid under the experience, they wake up with renewed warmth, none the worse of the experience.

The bee referred to above was a queen of one of the commonest of the species of humble-beesBombus terrestris-familiar in its black livery, with tawny, yellow bands on the thorax and abdomen, and a tawny, or sometimes dull, white tail. It has been noted that when it hibernates it generally selects for its burrow the northern aspect of a bank-the place on which the winter sun never shines except in an oblique and ineffectual way. The burrow is carried only about a couple of inches deep, and the cell is just large enough to hold the bee. Frequently in winter the earth is frozen solid to a much greater depth than this, and on a spot with a northern aspect it may remain frozen for a long time. From the frequency of the choice of such a site by the bee, it is inferred that cold troubles it not at all in its hibernating state, and that damp is the thing it has chiefly to guard against. On the warm side of the bank, subject to frequent freezings and thawings, the insect would run much more danger of dampness than on the northern side.

The queens thus stowed away will be asleep till the sun of May brings them to life again. Their 
first work will then be to dig themselves out. If they emerge on a dull day, they will probably retreat again and wait for a more encouraging occasion. Provided all is well and the sun shining, they will warm themselves in its rays, and will soon become strong enough to fly. Then their thoughts will turn to honey, and they will visit the spring flowers and feast on nectar. When the lady has quite recuperated she will proceed to search for a suitable site for a nest, and the selection of one will depend on the species to which she belongs. Some of the humble-bees make their nests very near the surface, just under the moss. Others, like the one referred to, want a burrow, which may be anything from two to three feet in length. The deserted burrows of mice serve them well. When they have found it they enlarge a chamber at the end of it, and proceed to construct cells for their first brood. There is nothing of regal state in the condition of the queen at this stage, for she must work very, hard to feed both her young family and herself. But soon the first brood come to maturity, and then her work is done. Henceforth the family do all the labour, and the mother is in reality a queen. 


\section{THE WILD SWAN}

ONCE upon a time there appeared in a country paper the following advertisement, which, for an indefinite number of days, was the occasion of torturing apprehension in the bosom of a certain small boy :-

" REWARD. $-£_{5}$ will be paid for information leading to the apprehension and conviction of the person who, during last week, STOLE the egg's from the swan's nest on — Loch.-Apply Estate Office."

Stamp-collecting and book-collecting, it has been said, are habits calculated to sap the moral fibre in the finest natures. Egg-collecting by youthful Britons gets in before the moral nature has begun to develop. At the age of thirteen the miscreant alluded to had formed a collection of eggs which seemed to need nothing to complete it but the splendid pale green oval of the swan, and, like the Roc's egg in the tale of Aladdin, the absence of this trophy reduced all the rest to nothing, yea, vanity. So one moonlight night in April he sallied forth on an expedition of truly marauding intent, tramped five miles, reached 
a well-known loch in a wood, braved the muddy traps of its bottom, waded to the artificial island on which two swans had their home, ravished it of its treasures-in number three-and beat a triumphant retreat with the spoils of enterprise. Next day when one of the eggs, blown and washed, was placed in the spot which yearned for it ; when the second was swapped for a knife with four blades, a corkscrew, a toothpick, and an indispensable apparatus for extracting stones from horses' shoes (without which no boy can consider himself equipped); and the third for a telescope ingeniously disguised as a walking-stick-that day was a day of days. Then came the day of dread, and many more of slowly diminishing fear.

Those eggs were the produce of the so-called mute swan, common on ornamental waters, a creature of great beauty, but doubtfully entitled to rank as, in a natural sense, a member of the British fauna. Indeed, no swan can be called unequivocally a native British bird; but two, the whooper and Bewick's swan, are classable among our real, natural, and regular winter visitors. And when people speak of having seen a wild swan it may be taken for granted that in ninety-five cases out of the hundred they mean the whooper, which is the common wild swan. There are few sights more curiously striking when first seen than that of a wild swan on the wing, and my own first sight of one is always associated with an idea which it suggested. How the folk-lorists explain the mediæval idea that witches rode on broomsticks I do not know, but a swan on the wingt 
conveys a hint with the force of a slap on the eye. The neck, a yard long, is projected straight in front, not gracefully curved backwards like the heron's. The feet prolong the line behind. On the line, like a figure astride a stick, is the round body, to which the wings seen on their upward movement give elevation. It is, in short, the legend embodied, and a person unfamiliar with the creature might puzzle in vain to explain it unless he had the fortune to see it rise. Then, indeed, there is little of mystery about the swan, for though, despite its size, it is a powerful flight bird, its rise is a performance of prodigious labour. It will splash along the surface of a loch for fifty or more yards before it can launch itself into the air, and it leaves behind it a wake like that of a motor-boat.

The wild swan is a regular winter visitor to many of the northern lochs, preferring the shallow ones, and probably no east coast estuary is for a winter season without it. Bewick's swan is not absolutely rare in the same region. But both are seen at their best and in the greatest abundance in the western isles and on the western lochs, and herein lies one of the little puzzles of migratory distribution. That the common wild swan, the whooper, should abound as a winter visitor on the west coast and in the islands is just what one would expect. The breeding-grounds of those that come to Scotland are almost certainly situated in Iceland and Finland, though some may come from remote Spitzbergen. If we take it that they come from Iceland, the west coast is the first suitable 
feeding-ground they touch-that is to say, a region where "slob lands," shallow lochs, and tidal flats are rarely or never frozen up. But Bewick's swan comes from the north-east of Europe, possibly Siberia, and the great bulk of them prefer to pass right over the eligible places of the Scottish east coast, and take up feeding quarters on the west. This is one of the preferences which, so far, no fellow has been able to understand.

The whooper, as I have said, is at home in Iceland, and thither in March or April our winter visitants proceed, and join in great flocks with those which have passed the winter on the open waters of the coast. Like Finland, Iceland is admirably suited to a bird with the peculiar habits of the swan. Every pair want a loch to themselves, and in both these countries the lochs, or, as they would be called in the Highlands, lochans, are almost without number. The swans build their nests on a small island, or, if there is no island, on a spit of land or a part of the loch-shore which is sufficiently marshy to be difficult of approach, there piling up a platform of the twigs of the willow and scrub birch, intermingled with moss and grass. A pair return to the same nest year after year, and if any interloper has tried to take possession will fight for their property. When the question of ownership is determined the pair set about furbishing up the old nest, which in this way grows in size from year to year, till at last the mass becomes of considerable dimensions, and two or three feet in height. On the top of this, on a fresh layer of moss, the eggs are deposited, not 
like those of the mute swan, of a pale greenish colour, but of a creamy white. They are hatched out about the middle of June, and the cygnets are ready to $\mathrm{fly}$ by the time that the rigour of the Arctic winter locks up all the home supplies of food.

The vast majority of birds are mature when they are a year old, and proceed to the responsibilities of rearing a family ; but as becomes an animal which may live for half a century and which mates for life, the swan waits till he is quite sure of his own mind. He does not take a mate till his third year, having no doubt thoroughly studied the lady, found out that her temper is good, and that her neck has the proper curve. Swans, it is reasonable to suppose, are rather exacting in the matter of a feature of such consequence-and length. It would, indeed, be horrible to be tied for life to a stiff-necked partner when the neck is a yard long.

There was a time when the swan was eaten in this country, and the ability to do justice to it was a high point in the equipment of the cook. In these degenerate days the goose is as much as we care to sit down in front of. But wild swans often do appear still on the market, and it is a subject for the inquiry of the curious what becomes of them. I have seen one in a poulterer's window, but was given to understand that its commercial uses began and ended in the function of advertisement-a poor function to be served by one of the handsomest of animals, which, if all tales be true, is capable of living happily for more than half a 
century, and of forming enduring connubial ties which should win it the sympathy of a nation of monogamists, and commend it generally to a people sentimentally appreciative of the domestic virtues. 


\section{WINTER PLAY OF BIRDS}

A GREAT silence holds the heart of the wood. The flight of a startled pigeon breaks in upon it with, by contrast, the effect of a clap of thunder, and you feel as if the noise must be audible a mile away. But you may dwell there for half a day and not see or hear another bird, unless some pheasant which escaped the shooters has strayed into the depths. Then all of a sudden the trees around you are alive with a merry company of noisy chitterers, and the brooding silence gives way to a bustling commotion of gay life. Five minutes more and the merry company is gone and silence reigns again.

What has happened is, that a composite flock of woodland birds, on business and pleasure bent, has gone careering through the wood, pausing for a few moments here and a few moments there, but lingering nowhere long. Are they downhearted? They do not look like it. The temperature may be many degrees below freezingpoint, and the ground may be covered deep with snow, but these wood-flocks always seem to have plenty of spirits for a running game. And a very curious assortment they make. Great tits are not the most numerous, but the most powerful 
and showy members of the band. With them go the blue tits, relatives, but at other seasons anything but allies of the friendly kind. Tree-creepers and gold-crests chum with these incongruous associates, hold together in company, and hunt and play as if they were all brothers of the same blood. At least three very distinct bird families are represented in the flock, but for the time being they act as if they were a society with one language, one nature, and of one kind.

It would be difficult to give any explanation of these curious associations except the love of company and the love of play. That many birds do play, all who have watched their habits know, and these little wood-people indulge in it in an unmistakable way. They chase one another, dodging and doubling in the flight, and though some of them are pugnacious in a high degree, pugnacity is not the driving power in the game. It seems to be just a case of high spirits expressing themselves in rapid motion, with the zest which even the young human animal puts into pretended pursuit.

Gold-crests, tits, and creepers are as different in dress and form as passerine birds could be, but they have one character in common which probably decides their companionship. They all seek the same kind of food, and seek it in not very markedly dissimilar ways. They are after insects, and have to find them even in the dead of winter. This necessity has made acrobats of them all. The tits search the angles of twigs and the crevices in bud-shoots. An enormous 
proportion of the buds produced by trees in the summer for next year's development go wrong. The subject is known to foresters who have studied it as " natural pruning," and if it were not carried out, trees would fall under their own weight. A large part of this pruning is effected by insects, which deposit eggs in the buds, from which hatch grubs. When the tits search the tree, hanging on to the twigs in every possible attitude, they are hunting and finding those grubs, dragging them out and making a meal of them. With their robust beaks they can tear a bud to fragments and extract the morsel which lies within it. The whole tribe has incurred some enmity as bud-destroyers, and though it is possible that they do destroy healthy buds, it is likely that the great majority of those they attack are recognized by them as already tenanted by a destroyer of another kind.

The gold-crest, tiny midget of a bird that it is, could not tear a bud in the strong-headed manner of the great tit; but in its own way it finds and consumes immense quantities of minute insect-life in its dormant winter state. In all their movements gold-crests resemble the tits, being, however, even more ceaselessly on the move. They prefer evergreens, particularly fir, spruce, and yewtrees, among the needles of which countless numbers of small things must lurk which amount to nothing in human eyes. But trees which, like the alder, bear catkins are almost equally interesting to them, and appear to yield them a rich feast. The tree-creepers are the most specialized members of the company. More exclusively insect-feeders 
than either tits or gold-crests, they search for their prey in the crevices of tree-bark, and their manner of hunting is always an interesting sight.

But when the whole company is bent on play, it is little work that the creepers get done. They fly with the band, and at every pause begin operations on a tree. Before they have made half a dozen turns, a heightened " chittering" tells them that the rest are away; and after the company they go, not wholly entering into the fun, but clearly not wishing to be left behind. In their normal movements there is little wing-work, and perhaps they feel when the temperature is low that a little " aviation" is excellent for promoting the circulation of the blood.

These wood-flocks of very small fowl do not hold together all day, like the flocks of serious feeders which frequent the farmyards. While the satisfaction of appetite is the dominant issue, each member labours on his own basis, and some of them may have special knowledge of wonderful stores of provision in the shape of cocoanuts or suspended lumps of fat. When a fair foundation has been laid, by early afternoon they come together and enjoy their daily scamper through the bare branches. Plodders neither by build nor inclination, they defy mere weather to squeeze the gaiety out of their lives. 


\section{THE ARMED PLANT}

A RICH crop of symbolical lore has grown up around the holly, in a special and pre-eminent degree the plant of the Christmas season. There are symbolical explanations of its evergreen leaves, of its red berries, and, of course, of its place in the decorative scheme of the festival. They are all simple and obvious enough, and fit happily and harmoniously into their place in history and legend. But it is really unnecessary to invent a tale to account for the part the holly plays in a midwinter feast. You find everything made clear by simply stepping into the wood or thicket in December and searching for something which will serve. Put aside the spruces and others of their kind, all aliens and unknown to our ancestors, and what is left? There is the ivy, clinging in robustly green masses to the bole of the elm and wandering over its major branches. Its decorative value is perceived on the spot, and the decorator takes heavy toll of its long and leafy limbs. And what more? Nothing but the holly. With its brilliantly green foliage and its vivid berryclusters, it would be chosen from among many competitors; but the simple and unavoidable inference is that it was taken for Christmas adorn- 
ment because there is little or nothing besides it to take. It was "Hobson's choice," but a very good choice none the less. The beauty of the holly is no doubt, in part, that of the rivalless state. In the summer woods it is not a particularly arresting tree. It is dark and stiff, with neither the majesty of the oak nor the grace and poise and colour of ash and birch. But against a ground of snow, flecked with the sere stalks of dead grass and the heads of dry umbels, it stands with a vigour of colour which holds and delights even the unobservant eye.

The holly, as everybody knows, is an armed plant, and certain peculiarities of its armour add not a little to the interest it holds for the student of Nature. If a well-grown specimen of the native British species, and one which has never been mutilated, is examined, it will soon be noticed that the typical arming of the foliage is not equally developed all over. In fact, it is only on those parts of the tree which come within three or four feet of the ground that the leaves are abundantly supplied with rigid spines. A little higher up the spiny quality falls away, and long before the top of the tree is reached the leaves will be found to be without anything of the nature of a prickle. They are oval in shape, and almost entire in the margins. From this it is no far-fetched inference that the holly is armed for a purpose, and that it troubles itself to produce defences only where they are needed. In short, it is armed against browsing animals, and does without arms at a height beyond the ordinary reach of grazers. 
This is the simple, uncontroversial statement of the case, but unfortunately for the lover of simplicity there is quite a holly problem. When the plant is used to make a hedge, and the hedge is periodically clipped, the holly will be found to grow spiny leaves to the very top. Similarly, when a holly, as sometimes happens, is clipped into dandified shapes, the leaves become armed to the uttermost extremity. This is the case with two hollies well known to the writer, which, though little, if any, short of twenty feet in height, have been clipped like a couple of vegetable poodle dogs. It is also, though in a less general way, the case with holly-trees which are every year despoiled of their berry-bearing shoots as a tribute to the spirit of the festive season. From these facts it has been inferred, and very strongly held, that the spiny character of the holly is not a natural trait of the plant at all, but merely a vigorous reaction against mutilation, and that if the tree were never mutilated or browsed it would fail to produce spiny leaves even near the ground. Very satisfactory evidence has, however, been produced that absolutely untouched hollies do produce the spiny leaves on their lower branches, and that therefore the tree possesses the power, without special stimulus, of arming itself as a precaution against attack, as well as the power of adding to its defences after attack, and that the spines on the lower leaves are a strictly hereditary character of the species. It is part of another and a far larger question-a question which separates two schools of biologists-whether this character 
originated as a reaction against the attacks of browsing animals and became hereditary, which would be the inheritance of an acquired character, or whether it originated in a chance variation which, being useful, was fixed by natural selection.

There is, of course, nothing approaching uniqueness in the fact that the holly has evolved for itself a defensive arm against animal attack. In a great variety of ways hundreds of plants and whole families of plants have done as much, and if the holly is at all distinguished, it is in its curious economy of means. The thorns of hawthorn and blackthorn and rose, the prickles of the whole cactus family, the spines of the thistles, the sting of the nettles, the harsh taste of many herbs and the bad smell of many others, are all strictly utilitarian adaptations aimed at defence. And it is a pretty sound inference that when a plant arms itself in any of those specialized ways for the protection of its substance or its foliage, it contains nutritious material which at one time was used as food by animals. Probably it was preyed upon to such an extent that the unprotected individuals of the species were exterminated, and only those which varied in the defensive direction survived to perpetuate the race. When the defence is purely mechanical, it often happens that some one animal is capable of disregarding it, as, for example, the donkey disregards the spines of the thistle and the goat the thorns of the wild rose, When it eats a thistle, the donkey may be said to prove that the thistle is a food plant under its forbidding exterior. A famous American experi- 
mentalist has taken the generalization that a mechanically protected plant is a food plant as a working hypothesis for experiment. Thus he is reported to have laboured successfully to produce a spineless cactus, in the belief that by means of such a plant, containing in its substance both food and drink, large areas of scrub and semidesert might be turned to account for the grazing of animals. It is hardly likely, however, that the animals reared under such condition would be worth the trouble of providing them with the food supply. But it is possible that the experimenter might make something useful out of the thistle if, by depriving it of its defences, he constrained it once again to take up its old place as a food plant, for most members of the family have the power of growing on ground on which the food plants of cultivation cannot thrive. 


\section{INDEX}

Antlers of Red-deer, 227 Antlers, reduction of size, 233 Antlers eaten by hinds, 234 Antlers, renewal, 236 Ants in garden, 185 Ants, their industry, 187

Bees robbing flowers, I90 Bees, distinction of sexes, 215 Bees, hibernation of, 301 Bees, colony forming, 305 Birds and cold, I7

Birds and hunger, 7

Birds as housekeepers, 3 I

Birds in storm, 285

Blackbird fights, 55

Blackbird courtship, 67

Blackbird thefts, I I3

Blackbird's nest, 147

Black-headed gulls, 28

Black-headed gulls' nestingplaces, 74

Blue Tits' food, 30

Blue Tits nesting in box, 107

Blood appetite of gnat, 169

Bramble, 246

Bramble, possibilities of, 249

Brambling, I9

Bulbs in plant strategy, $4 \mathbf{I}$
Bullfinches and buds, 116

Buried seed, 27

Capercailie hen in male plumage, 255

Cat as hunter, 149

Cats, wild, their numbers, I 19

Cats, wild, ease of capture, 201

Charlock, 24

Chickweed, 26

Creeper, 18, 313

Dock seed, 26

Dipper, 162

Drones and drunkenness, 212

Earwig, 270

Earwig fight with spider, 27 I

Earwig brooding young, 272

Fairy Ring mushrooms, 237 Female birds in mạle plumage, 255

Ferns' spores, their universality, 253

Fish, unteachableness of, 63

Flocking of birds, 289

Flowers and competition, 40

Food problem of birds, 17 
Foxes of the hills, I77

Foxes, their prey, 179

Gnats, armature, $35^{-167}$

Golden-crested wren, 18

Greenfinch and seed, II6

Groundsel seed, 26

Grouse, 195

Gulls, disgorging powers of, 76

Gulls as garbage feeders, 31, 72

Gulls as divers, 76

Gulls, nesting-places of, 75

Hares, 78

Hares, mode of reproduction of, $8 \mathrm{I}$

Hawks in town, 294

Holly and its armature, 316

Hooded Crow, 2 r

House Martin's nest, 262

House Sparrow, 49, II3

Humble-bee, hibernation, 301

Humble-bee, colony forming 305

Insects and frost, 35

Isolated waters, stocking of, 16I

Kestrel in town, 295

Kestrel, prey of, 297

Kittiwake, 77

Lapwing's eggs, 91

Lapwing's enticements, 93

Manure and birds, 29

Microscopic vision of birds, 27
Midge, 33

Mountain Hare, 80

Mushrooms, edible, but not eaten, 24 I

Nest-building, r 44

Nest-building of Blackbird, 147

Nest of Blackheaded Gull, 74

Nest of Blue Tit, 107

Nest of House Martin, 262

Nest of House Sparrow, 49

Nest of Kittiwake, 77

Nest of Lapwing, 9 I

Nest of Robin, I 18

Nest of Sand Martin, 26r

Nest of Terns, 134

Nest of Thrush, I45

Ova, dispersal of, 159

Plovers' eggs, 91

Rain and hill sculpture, roo

Red-deer calves, 122

Red-deer, tameness of calves, I26

Red-deer forming harem, 280

Red-deer in summer, 173

Ring-plover in wind, 285

Robin fights, 56

Robin courtships, 95

Robin nesting, I 18

Rookery, 44

Rook shooting, 139

Sand Martin's nest, 26I

Sand Martin and vermin, 32

Seed dispersal, 250 
Seed, prodigal provision of, 252 Seed awaiting opportunity, 25

Seed, vitality of, 24

Sexual selection, 98

Siskin, 19

Snails, 85

Snowdrop, 39

Sparrow's holiday, 216

Starling, feeding, $5^{8}$

Starling, song of, $7 \mathrm{x}$

Starling, in autumn, 265

Swallows, 260

Swallows in caves, 263

Swan, wild, 306

Terns' eggs sold as plovers' eggs, 9I

Terns' nesting-places, I34
Thrush, nest of, 145

Tits' love of suet, 69

Tits nesting in box, 108

Tits and buds, I I5

Tree-sparrow, 50

Tree-creeper, $18,3{ }^{1} 3$

Trout, cunning of, $6 \mathrm{r}$

Trout and flies, 129

Trout in isolated lochs, ${ }_{57}$

Wasps, plagues of, 204

Wasps' nest-building, 206

Wasps and ripe fruit, 208

Water-vole, 222

Water thrushes, I66

Wild cats, I I9

Winter play of birds, 312

Wood lark, 27 
Che Bresbam Dress,

UNWIN BROTHERS, LIMITED,

WOKING AND IONDON. 

UNIVERSITY OF CALIFORNIA LIBRARY

Los Angeles

This book is DUE on the last date stamped below.

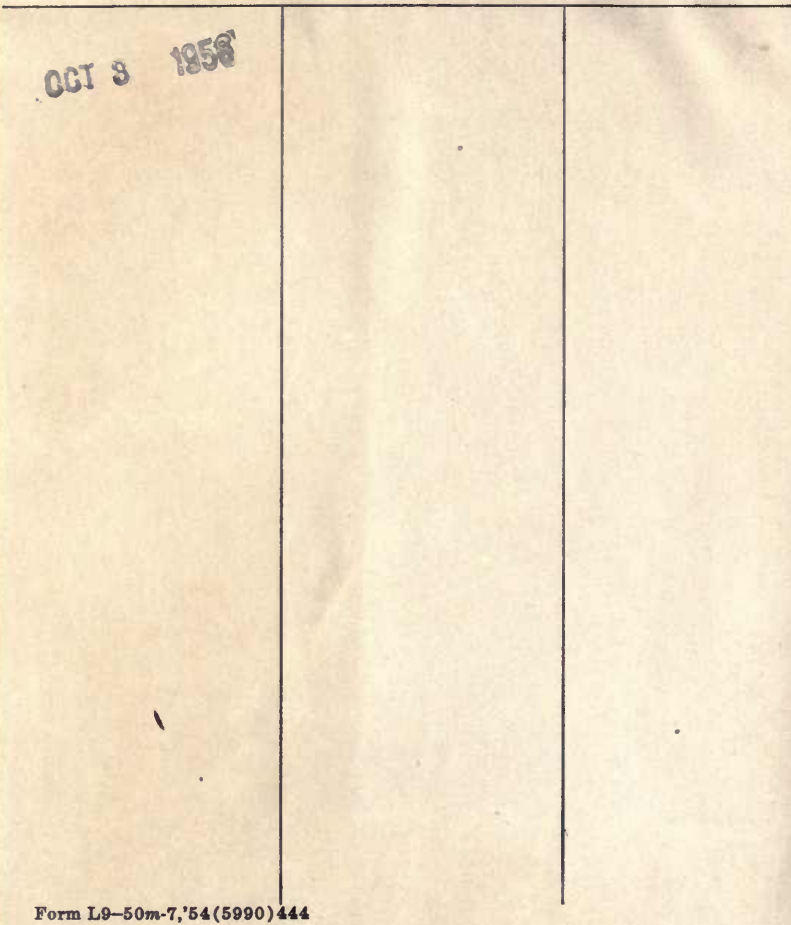


QH

81

U790 
\#+N

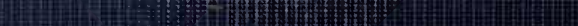

